\title{
Investigations into the mode of action of the DNA uridine endonuclease Mth212 of
} Methanothermobacter thermautotrophicus $\Delta \mathrm{H}$

\author{
Dissertation \\ zur Erlangung des Doktorgrades \\ der Mathematisch-Naturwissenschaftlichen Fakultäten \\ der Georg-August Universität zu Göttingen
}

Vorlegt von

Elena Ciirdaeva (geb. Jivotovscaia)

aus Chişinău, Moldova

Göttingen 2009 
D7

Referent:

Prof. Dr. Hans-Joachim Fritz

Korreferent:

PD Dr. Wilfried Kramer

Tag der mündlichen Prüfung:

22. Januar 2010 


\section{Table of contents}

1 Introduction

1.1 DNA structure, stability, and dynamics .......................................................... 1

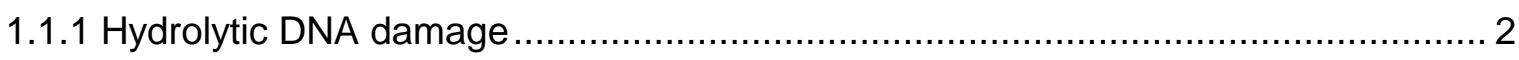

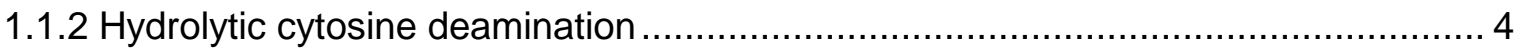

1.1.3 Phylogenetic distribution of uracil-DNA glycosylases ...................................... 5

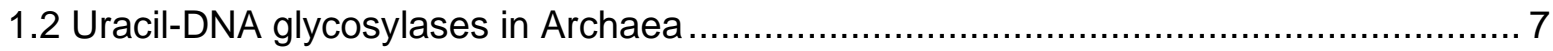

1.2.1 Methanothermobacter thermautotrophicus as a model organism ......................... 8

1.2.2 Discovery of Mth212 as a DNA uridin endonuclease in M.thermautotrophicus ........ 8

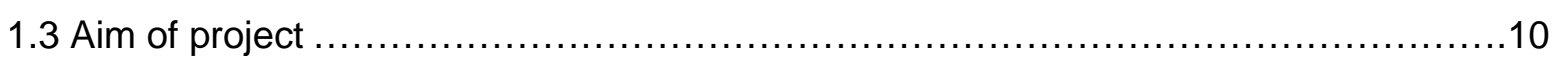

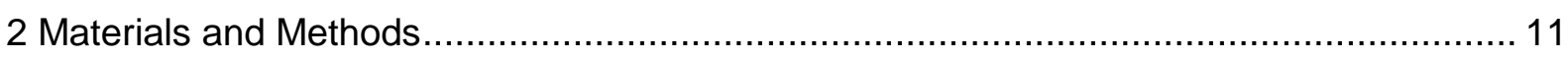

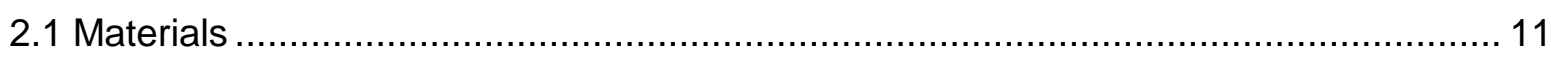

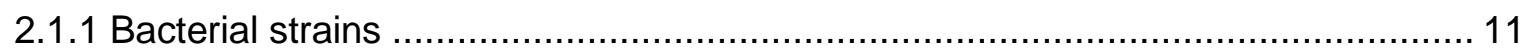

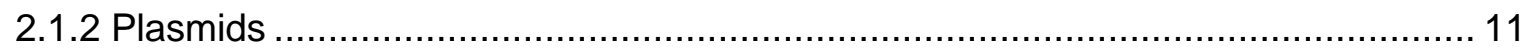

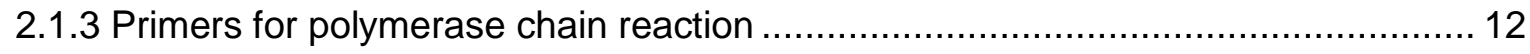

2.1.4 2'-Desoxyriboseoligonucleotides for enzymatic activity assay ............................ 13

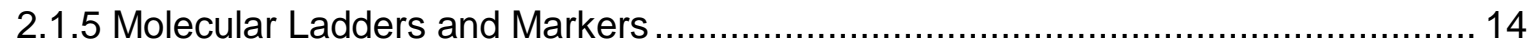

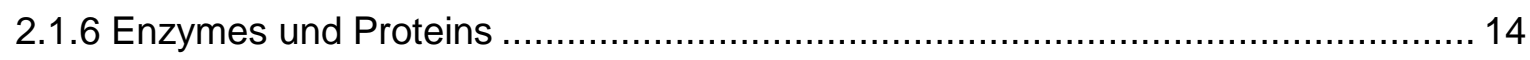

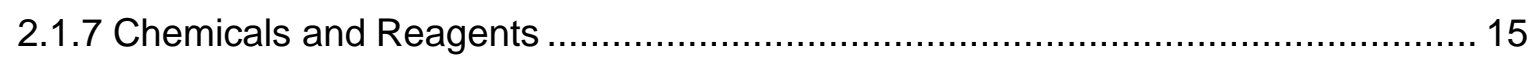

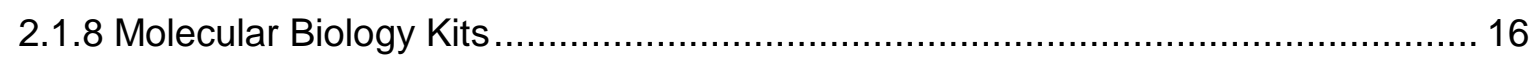

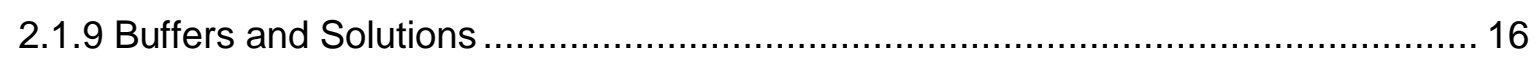

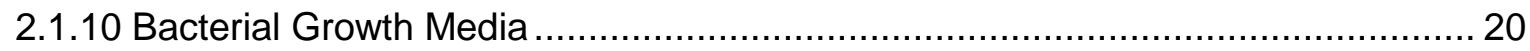

2.1.11 Molecular Biology Equipment and computer hardware ..................................... 20

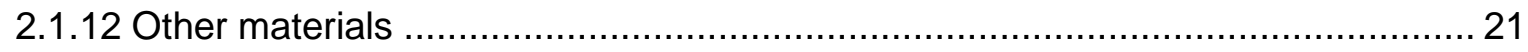

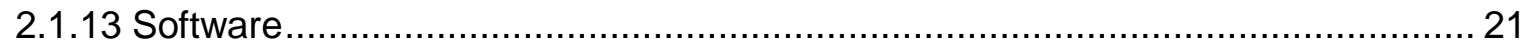

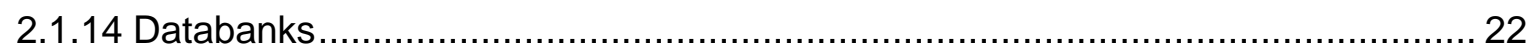

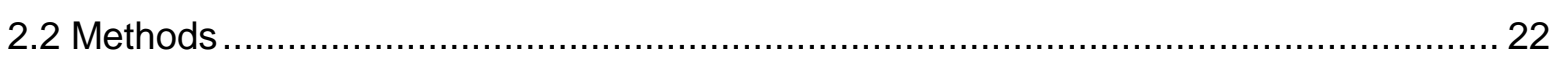

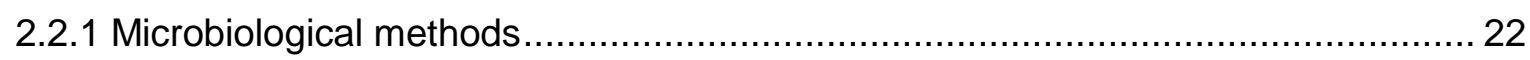

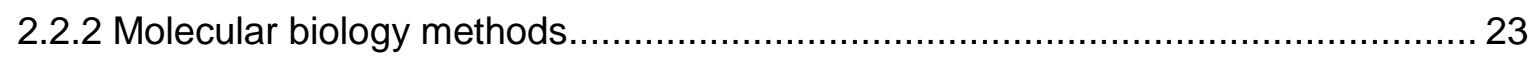

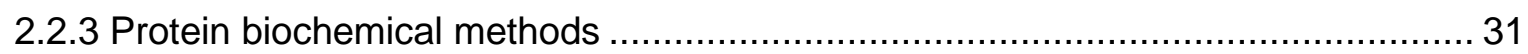

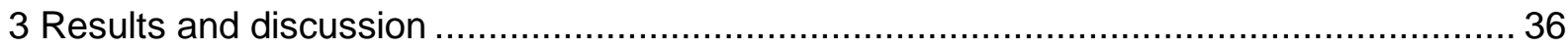

3.1 Construction and properties of Mth212/D151N mutant....................................... 36

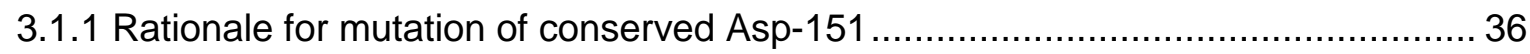

3.1.2 Mth212/D151 mutants: construction and expression ........................................ 37

3.1.3 Endonuclease assays with Mth212/D151 variants ............................................ 41

3.1.4 Gel-retardation assays with Mth212/ D151 variants ...................................... 43 
3.1.4.1 EMSA with Mth212/D151N and Substrate I 43

3.1.4.2 EMSA with Mth212/D151N, Substrate I and pET-vector as a competitor DNA ... 45

3.1.4.3 EMSA with Mth212/D151A and Mth212/D151S, Substrate I and pET- vector as a competitor DNA

3.1.4.4 EMSA with Mth212/D151N, Substrate II and 20-mer oligonucleotides as a competitor DNA

3.1.4.5 EMSA with Mth212/D151N, Substrate III and 20-mer oligonucleotides as a competitor DNA 50

3.1.4.6 EMSA with Mth212/D151N, Substrate III (with U/C, U/T and U/A) and 20-mer oligonucleotides as a competitor DNA 52

3.2 Semi-quantitative investigation of wt Mth212 substrate preferences 55

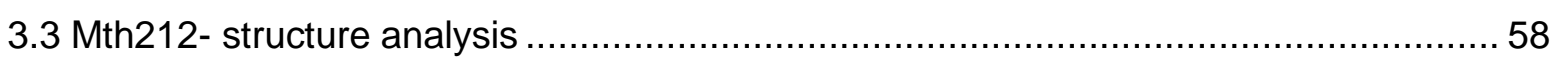

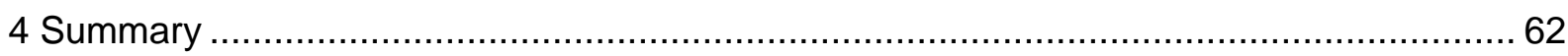

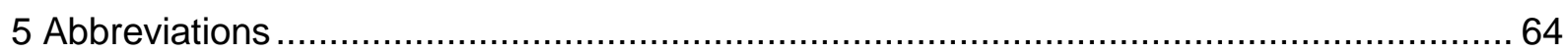

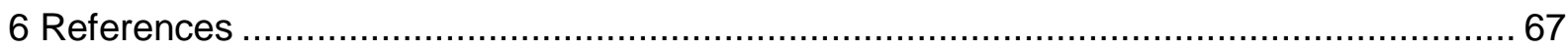

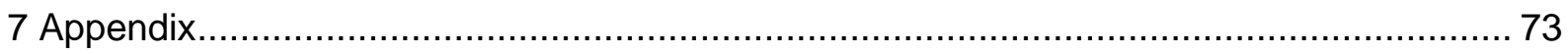

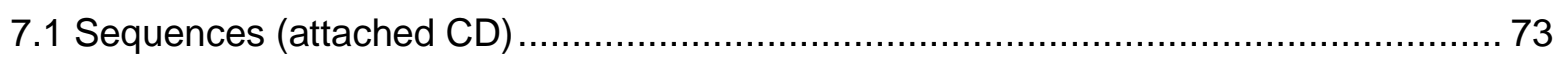

7.1.1 pET_B_001 sequence and restriction map................................................... 73

7.1.2 Mth212 nucleotide and amino acid sequences, restriction map........................... 73

7.1.3 Mth212/D151X (X: N, A, S) mutants verification .............................................. 73

7.1.3.1 pET_B001_Mth212/D151N sequencing data ................................................ 73

7.1.3.2 pET_B001_Mth212/D151A sequencing data................................................. 73

7.1.3.3 pET_B001_Mth212/D151S sequencing data............................................... 73

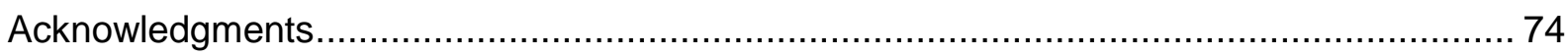

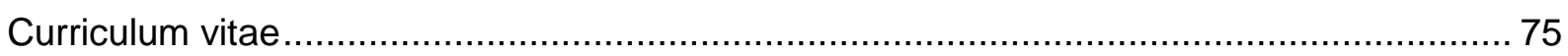




\section{Introduction}

\subsection{DNA structure, stability, and dynamics}

DNA is the material bearer of hereditary information in all living cells and DNA viruses. This information is written in a sequence of desoxyribonucleotide bases - the structural monomers of DNA molecule. DNA is a polymer composed of covalently bound mononucleotides of two types: pyrimidines (thymine $(T)$, cytosine $(C)$ ) and purines (adenine $(A)$ guanine $(G)$ ). In solution DNA molecule exists in form of a double helix. Two polynucleotide chains are held together by hydrogen bounding between complementary bases (A:T and $G: C)$ and by hydrophobic interaction between adjacent stacked base pairs.

The realisation that DNA directs all cell activities suggests that this molecule is relatively stable. However, studies of DNA metabolism processes such as replication, transcription, repair, and recombination revealed dynamical state of DNA molecule in the cell. Furthermore, different extrinsic and intrinsic factors, also known as mutagens, induce structural changes in DNA molecule, evidencing its limited chemical stability. The major extrinsic mutagens that impair DNA integrity are harmful chemicals (e.g. oxidative and alkylating agents), ionizing radiation, and UV-light. The intrinsic mutagenic factors include reactive cellular metabolites (e.g. reactive oxygen species (ORS), S-adenosyl-L-methionine (SAM) and water (Nickoloff, 1998).

Structural changes in DNA, if not repaired rapidly and appropriately, represent a serious threat to genomic stability and cell survival. Fortunately, during evolution all living organisms have evolved efficient mechanisms to repair various DNA damages. There are three major DNA repair pathways: 1) Direct reversion of DNA damage by enzymatic dealkylation and photoreactivation; 2) Excision repair, where DNA lesion is restored through enzymatic excision of the damage region and re-synthesis prior to DNA replication and cell division. Excision repair include base excision repair (BER), nucleotide excision repair (NER), and mismatch repair MMR); 3) Recombinational repair, where damaged DNA may be exchanged, reciprocal or nonreciprocal, with homologous region of DNA (homologous recombination (HR) and non-homologous end joining (NHEJ)) (Grogan, 2004). Some of the principal agents that can impair DNA integrity as well as examples of DNA damages and possible mechanisms of their restoration are summarised in Table 1. 
Table 1: Mutagens, types of DNA damage and possible repair mechanisms (D. Hartl and W.Jones, 2002)

\begin{tabular}{|c|c|c|}
\hline Mutagen & Example of DNA alterations & Repair mechanisms \\
\hline Water & $\begin{array}{l}\text { Depurination or deamination of nucleobases; } \\
\text { sinlgle-strend breaks (SSB) }\end{array}$ & BER, MMR, NER \\
\hline $\begin{array}{l}\text { Reactive intracellular } \\
\text { metabolites }\end{array}$ & $\begin{array}{l}\text { Oxidation, alkylation of nucleobases; sigle-strend } \\
\text { breaks; }\end{array}$ & BER, MMR, NER \\
\hline Chemical agents & $\begin{array}{l}\text { Deamination, alkylation or oxidation of } \\
\text { nucleobases; intramolecular crosslink }\end{array}$ & $\begin{array}{l}\text { BER, MMR, NER, } \\
\text { Recombinational repair }\end{array}$ \\
\hline UV-light & $\begin{array}{l}\text { Intermolecular crosslink (T-T dimmers); strand } \\
\text { breaks }\end{array}$ & $\begin{array}{l}\text { Photoreactivacion, } \\
\text { BER, MMR, NER }\end{array}$ \\
\hline Ionizing radiation & $\begin{array}{l}\text { Single- and double-strand beaks (DSB); } \\
\text { alteration of the nucleobases }\end{array}$ & HR, BER, MMR, NER \\
\hline
\end{tabular}

\subsubsection{Hydrolytic DNA damage}

Apart from harmful chemicals, ionizing radiation and UV-light known to promote deleterious effect on DNA structure, water - the universal milieu for all intracellular chemistry - is considered as a major mutagen causing spontaneous hydrolysis of DNA.

It has been found that in vitro nucleic acids undergo rapid spontaneous decomposition in solutions. Hence in metabolically active cell, whereby DNA exists in fully hydrated form, it would be particularly prone to spontaneous hydrolysis (Friedberg, 2003; Lindahl, 1993). The target sites within desoxyribonucleotide sequence susceptible to intrinsic hydrolytic attack are shown in Figure 1.

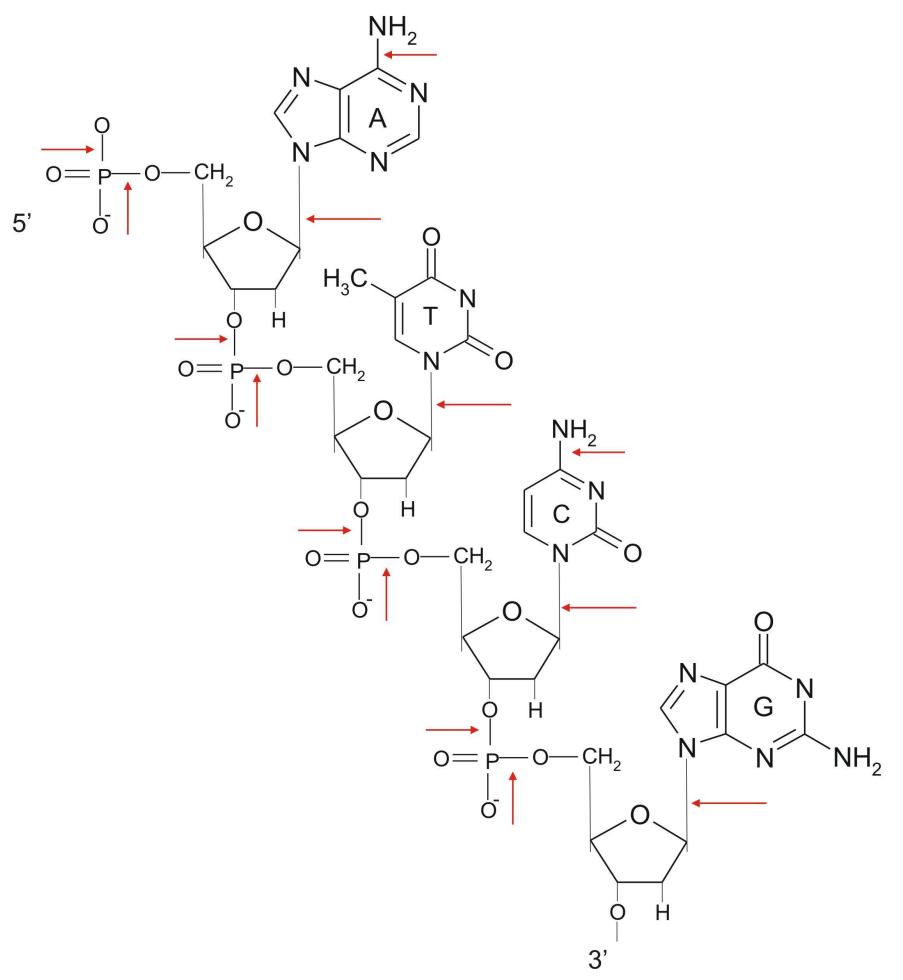

Figure 1: Target sites of spontaneous DNA hydrolysis (T. Lindahl, 1993)

A fragment of primary DNA structure with four normal nucleobases: A-adenine, T-thymine, C-cytosine and Gguanine. Red arrows indicate sites undergoing spontaneous hydrolysis. 
Diesters, like sugar-phosphate linkage in DNA backbone, are normally quite labile and subject to the hydrolytic attack. Direct cleavage of the phosphate backbone has been estimated to be the most frequent type of hydrolytic damage resulting in a single-strand nick (Table 2).

The sugar-base glycosidic bond is also relatively labile and is subject to spontaneous hydrolysis. Hydrolytic cleavage of glycosydic bond, termed depurination and depyrimidination, results in formation of baseless or abasic sites (AP-site). The replication system usually inserts an adenine nucleotide in the daughter strand opposite the AP-site. After another round of replication, the DNA duplex would undergo a transition or transversion mutation. AP-sites can undergo further hydrolytic cleavage, resulting in single-strand breaks. The later occur at rates similar to or slightly slower than depurination. DNA strand breaks are potentially mutagenic and can have deleterious consequences such as cell cycle arrest and cell death (Bernstein, 1991; Lindahl, 1977; Nickoloff, 1998).

Aside from the hydrolytic cleavage of phosphodiester and glycosydic bond, DNA bases (cytosine, adenine, and guanine) containing exocyclic amino groups can undergo hydrolytic deamination. The hydrolytic cleavage of their exocyclic amino groups results in conversion of affected bases into uracil, hypoxanthine and xanthine, respectively (Lindahl, 1977). The rates of spontaneous DNA damage estimated in mammalian cells at neutral $\mathrm{pH}$ and $37^{\circ} \mathrm{C}$ are represented in Table 2.

Table 2: The rates of spontaneous hydrolytic DNA damage

in mammalian cells at $37^{\circ} \mathrm{C}$ (Bernstein C, 1991)

\begin{tabular}{|l|l|}
\hline Damage & Events per cell per day \\
\hline Single-strand breaks & 55.200 \\
\hline Depurination & 12.000 \\
\hline Depyrimidination & 600 \\
\hline Cytosine deamination & 192 \\
\hline
\end{tabular}

The data presented in Table 2 evidence significant instability of DNA molecule even under physiological solvent conditions.

Changes in DNA structure can have deleterious effect on the integrity of cellular genetic material. Insertion of inappropriate or modified bases in particular may lead to the replication block and cell depth or to genetic mutations, unless they are actively restored. Hence, cellular DNA-repair system is the principle factor defining the normal function of the DNA and genetic stability of the entire organism.

Base excision repair (BER) is the main pathway to repair spontaneous DNA damages including modified bases, AP-sites, strand breaks, and short gaps in DNA. BER is initiated by a specific DNA glycosylase that recognises and removes the damaged base leaving an 
abasic site (AP-site) behind. Then an AP-site specific endonuclease incises DNA strand at the AP-site resulting in one-nucleotide gap. The original nucleotide sequence is then restored by consequent function of DNA-polymerase and DNA-ligase.

\subsubsection{Hydrolytic cytosine deamination}

Alongside with strand beaks and base loss, hydrolytic cytosine deamination to uracil is one of particularly common and genotoxic process in that it gives rise to pre-mutagenic $U: G$ mismatch, which if left unrepaired after second round of replication produces $G C \rightarrow A T$ transition mutation in $50 \%$ of the progeny (Figure 2 ).

A<smiles>[R]N1C=CC(N)(O)NC1=O</smiles>

B

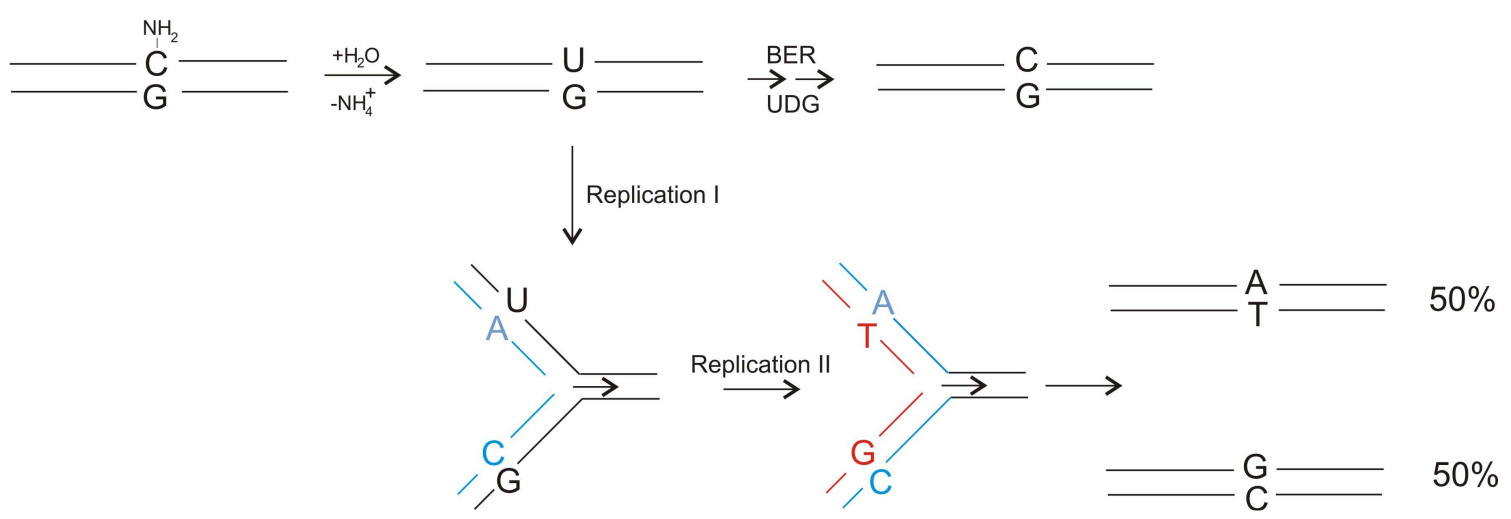

Figure 2: Schematic representation of hydrolytic cytosine deamination and outcomes of U:G mismatch A: hydrolytic deamination of cytosine $(\mathrm{C})$ to uracil $(\mathrm{U})$ by nucleophilic attack of a primary amine on $\mathrm{C} 4$ of the pyrimidine ring. B: hydrolytic deamination of cytosine in dsDNA results in U:G mispair incorporation. U:G mismatch can be effectively repaired by base excision repair (BER) with the restoration of native C:G base pair, alternatively a $C G \rightarrow A T$ transition mutation appears in $50 \%$ of the progeny, as a result of the replication past U:G lesion. UDG: uracil-DNA glycosylase-an uracil specific enzyme, that recognises and excises the mispaired uracil from DNA initiating BER.

To counteract this mutagenic effect, most organisms eliminate uracil residues from DNA by means of the uracil-excision DNA repair pathway, which is initiated by a specific uracil-DNA glycosylase (UDG). UDGs exquisitely recognise and excise uracil from DNA as a free base by hydrolysing $\mathrm{C1}^{\prime}$-N-glycosidic bond leaving an AP-site behind. Uracil-DNA glycosylases are highly conserved and widespread DNA repair enzymes found in almost all living organisms (Krokan et al., 1997). 


\subsubsection{Phylogenetic distribution of uracil-DNA glycosylases}

Numerous representatives of uracil specific glycosylases were classified into five families and later combined into UDG-superfamily based on substrate specificity and/or structural similarities, (Aravind, 2000). The phylogenetic overview of UDG-superfamily is represented in Table 3.

Table 3: The phylogenetic overview of UDG superfamily

\begin{tabular}{|l|c|c|c|c|c|}
\hline $\begin{array}{r}\text { Family number and } \\
\text { Protein example } \\
\text { Organism }\end{array}$ & $\begin{array}{c}\mathrm{F}^{*} 1 \\
\mathrm{UNG}\end{array}$ & $\begin{array}{c}\mathrm{F} 2 \\
\text { Mug/TDG }\end{array}$ & $\begin{array}{c}\mathrm{F} 3 \\
\text { sMUG }\end{array}$ & $\begin{array}{c}\mathrm{F} 4 \\
\text { tUDGa }\end{array}$ & $\begin{array}{c}\mathrm{F} 5 \\
\text { tUDGb }\end{array}$ \\
\hline Eubacteria & + & + & - & - & - \\
E.coli & + & + & - & + & + \\
\hline $\begin{array}{l}\text { E.thermophilus } \\
\text { Eukaryotes }\end{array}$ & + & + & + & - & - \\
S.cerevisiae & + & - & - & - & - \\
\hline \multicolumn{1}{|c|}{ Archaea } & & & & & - \\
A. fulgidus & - & - & - & + & - \\
M.thermautotrophicus & - & + & - & - & - \\
\hline
\end{tabular}

Symbols and abbreviations are: * $F$ - a family number, + - encoded in genome, - not detected, Ung - Uracil N-Glycosylase, Mug/TDG - Mismatch specific Uracil-DNA-Gglycosylase/Mismatchspecific Thymine-DNA-Glycosylase, sMUG - Single-strand-specific Monofunctional Uracil-DNAGlycosylase, tUDGa and tUDGb - Thermostable Uracil-DNA Glycosylases.

Uracil-N-Glycosylase (UNG) from E.coli is the first found (Lindahl, 1974) and most extensively studied enzyme within UDG super-family (Varshney and van de Sande, 1991). E.coli UNG is a prototype for Family 1 uracil DNA glycosylases (UNGs). Structural basis of UNG specific substrate recognition and catalysis is well studied (Renos Savva, 1995). E.coli UNG is able to remove uracil base from both single and double-stranded DNA irrespectively of nucleotide opposing the target uracil (Lindahl, 1977). Uracil base is flipped out from the base stack into the enzyme catalytic site, followed by hydrolysis of the $\mathrm{N}$-glycosydic bond between base and 2'-desoxyribose (Kunkel and Wilson, 1996). Representatives of UNG Family can be effectively inhibited by Uracil-DNA glycosylase inhibitor (Ugi) - a competitive inhibitor encoded by Bacillus subtilis bacteriophages PBS1 and PBS2 (Mol et al., 1995a; Wang, 1989).

The second UDG family is comprised of TDG/MUG homologs. Mismatch-specific Thymine DNA Glycosylase (TDG) purified from HeLa cells is known to cleave both $T: G$ and U:G mispairs (Neddermann and Jiricny, 1993). Mismatch Úracil-DNA Glycosylase (MUG) from E.coli was found as a functional homologue of human TDG (hTDG). E.coli MUG is primarily $G: U$ mismatch specific, although it does display activity on $T: G$ mismatch at high 
enzyme concentrations (Barrett et al., 1998; Gallinari and Jiricny, 1996). Unlike UNG, both TDG and MUG enzymes are found to repair mismatched bases exquisitely on the double-stranded DNA substrates (Neddermann and Jiricny, 1994).

First representative of the Family 3 UDGs was identified and characterised in Xenopus and denoted as a Single-strand-specific Monofunctional Uracil-DNA Glycosylase (SMUG) (Haushalter et al., 1999). Later on, SMUG homologous were identified in humans, insects and some bacteria. SMUG family representatives were first characterised as singlestranded DNA specific enzymes prone to remove uracil and 5-hydroxymethyluracil. However, recent studies of human SMUG homologue (hSMUG1) revealed that this enzyme was able to excise uracil from both double- and single-stranded DNA and had broader substrate specificity, including 5-hydroxymethyluracil (5hmUra) and 3, $\mathrm{N}^{4}$-ethenocytosine (Kavli et al., 2002; Pettersen et al., 2007).

The thermostable uracil-DNA glycosylases were combined into Family 4 tUDGs. First tUDG was discovered in thermophilic bacteria Thermotoga maritima and denoted as TmUDG. This enzyme is heat stable up to $75^{\circ} \mathrm{C}$ and ha s a week sequence similarity to E.coli MUG. TmUDG can remove uracil from both single- and double-stranded DNA containing U:A or U:G base opposition (Sandigursky and Franklin, 1999). Homologs of TmUDG were found in both thermophilic eubacteria and archaea (Sandigursky and Franklin, 2000; Sartori et al., 2001; V. Starcuviene and H.-J.Fritz, 2002). Representatives of tUDG family were later divided into two distinct sub-families, namely Family 4 tUDGA and Family 5 tUDGB, according to their deferent substrate specificities. Both IUDGA and tUDGB were discovered in Thermus thermophilus - a thermophilic eubacterium (V. Starcuviene and H.-J. Fritz, 2002). tUDGA displays singe- and double-stranded DNA specificity. It is highly selective for uracil residue regardless of the opposing base, but enable to remove thymine from G:T mismatch. tUDGB, unlike tUDGA, is able to remove uracil exquisitely from double-stranded DNA substrate (Hoseki et al., 2003; V.Starcuviene and H.-J.Fritz, 2002). Some representatives of tUDGA family were found to possess the iron-sulphur (4Fe-4S) cluster. (Hinks et al., 2002; Hoseki et al., 2003). Representatives of fifth UDG family contain non polar residue in the active-site motive I (GLAPAG- $\mathrm{X}_{10}-\mathrm{F}$ ), which is proposed to activate a water molecule in other UDGs (Sartori et al., 2002; V. Starcuviene and H.J. Fritz, 2002).

To summarize, enzymes of Family 1 UNGs are widely distributed in eubacteria, eukaryotes and even DNA viruses with the notable exception of Drosophila melanogaster. The Family 2/TDG homologous genes were found in all life domains: Archaea, Bacteria and Eukaryotes. SMUG family genes were found so far only in Eukaryotes and some Bacteria. Neither SMUG nor UNG family genes were found in Archaea.

Until recently UNG was considered to be the major enzyme responsible for general uracil repair, mostly based on its strong conservation from bacteria to humans, exquisite 
specificity for the excision of 2'dU residue regardless of DNA sequence context and its high expression level in growing cells. Furthermore, the presence of at least one representative of UDG family in almost all organisms evidences an important role of uraci repair in the restoration of genome integrity (Pettersen et al., 2007). The most striking here is perhaps the lack of this otherwise highly conserved UNG family genes in Archaea - the third domain of live. The later fact suggests that Archaea may have an alternative DNA-uracil repair pathway.

\subsection{Uracil-DNA glycosylases in Archaea}

Most Archaea studied so far are extremophiles that exist in extreme conditions (high temperatures, acidity or in the saturated salt solution) that affect significantly theirs genome integrity. Elevated temperatures in particular directly destabilise the primary and secondary structure of DNA and accelerate spontaneous DNA decomposition reactions (such as deamination and depurination) (Lindahl, 1993). For these reasons Archaea and particularly hyperthermophilic Archaea are expected to have more effective and optimal systems for DNA repair and in particular for hydrolytic DNA damage repair.

As was mentioned earlier, no genes for otherwise ubiquitous Family 1 uracil-DNA glycosylases have been identified in Archaea. However, Family4 tUDG glyosylases were isolated from some thermostable Archaea. A representative of thermostable uracil-DNA glycosylases was found in extreme thermophilic archeon - Archaeoglobus fulgidus (optimal growth temperature $8^{\circ} \mathrm{C}$ ). This enzyme, denoted as AfUDG, revealed a high degree of primary amino acids sequence similarity to Family 4 TmUDG from $T$. maritima. A homologous ORF with significant sequence similarity to TmUDG and AfUDG was identified in a hypertermophilic archaeon - Pyrobaculum aerophilum (optimal growth temperature $100^{\circ}$ ). All these enzymes can remove uracil both from single- and double-stranded DNA containing either $U: G$ or $U: A$ oppositions.

Interestingly, some Archaea with completely sequenced genome seem to be devoid of UDG family genes. Among them is a thermophilic archaeon - Methanothermobacter thermautotrophicus (optimal growth temperature $65^{\circ}$ ). However, two mis match-specific DNA glycosilyses, namely Mig.Mthl and Mig.Mthll, members of Mig/MBD4 family DNA glycosylase, were isolated and characterised in M. thermautotrophicus (Horst, 1996; Starcuviene, 2001). Mig/MBD4 homologs comprise the second, after UDG, superfamily of DNA glycosylases, namely the helix-hairpin-helix-GPD (HhH-GPD) structure superfamily. The name of this family derived from specific motif: $\mathrm{HhH}$ and Gly/Pro rich loop (GP) followed by a conserved aspartate (ㅁ) (Krokan et al., 2002). MBD4 (methyl CpG binding domain protein 4) was isolated and characterised in human and mouse. Mig/MBD4 substrate specificity is similar to the Family 2 TDGs recognising G:T and G:U mismatches within 
definite context. MBD4 is a sequence specific enzyme that binds preferentially to $\mathrm{CpG}$ context, in particular to the 5-meCpG-TpG mismatches, presumably counteracting the mutagenic effect of deamination of 5 me-C to thymine (Hendrich et al., 1999). The relating members of HhH-GPD superfamily including three from E.coli: 8-oxoG:A mispair-specific glycosidase MutY (Fromme et al., 2004), thymine glycolglycosylase Endolll (Thayer et al., 1995), 3-methyladenine DNA glycosylase II (AlkA) (Hollis et al., 2000), and human 8-oxoguanin DNA glycosylse (OGG1) (Bruner et al., 2000) remove divers types of damaged DNA bases, including uracil, oxidised and alkylated bases.

Unlike UNG family enzymes, members of Mig/MBD4 family are context-dependent enzymes with broader substrate specificity and with residual uracil-excision activity, if any at all. Hence, nether Mig.Mthl nor Mig.Mthll can be considered as a general uracil-DNA glycosylase initiating and coordinating efficient repair of a deaminated cytosine (or $\mathrm{U}: \mathrm{G}$ mismatch) in $M$. thermautotrophicus. From all these, the nature of uracil repair in Methanothermobacter thermautotrophicus and possibly in other thermophilic and hyperthermophilic Archaea with similar distribution of DNA repair genes was, until recently, unclear.

\subsubsection{Methanothermobacter thermautotrophicus as a model organism}

M. thermautotrophicus str. $\Delta H$ belongs to the domain Archaea, Eeuryarchaeota, Methanobacteria. The archaeon $M$. thermautotrophicus (Mth) is a strict anaerobe that converts hydrogen and carbon dioxide to methane and grows optimally at $65^{\circ} \mathrm{C}$ (Zeikus and Wolfe, 1972). Mth genome was completely sequenced (Smith et al., 1997) and represents a single circular DNA molecule of 1.7 million base pair (bp) length. The $\mathrm{G}+\mathrm{C}$ content comprises $49.5 \%$ of the genome (in comparison to E.coli (51\%) and S. cereviciae (38\%)). $42 \%$ of ORFs were found to be similar to bacterial sequences and $13 \%$ of ORFs were similar to eukaryal sequences. Genomic analysis has confirmed that archaeal DNA-processing enzymes are more similar to those found in eukaryotes than in bacteria. In fact archaea share many features with eukaryotes and bacteria and therefore serve as alternative model systems (adapted to harsh environmental conditions) for the studying molecular diversity of DNA stability and repair as well as for the better understanding of these processes both in bacteria and eukaryotes (Grogan, 2004; Kelman and White, 2005; Majernik et al., 2004).

\subsubsection{Discovery of Mth212 as a DNA uridin endonuclease in M. thermautotrophicus}

A new type of uracil specific DNA repair enzyme, namely Mth212, an Exolll homologue from Methanothermobacter thermautotrophicus (Mth), was discovered and biochemicaly characterised in our laboratory (Georg et al., 2006). Mth212, in addition to the numerous enzymatic activities inherent to Exolll homologues, recognises DNA-U and cleaves the 
phosphordiester backbone direct to the 5'side of the 2'dU residue. More recently, essential role of Mth212 in DNA-U repair initiation was established during in vitro reconstruction of $U / G$ mismatch repair pathway in Mth cell extract (Schomacher et al., 2009). Amino acid sequence analysis revealed that Mth212 shares 30\% sequence identity with E.coli exonuclease III (ExollI) and 40\% identity with human AP-endonuclease Ape1 (Figure 3).

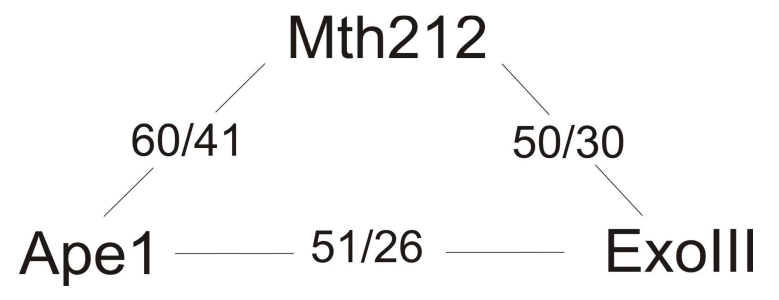

Figure 3: Amino acid sequence similarity and identity within homologous proteins Mth212 from $M$. thermautotrophicus, Exolll from E.coli and Ape1 from H.sapiens. Numbers on the left indicate sequence similarity and on the right sequence identity in percentage.

A number of conserved catalytically important amino acids known from human Ape1 and Exolll (Barzilay et al., 1995; Rothwell et al., 2000) are conserved in Mth212 as well(Figure 4).

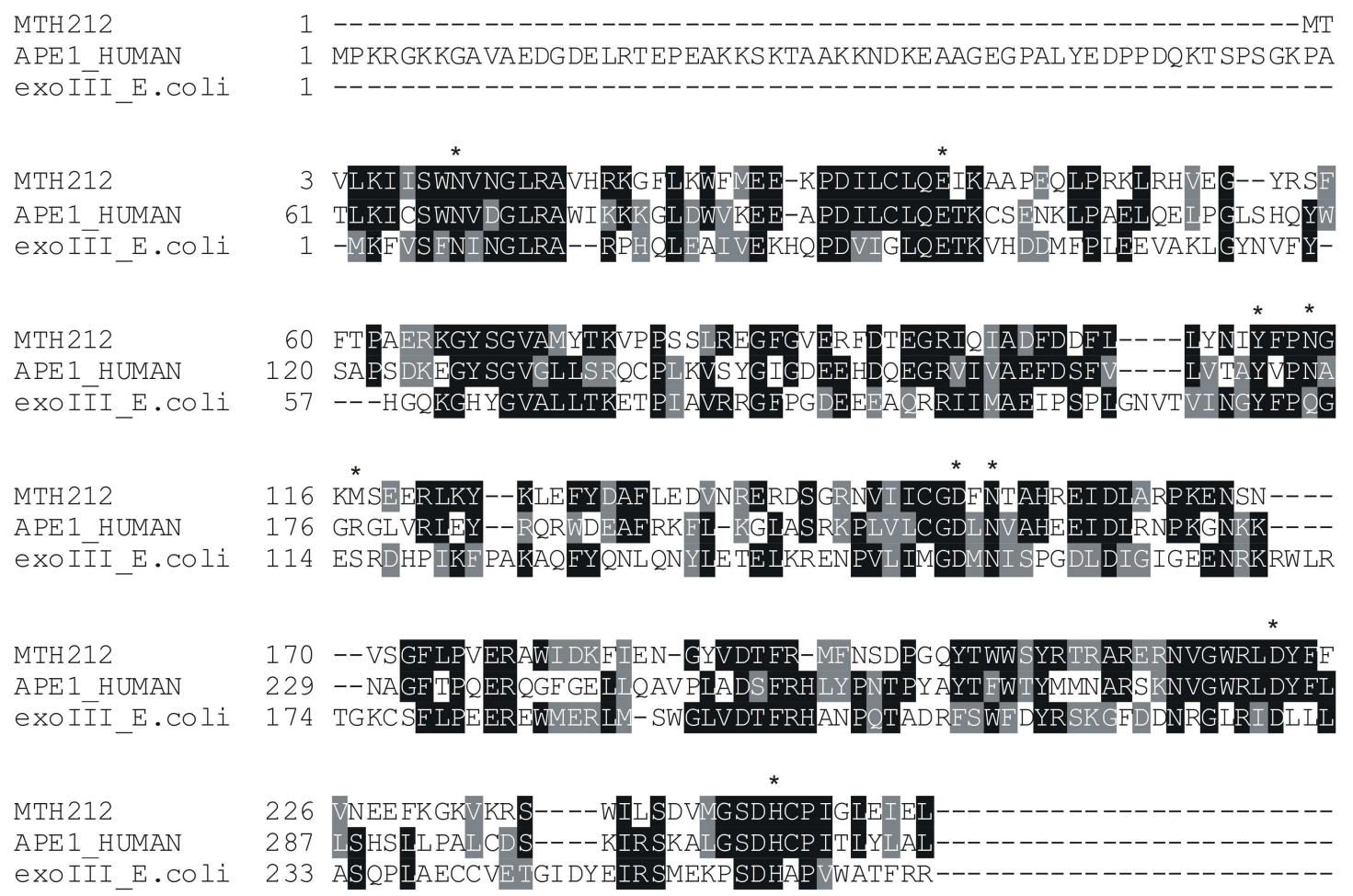

Figure 4: Multiple amino acid sequence alignment of Mth212 (Methanothermobacter thermautotrophicus) with Exolll (Escherichia coli) and Ape1 (Homo sapiens)

Amino acid residues involved in the catalysis by Ape1 according to (Mol et al., 2000) and (Rothwell et al., 2000) are marked with an asterisk. Alignment was performed using WISCONSIN PACKAGE version 10.3 (Womble, 2000) and arranged with BOXSHADE version 3.21. 
The three-dimensional structure (3D) of Mth212 apo-enzyme was determined (K. Lakomek, 2009). As the result of the 3D structure analysis, Mth212 was assigned to the DNase I structure family, who's most extensively characterized representatives are bovine DNase I (Weston et al., 1992), E.coli Exolll (Mol et al., 1995b) and human Ape1(Mol et al., 2000) (Figure 5).

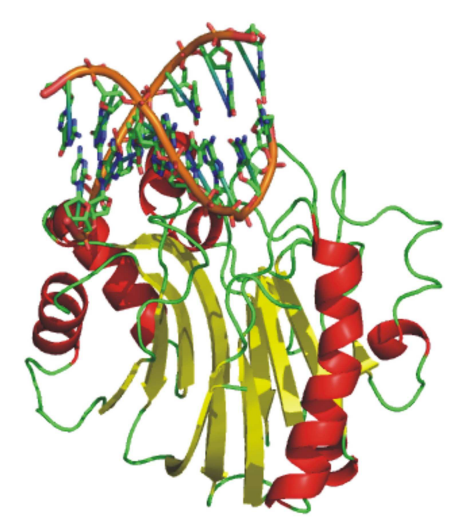

DNasel

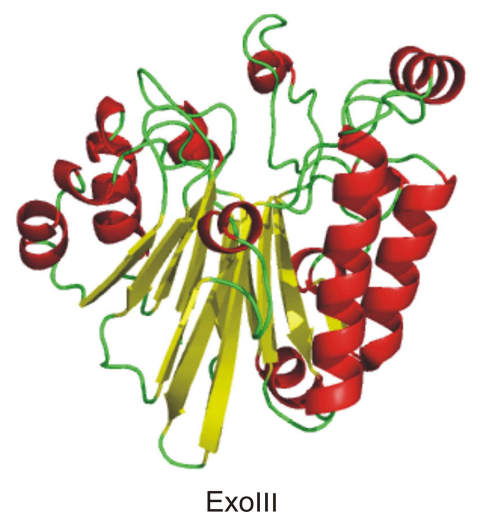

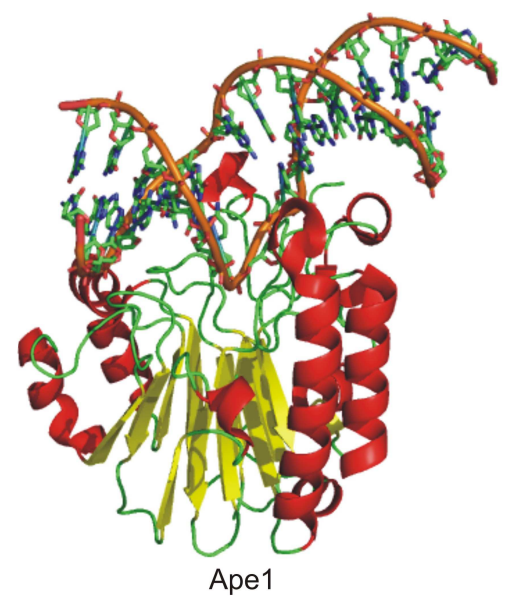

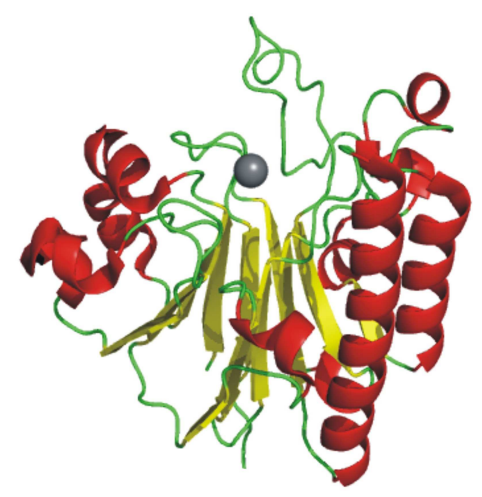

Mth212

Figure 5: 3D structure comparison within DNase I structure family

The structural data for DNase I-DNA (1DNK; Weston et al., 1992) and Ape1-DNA complexes (1DEW; Mol et al., 2000) as well as apo-Exolll (1AKO; Mol et al., 1995b) and apo-Mth212 (3G91, K. Lakomek, 2009) were processed using PyMOL (DeLano Scientific LLC) software. $\alpha$-helices are shown in red coils, $\beta$-sheets are shown in yellow arrows, coils are shown in green tubes. DNA helix (orange) with the nucleotide bases represented as atom coloured sticks. A metal ion (here $\mathrm{Mg}^{2+}$ ) bound in Mth212 active site is shown as a grey sphere.

\subsection{Aim of project}

Despite high sequence and structure similarity found within Exolll family members characterised so far, Mth212 is the only representative able to recognise and repair DNA uridin. The questions is: does this newly discovered unique activity of Mth212 reside in the same active site as AP-endo and 3 ' $\rightarrow 5$ ' exonuclease activities?

The main purpose of this project was to determine whether Mth212 has unique structural features responsible for DNA-U specificity in addition to the other catalytic activities inherent to Exolll homologues. 


\section{Materials and Methods}

\subsection{Materials}

\subsubsection{Bacterial strains (Escherichia coli)}

2.1.1.1 DH5a (Invitrogen, Carlsbad, CA)

F-, Ф80dlacZ M15, endA1, recA1, hsdR1 (rK-mK+), supE44, thi-1, gyrA96 (NalR), relA1, (lacZYA-argF) U169

2.1.1.2 BL21-CodonPlus (DE3)-RIL (Stratagene, La Jolla, CA)

E. coli B, F-, ompT, hsdS (rB-mB-), dcm+, TetR, gal ı(DE3), endA, Hte [argU, ileY, leuW, $\mathrm{CmR}$

2.1.1.3 BL21_UX (Georg et al., 2006, this paper) (based on BL21-CodonPlus(DE3)-RIL (Stratagene, La Jolla, CA)

E. coli B, F-, ompT, hsdS (rB-mB-), dcm+, TetR, gal I(DE3), endA, Hte [argU, ileY, leuW, $\mathrm{CmR}]$, sung::kan

\subsubsection{BL21_UXX}

E. coli B, F-, ompT, hsdS (rB-mB-), dcm+, TetR, gal ı(DE3), endA, Hte [argU, ileY, leuW, $\mathrm{CmR}]$, ung

\subsubsection{XL1-Bleu}

XL1-Bleu MRF'(Stratagene USA, (Bullock et al., 1987))

RecA1 endA1 gyrA96 thi-1 hsd17 supE44 relA1 lac; F'lacla lacZ $\Delta M 15$ proA $A^{+} B^{+}$Tn10 (tet') Amy $\mathrm{cam}^{r}$

\subsubsection{Plasmids}

2.1.2.1 pET_B_001 (Georg et al., 2006)

pET_B_001 is a derivative of vector pET-21d (Novagen, San Diego, CA), in which the multiple cloning site between $\mathrm{Ncol}$ and $\mathrm{Xhol}$ is replaced by the following $14 \mathrm{nt}$ section: dTCTGCGGCCGCACA. The nucleotide sequence and restriction map of the vector can be seen in Appendix 7.1.1. 


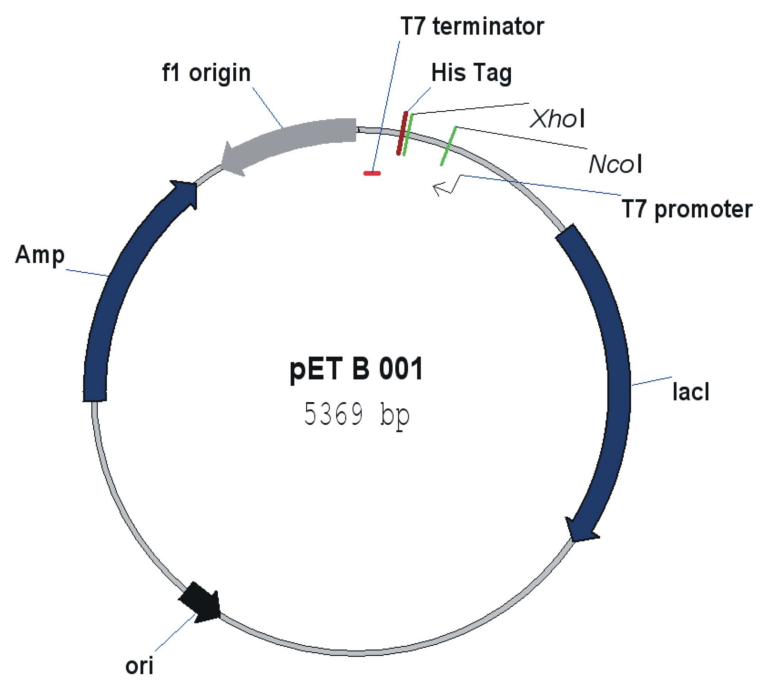

Figure 6: Schematic representation of PET_B_001 vector

Genes for ampicillin resistance mediation (Amp, $\bar{\beta}$-lactamase), and lac repressor (lacl) are indicated in blue; Origin of replication of phage $\mathrm{f} 1$ is indicated in grey. Arrows indicate the direction of transcription and replication. Positions of selected restriction sites are marked with green bars and labelled by unique occurrence in the vector with grey letters. His-Tag (ruby stick): nucleotide sequence that encodes the 6-His tail. Positions of T7 promoter and T7 terminator are shown in blue and red correspondingly. Black arrow: indicates the origin of replication of the plasmid. The scheme was created using Vector NTI Software (Invitrogen) (see section 2.1.13).

\subsubsection{Primers for polymerase chain reaction}

\subsubsection{Primers for site-directed mutagenesis:}

Primers for Mth212/D151N mutant generation:
212_D151N_FOR (DNA, 27mer)
5'-GATTATATGTGGG AAC TTCAACACAGC-3'
212_D151N_REV (DNA, 27mer)
5'-GCTGTGTTGAA GTT CCCACATATAATC-3'

Primers for Mth212/D151A mutant generation:
212_D151A_FOR (DNA, 27mer)
5'-GATTATATGTGGG GCA TTCAACACAGC-3'
212_D151A_REV (DNA, 27mer)
5'-GCTGTGTTGAA TGC CCCACATATAATC-3'

Primers for Mth212/D151S mutant generation:
212_D151S_FOR (DNA, 27mer)
5'-GATTATATGTGGG TCA TTCAACACAGC-3
212_D151S_REV (DNA, 27mer)
5'-GCTGTGTTGAA TGA CCCACATATAATC-3'

\subsubsection{Primers for nucleotide sequence analysis}

pET-vector sequencing primers (pET_B_001 und pET-28a):

$\begin{array}{ll}\text { PETS1_UP (18mer) } & \text { 5' CAGCAGCCAACTCAGCTT 3' } \\ \text { PETS1_LO (18mer) } & \text { 5' ATAGGGGAATTGTGAGCG 3' }\end{array}$


pCR-Blunt II-Topo-vector sequencing primers:

M13 Forward (16mer) 5' GTAAAACGACGGCCAG 3“

M13 Reverse (17mer) 5' CAGGAAACAGCTATGAC 3'

\subsubsection{2'-Desoxyriboseoligonucleotides for enzymatic activity assays}

The oligonucleotides were synthesised by either PURIMEX (Grebenstein) or Sigma (Munich).

Oligonucleotides for Endonuclease assay:

Prince-U (40mer)

40_PRI_AP(40mer)

PRINCE_G (35mer)

23-M (23mer)
5' (F)GGGTACTTGGCTTACCTGCCCTGUGCAGCTGTGGGCGCAG 3' 5'(F)GGGTACTTGGCTTACCTGCCCTG(AP)GCAGCTGTGGGCGCAG3' 5' CTGCGCCCACAGCTGCGCAGGGCAGGTAAGCCAAG 3' 5'(F)GGGTACTTGGCTTACCTGCCCTG 3'

\section{Oligonucleotodes for EMSA:}

40 PRI AP Dunkel

PRINCE C

PRINCE_U_Dunkel

Prince_A_Blunt

Prince_T_Blunt

Prince_C_Blunt

Prince_G_Blunt

40_Prince-G

20_UP_Prince

20_LO_Prince

40_Prince_C

40_Prince_A

40_Prince_T
5'dGGGTACTTGGCTTACCTGCCCTG(AP)GCAGCTGTGGGCGCAG 3' 5'dGGGTACTTGGCTTACCTGCCCTGCGCAGCTGTGGGCGCAG 3' 5'dGGGTACTTGGCTTACCTGCCCTGUGCAGCTGTGGGCGCAG 3' 5' dCTGCGCCCACAGCTGCACAGGGCAGGTAAGCCAAGTACCC 3' 5' dCTGCGCCCACAGCTGCTCAGGGCAGGTAAGCCAAGTACCC 3' 5' dCTGCGCCCACAGCTGCCCAGGGCAGGTAAGCCAAGTACCC 3' 5' dCTGCGCCCACAGCTGCGCAGGGCAGGTAAGCCAAGTACCC 3' 5' dCCCACAGCTGCGCAGGGCAGGTAAGCCAAGTACCCTACGT 3' 5' dCTGCCCTGCGCAGCTGTGGG 3' 5' dCCCACAGCTGCGCAGGGCAG 3' 5' dCCCACAGCTGCCCAGGGCAGGTAAGCCAAGTACCCTAGCT3' 5' dCCCACAGCTGCACAGGGCAGGTAAGCCAAGTACCCTAGCT3' 5' dCCCACAGCTGCICAGGGCAGGTAAGCCAAGTACCCTAGCT3'

Nucleotides shown in bold build a mismatch pair in substrate oligonucleotides used in enzymatic tests. F: fluorescein (6-isomer), P: phosphate, U: 2'-d-Uridin residue, [AP]: model of a stable AP site (see section 3.1.3, Figure 14, A and B) 


\subsubsection{Molecular Ladders and Markers}

\subsubsection{DNA size marker}

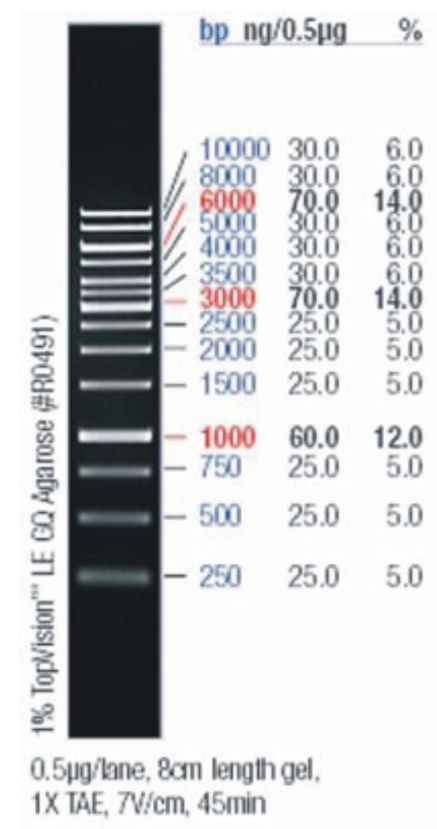

Figure 7: GeneRuler TM $1 \mathrm{~kb}$ (Fermentas, Burlington, Ontario)

The DNA molecular length standards were adjusted with TE buffer (2.1.9) and 6x loading dye solution

(Fermentas) to the DNA concentration of $0.1 \mu \mathrm{g} / \mu \mathrm{l}$ and stored at $4^{\circ} \mathrm{C}$. Lengths are indicated in base pa irs (bp).

\subsubsection{Protein size marker}

The unstained protein molecular weight marker (Fermentas, Burlington, Ontario) was used in all SDS-PAGE analysis.

\begin{tabular}{|c|c|c|c|}
\hline & MW, kDa & Protein & Source \\
\hline$\longrightarrow$ & -116.0 & $\beta$-galactosidase & E.coli \\
\hline$\longrightarrow$ & -66.2 & Bovine serum albumin & bovine plasma \\
\hline$-\infty$ & -45.0 & Ovalbumin & chicken egg white \\
\hline- & -35.0 & Lactate dehydrogenase & porcine muscle \\
\hline$\longrightarrow$ & -25.0 & REase Bsp98I & E.coli \\
\hline- & -18.4 & $\beta$-lactoglobulin & bovine milk \\
\hline - & -14.4 & Lysozyme & chicken egg white \\
\hline
\end{tabular}

Figure 8: Unstained protein molecular weight marker (Fermentas, Burlington, Ontario) In addition to the relative molecular weights $\times 10^{-3}$ of the various proteins, their sources are given as well. 


\subsubsection{Enzymes und Proteins}

BioGenes (Berlin)

Boehringer (Mannheim)

Fermentas (Burlington, Ontario)

New England Biolabs Inc. (Ipswich, MA)

Sigma (St. Louis, MO)
Polyclonal Anti-Mth212-Anticorper

Ribonuclease A (RNaseA)

Restriction endonucleases

Pfu-DNA-Polymerase (recombinant)

T4-DNA-Ligase

Calf Intestine Alkaline Phosphatase

Restriction endonucleases

Taq-DNA-Polymerase

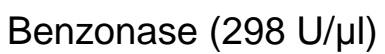

\subsubsection{Chemicals and reagents}

\section{AGS GmbH, Heidelberg:}

Qualex Gold Agarose

\section{AppliChem, Darmstadt:}

Acrylamid 4k - 30\% solution; Ampicillin (Na-salt); Bisacrylamid

4K-2\% solution; Chloramphenicol; Coomassie Brilliant Blue G250 und R250; Dithiothreitol (DTT); Methanol; 2-(N-morpholino) ethanesulfonic acid (MES); Nickel (II)-Chloride;

Phenylmethansulfonylfluorid (PMSF);

\section{Fermentas:}

Isopropyl- $\beta$-D-Thio-Galactopyranosid (IPTG)

\section{Fluka, Neu-Ulm:}

Bromphenol blue; Dimethylpimelinidat (DMP); Glutathion (reduced); Glycerol, 87\%;

Formamide; Polyethylene glykol (PEG) 6000; Silver nitrate

\section{GE Healthcare, Uppsala, Sweden:}

Chelating Sepharose ${ }^{\mathrm{TM}}$ Fast Flow

Invitek, Berlin:

dNTP (2'-Desoxyribosenucleosidtriphosphate)

\section{Invitrogen GmbH, Carlsbad, CA:}

SYBR $^{\circledR}$ Gold Nucleic Acid Gen Stain;

Dynabeads ${ }^{\circledR}$ Protein G- Immunoprecipitation kit 


\section{Merck, Darmstadt:}

2-Mercaptoethanol; Calcium chloride dehydrate; Formaldehyde; Magnesium chloride hexahydrat

\section{MJ Research, Waltham, MA:}

Chill-out ${ }^{\mathrm{TM}}$ liquid wax

\section{Oxoid, Cambridge, UK:}

Yeast extract; Tryptone; Bacteriological agar

\section{Roth GmbH, Kalsruhe:}

Ammonium acetate, Ammonium chloride, Ammonium sulphate, Ampicillin sodium salt, Chloramphenicol, Citric acid monohydrate, Disodium phosphate, Ethanol, Ethidium bromide, Acetic acid, Urea, (4-(2-hydroxyethyl)-1-piperazineethanesulfonic acid (HEPES), 2-Propanol, Kanamycin, Potassium chloride, Potassium hydroxide, Methanol, Sodium acetate, Sodium chloride, Monosodium phosphate, Sodium hydroxide, Sodium thiosulfate, Phenol, Phosphoric acid, Rotiphorese ${ }^{\circledR}$ Gel30 (Acrylamide:Bisacrylamide 37.5:1), Sucrose, Hydrochloric acid (smoking), Tris (hydroxymethyl) aminomethane

\section{Scharlau Chemie, Barcelona, Spain:}

Chloroform, Boric acid, Imidazole

\section{Serva, Heidelberg:}

Ammonium persulfate, Ethylenediaminetetraacetic acid (EDTA), Glycine, Sodium laurylsulphate (SDS), N,N,N',N'- Tetramethylethylenediamine(TEMED)

\section{Sigma, Steinheim:}

Tetrasodium pyrophosphate, Triethanolamine, Triton X-100 (Octylphenol-Polyethylenglycol), Polyethylenglycol-Sorbitan-Monolaurat $\left(\right.$ TWEEN $\left.^{\circledR} 20\right)$, Xylencyanol FF, L-Arabinose

\subsubsection{Molecular biology Kits}

Genomed, Bad Oyenhausen

Macherey-Nagel, Düren

Invitrogen, Carlsbad, CA

\subsubsection{Buffers and solutions}

ALF-marker
JETSTAR Plasmid Purification Kit NucleoTrap ${ }^{\circledR}$ and NucleoSpin ${ }^{\circledR}$ Gel extraction Kit Zero Blunt ${ }^{\circledR}$ TOPO ${ }^{\circledR}$ PCR Cloning Kit

95\% Formamide, 20mM EDTA pH 8.0, $5 \mathrm{mg} / \mathrm{ml}$

Dextran-Blue, stored at $4^{\circ} \mathrm{C}$ 
APS stock solution, $10 \%$

dNTP stock solution

EDTA stock solution

DTT stock solution

Ethidium bromide stock solution Isopropyl- $\beta$-D-thiogalactopyranosid (IPTG) stock solution

PBS-Buffer (1x)

Phenol/Chloroform

Phenol/TE

SDS-PAGE Loading buffer

RNase A stock solution

SSC-Buffer

Sucrose marker (DNA loading buffer)

50x TAE buffer

10x TBE buffer

T4-DNA-Ligase buffer

TE-buffer

1XTB-buffer (EMSA running buffer) 10x Taq-DNA-polymerase buffer
Ammonium persulfate in $\mathrm{H} 2 \mathrm{O}$, stored in aliquots at $-20{ }^{\circ} \mathrm{C}$

$10 \mathrm{mM}$ of each dNTP in $\mathrm{H} 2 \mathrm{O}$, stored at $-20^{\circ} \mathrm{C}$

500 mM EDTA dissolved in $\mathrm{H} 2 \mathrm{O}$ with addition of solid $\mathrm{NaOH}$

$1 \mathrm{M}$ DTT in $\mathrm{H} 2 \mathrm{O}$, sterilised $(0.45 \mu \mathrm{m}$ pore size filter) and stored at $-20^{\circ} \mathrm{C}$ $10 \mathrm{mg} / \mathrm{ml}$ Ethidium bromide

1M IPTG in $\mathrm{H} 2 \mathrm{O}$, sterilised $(0.45 \mu \mathrm{m}$ pore size filter) and stored at $-20^{\circ} \mathrm{C}$

10 mM Na2HPO4, 1.8 mM KH2PO4 pH 7.3, $140 \mathrm{mM} \mathrm{NaCl}, 2.7 \mathrm{mM} \mathrm{KCl}$

$25 \mathrm{vol}$. of phenol/TE, $24 \mathrm{vol}$. of Chloroform, 1 vol. of Isoamyl alcohol

Phenol, saturated with TE-Buffer, $0.1 \%(w / v)$

8-Hydroxychinolin

98\% Formamide, 10 mM EDTA pH 8.0,

0.025\% Xylencyanol FF, 0.025\% Bromphenol blue

$10 \mathrm{mg}$ RNaseA in $1 \mathrm{ml}$ of $10 \mathrm{mM}$ Tris/ $\mathrm{HCl} \mathrm{pH}$ 7.5, $15 \mathrm{mM} \mathrm{NaCl}$. The mix was preheated for $15 \mathrm{~min}$ at $100{ }^{\circ} \mathrm{C}$ and cooled down at RT $50 \mathrm{mM} \mathrm{NaCl}, 15 \mathrm{mM}$ Sodium citrate $60 \%(w / v)$ Sucrose, $0.05 \%(w / v)$ Bromphenol blue, $0.05 \%(w / v)$ Xylencyanol FF in TAE-Buffer 2M Tris/Acetate, $50 \mathrm{mM}$ EDTA 0.89M Tris/Borate pH 7.9, 25 mM EDTA $400 \mathrm{mM}$ Tris/HCl pH 7.8, 100 mM MgCl2, 100 mM DTT, 5 mM ATP $10 \mathrm{mM}$ Tris/HCl pH 8.0, $0.5 \mathrm{mM}$ EDTA $0.89 \mathrm{M}$ Tris/Borate $\mathrm{pH} 7.9$ $100 \mathrm{mM}$ Tris/HCl pH 9.0, $500 \mathrm{mM} \mathrm{KCl}$, $15 \mathrm{mM} \mathrm{MgCl}$, 1\% (v/v) Triton X-100 


\section{Antibiotika-Stammlösungen:}

Ampicillin stock solution

Chloramphenicol stock solution

Kanamycin stock solution

Tetracycline stock solution

100 mg/ml Ampicilin (Na-Salt)

$25 \mathrm{mg} / \mathrm{ml}$ in Ethanol, sterilised $(0.45 \mu \mathrm{m}$ pore

size filter) and stored at $-20^{\circ} \mathrm{C}$

$50 \mathrm{mg} / \mathrm{ml}$ in $\mathrm{H} 2 \mathrm{O}$, sterilised $(0.45 \mu \mathrm{m}$ pore size filter) and stored at $-20^{\circ} \mathrm{C}$

$25 \mathrm{mg} / \mathrm{ml}$ in $\mathrm{H} 2 \mathrm{O}$, sterilised $(0.45 \mu \mathrm{m}$ pore size filter) and stored at $-20^{\circ} \mathrm{C}$

Activity assay buffers:

Endonuclease buffer (1x)

20 mM H2KPO4/HK2PO4 buffer pH 6.2,

$50 \mathrm{mM} \mathrm{KCl}, 1 \mathrm{mM} \mathrm{MgCl} 2,0.1 \mathrm{mg} / \mathrm{ml}$ BSA

\section{Bradford assay buffer:}

Bradford dye solution

100 mg Coomassie brilliant blue G-250, $50 \mathrm{ml}$ 95\% Ethanol, $100 \mathrm{ml}$ 85\% Phosphoric acid, add $\mathrm{H} 2 \mathrm{O}$ up to $1 \mathrm{~L}$

BSA stock solution

$0,25,50,75,100$, and $150 \mu \mathrm{g}$ of BSA in $100 \mu \mathrm{l}$ 1XPBS buffer

Buffers for chromatography:

IMAC wash buffer

IMAC-elution buffer

$25 \mathrm{mM}$ HEPES / $\mathrm{KOH} \mathrm{pH} 7.6,0.5 \mathrm{M} \mathrm{NaCl}$

$30 \mathrm{mM}, 60 \mathrm{mM}, 70 \mathrm{mM}, 80 \mathrm{mM}, 90 \mathrm{mM}$, $100 \mathrm{mM}, 300 \mathrm{mM}$, and $500 \mathrm{mM}$ Imidazole in IMAC wash buffer

Heparin column wash buffer $20 \mathrm{mM}$ HEPES/KOH pH 7.6, $5 \mathrm{mM}$ 2-Mercaptoethanol (sterile filtrated)

Wash buffer for making salt gradient

$3 \mathrm{M} \mathrm{NaCl}$, sterile filtrated

\section{JETSTAR buffers (Genomed, Bad Oeynhausen):}

E1

E2

E3

E4

E5

E6
50 mM Tris/HCl pH 8.0, 10 mM EDTA

$200 \mathrm{mM} \mathrm{NaOH}, 1 \%(\mathrm{w} / \mathrm{v})$ SDS

3.1M Potassium acetate $\mathrm{pH} 5.5$

$100 \mathrm{mM}$ Sodium acetate $\mathrm{pH}$ 5.0, $600 \mathrm{mM} \mathrm{NaCl}$, $0.15 \%$ Triton $X-100$

$100 \mathrm{mM}$ Sodium acetate $\mathrm{pH}$ 5.0, $800 \mathrm{mM} \mathrm{NaCl}$, $100 \mathrm{mM}$ Tris/HCl pH 8.5, 1.25 M NaCl 


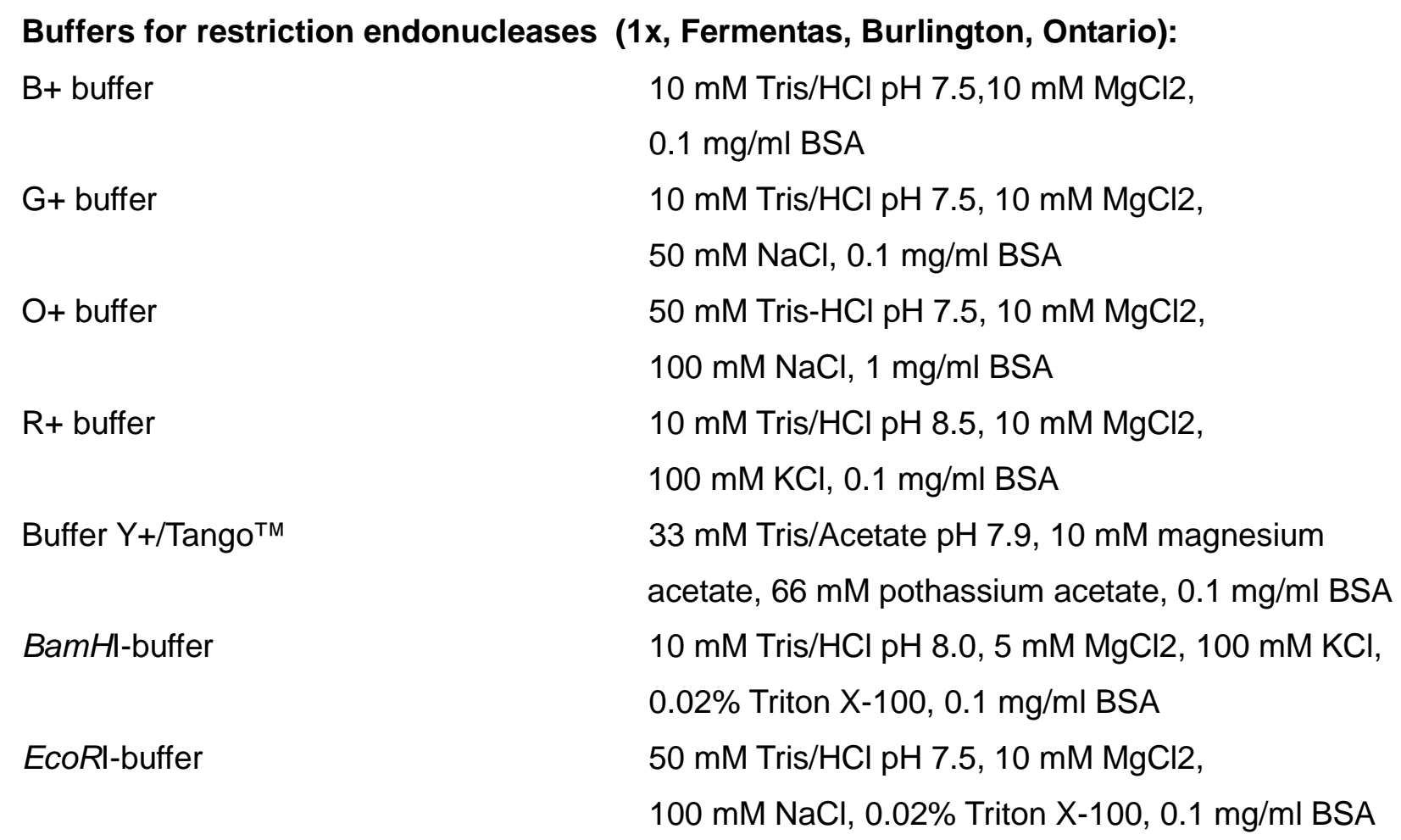

Buffers for restriction endonucleases (1x, New England Biolabs, Ipswich, MA):

NEB 1

$10 \mathrm{mM}$ Bis-Tris Propane/HCl pH 7.0, 10 mM MgCl2, $1 \mathrm{mM}$ DTT

NEB 2

$10 \mathrm{mM}$ Tris/HCl pH 7.9, 10 mM MgCl2,

$50 \mathrm{mM} \mathrm{NaCl}, 1 \mathrm{mM}$ DTT

NEB 3

$50 \mathrm{mM}$ Tris/ $\mathrm{HCl} \mathrm{pH} \mathrm{7.9,} 10$ mM MgCl2, $100 \mathrm{mM} \mathrm{NaCl}, 1 \mathrm{mM}$ DTT

NEB 4

$20 \mathrm{mM}$ Tris/Acetate $\mathrm{pH}$ 7.9, 10mM Magnesium acetate, $50 \mathrm{mM}$ Potassium acetate, $1 \mathrm{mM}$ DTT

SDS-PAGE buffers:

Coomassie R250 dye solution

$0.7 \%(w / v)$ Coomassie R-250 in Methanol, $20 \%$ Acetic acid, mixed at 1:1 before use

Loading dye (or sample buffer) $200 \mathrm{mM}$ Tris/HCl, 8M urea, $200 \mathrm{mM}$ DTT, $2 \%$ (w/v) SDS, $0.05 \%$ Bromphenol blue

Laemmli buffer (1x) 25 mM Tris/HCl pH 8.4, 200 mM Glycin, $0,1 \%(w / v)$ SDS

SDS $10 \%(w / v)$ SDS in $\mathrm{H} 2 \mathrm{O}$

Stacking gel buffer 1.25M Tris/ $\mathrm{HCl} \mathrm{pH} 6.8$

Separating gel $1.875 \mathrm{M}$ Tris/HCl pH 8.8 


\subsubsection{Bacterial Growth Media}

dYT- (double Yeast Tryptone)

$1.6 \%(\mathrm{w} / \mathrm{v})$ Trypton, $1 \%(\mathrm{w} / \mathrm{v})$ yeast extract,

$0.5 \%(\mathrm{w} / \mathrm{v}) \mathrm{NaCl}$ in $\mathrm{H} 2 \mathrm{O}$, autoclaved

dYT-Agar

$1.6 \%(\mathrm{w} / \mathrm{v})$ Trypton, $1.5 \%(\mathrm{w} / \mathrm{v})$ Agar, 1\% (w/v)

yeast extract, $0.5 \%(\mathrm{w} / \mathrm{v}) \mathrm{NaCl}$ in $\mathrm{H} 2 \mathrm{O}$,

autoclaved

Antibiotics were added after the media were autoclaved and cooled to below $60^{\circ} \mathrm{C}$.

\subsubsection{Molecular Biology Equipment and computer hardware}

Automated Laser Fluorescence

DNA Sequencer (A.L.F.-sequencer)

Incubator

Constant Cell Disruption System

Electrophoresis unit

Midget

Gel Jet Imager

Gene Pulsar ${ }^{\circledR}$ and Pulse Controller

Metal block thermostat

Milli- $Q^{\circledR}$ Water Purification System

Pipetman ${ }^{\circledR}$ Model P1000, P200, P20

pH-Meter-526

Rotary shaker

Thermocycler Primus 96plus

Branson Sonifier W-250

UV-VIS Spectrophotometer

UVT2035 UV transilluminators

Precision Balances L $420 \mathrm{P}$

Precision Balances U 4800 P

Vision Workstation, BioCad ${ }^{\circledR}$ Family

Vortex Genie 2 ${ }^{\mathrm{TM}}$

\section{Electrophoresis power supplies:}

ECPS $3000 / 150$

LNGs 350-06

\section{Centrifuges:}

Centrikon T-1055
GE Healthcare, Uppsala, Sweden

W. C. Heraeus $\mathrm{GmbH}$, Hanau

Constant Systems Ltd, Northants, England model 2050

GE Healthcare, Uppsala, Sweden

Intas, Göttingen

BioRad, Munich

Institute of Microbiology and Genetics,

University of Göttingen

MILLIPORE, Eschborn

Gilson, Bad Camberg

Schütt Labortechnik, Göttingen

Infors AG, Bottmingen, Switzerland

MWG Biotech, Ebersberg

Heinemann, Schwäb. Gmünd

UV-1601 SHIMADZU Corporation, Kyoto, Japan

Herolab, Wiesloch

Sartorius, Goettingen

Sartorius, Goettingen

Applied Biosystems, Foster City, CA

Bender \& Hobein AG, Zurich, Switzerland

GE Healthcare, Uppsala, Sweden

Heinzinger, Rosenheim

Kendro, Langenselbold 
Mikroliter

Mikro Rapid/K

Rotanta/RPC

Roto Silenta/RP

Sorvall ${ }^{\circledR}$ RC5C (Rotor SS34)

\subsubsection{Other materials}

Baktolin 5.5 (Disinfection solution)

Dialysis tubes VISKING®

Disposable Syringes

Glass flasks and test tubes

Glass pipettes

Glass plates for SDS gels

Heparin column, Poros ${ }^{\circledR}$ HE 20

Meliseptol (disinfection solution)

Parafilm

$\mathrm{pH}$-Indicator stick

PCR cups

Petri dishes

Pipette tips

Precision Cells-Quartz glass cuvettes

Reaction Vessels $(1,5 \mathrm{ml}, 2 \mathrm{ml}, 50 \mathrm{ml})$

Scalpel blades

Ultrafiltration tubes
Hettich, Tuttlingen

Hettich, Tuttlingen

Hettich, Tuttlingen

Hettich, Tuttlingen

Kendro, Langenselbold

Bode Chemie, Hamburg

SERVA, Heidelberg

Perumo®Syringe, Leuven, Belgium

Schott, Mainz

Brand, Wertheim

GE Healthcare, Uppsala, Sweden

Applied Biosystems, Foster City, CA

Braun Melsungen AG, Melsungen

American National Can., Chicago, USA

Merck, Darmstadt

Biozym, Hess.-Oldendorf

Greiner, Nürtingen

Sarstedt, Nümbrecht

Hellma, Mühlheim/Baden

Sarstedt, Nümbrecht

Bayha $\mathrm{GmbH}$, Tuttlingen

Vivaspin Vivascience $\AA$, Hannover

\subsubsection{Software}

ALF-Manager

BOXSHADE

Chromas $^{\odot}$

CLUSTAL W

CoreIDRAW ${ }^{\circledR} \mathrm{X} 3$

Endnote

$\mathrm{ISIS}^{\mathrm{TM}} /$ Draw
Version 3.02 (1995), GE Healthcare, Uppsala, Sweden

Version 3.21, K. Hofmann and M. Baron

(www.ch.embnet.org/software/BOX_form.html)

Version 1.45 (32 bit), Version 2.01 and Version 2.31

Technelysium Pty. Ltd.

Service of European Bioinformatics Institute (EBI)

http://www.ebi.ac.uk/Tools/clustalw/

Version 13.0, Corel GmbH, Unterschleissheim

Version 7, Thomson ISI Research Soft, Carlsbad, CA

Version 2.1.3d, MDL Information Systems Inc., San

Ramon, CA 
Fragment Manager

OligoCalc

Protein Molecular Weight

PyMOL $^{\text {TM }}$

RNAfold

SigmaPlot

TreeView

\section{Vision Workstation Perfusion}

Chromatography

Wisconsin Package

Microsoft ${ }^{\circledR}$ Office Word

Vector NTI
Version 1.2 (1995), GE Healthcare, Uppsala, Sweden

Service of Northwestern University Medical School

http://www.basic.northwestern.edu/biotools/oligocalc.html

Service of Bioinformatics Organisation Inc.

http://www.bioinformatics.org/sms/prot mw.html

Version 0.98 (2005), DeLano Scientific LLC,

San Carlos, CA

Vienna RNA Package, Vienna, Austria

Version 6.0, SPSS Inc., Chicago, IL

Version 1.6.6, Roderic D.M. Page, 2001

Version 2.0, Applied Biosystems, Foster City, CA

Version 10.0, Genetic Computer Group (GCG),

Madison, WI

Version 2007, Microsoft GmbH, Unterschleißheim

Version 10.3, Invitrogen, Carlsbad, CA

\subsubsection{Databanks}

NCBI-Databank for protein, nucleotide, and genomic sequences:

http://www.ncbi.nlm.nih.gov/

Repertoire of T/G-, dU-Repair Enzymes in Different Organisms:

http://www.gobics.de/repairenzymes/maintable

(User name: gast, Password: Sac2haromyces)

\subsection{Methods}

\subsubsection{Microbiological methods}

\subsubsection{Bacterial media and stocks preparation}

Bacterial growth media, buffers and thermostable solutions were sterilized by autoclaving for $20 \mathrm{~min}$ at $212^{\circ} \mathrm{C}$. Antibiotics were sterile filtered using a syringe and $0.2 \mu \mathrm{m}$ sterile filters. For selective media preparation, the autoclaved media solutions were cooled down to approximately $50^{\circ} \mathrm{C}$ and sterile antibiotic solution was added. 


\subsubsection{E.coli culture and storage}

For the initiation of a new cell culture, $50 \mu \mathrm{l}$ of E.coli glycerine culture were inoculated into 50 $\mathrm{ml}$ of $\mathrm{dYT}$ medium and incubated at $3^{\circ} \mathrm{C}$ over night. E.coli cells were grown in dYT medium (2.1.10) at $37^{\circ} \mathrm{C}$ on a shaker. Cell growth was monit ored by absorption at $600 \mathrm{~nm}\left(\mathrm{OD}_{600}\right)$. In order to obtain single cell colonies, cultures were diluted and plated on dYT/agar or LB/agar plates. E.coli glycerine culture stocks were made by re-suspending of $1 \mathrm{ml}$ over night culture in glycerine at $1: 1$ ratio $(\mathrm{v} / \mathrm{v})$ and stored at $-20^{\circ} \mathrm{C}$. Alternatively, $9 \%$ DMSO culture stock was made and stored at $-80^{\circ} \mathrm{C}$.

\subsubsection{Molecular biology methods}

\subsubsection{Ethanol precipitation of DNA}

This method allows concentration of DNA samples, as well as removal of salts and small organic molecules. $1 / 10$ vol. of $7 \mathrm{M}$ ammonium acetate and 3 vol. of $96 \%$ ethanol were added to DNA samples followed by incubation at $-20^{\circ} \mathrm{C}$ for $30 \mathrm{~min}$. DNA was pelleted by centrifugation for $30 \mathrm{~min}$ at $15000 \mathrm{rpm}$ and $4^{\circ} \mathrm{C}$ (Mik ro Rapid/K Hettich). DNA pellets were washed with $70 \%$ ethanol, centrifuged for $15 \mathrm{~min}$ at $4^{\circ} \mathrm{C}$, and dried at $3^{\circ} \mathrm{C}$. Finally, dried DNA pellets were dissolved in double distilled water ( $\mathrm{ddH} 2 \mathrm{O})$ and stored at $-20^{\circ} \mathrm{C}$.

\subsubsection{Phenol/Chlorophorm DNA extraction}

Phenol/Chlorophorm extraction was mostly used to remove protein contaminants from DNA samples subjected to a restriction endonuclease digestion. DNA samples (min $50 \mu \mathrm{l}$ ) were consecutively mixed with corresponding volumes of phenol (pH8.0), phenol/chlorophorm/isoamilalkohol (25:24:1, v/v), and chlorophorm. Before each solution change, samples were centrifuged for $5 \mathrm{~min}$ at $15000 \mathrm{rpm}$ and RT and DNA containing top aqueous phase was transferred into a new tube. DNA was finally precipitated with ethanol (see 2.2.2.1).

\subsubsection{Plasmid DNA mini-preparation (alkaline lysis)}

$2 \mathrm{ml}$ of bacterial culture grown over night at $37^{\circ} \mathrm{C}$ were used to prepare plasmid DNA by modified alkaline/SDS lysis method using JetStar E1, E2, E3-solutions (Birnboim and Doly, 1979). E.coli cells were pelleted by centrifugation for $1 \mathrm{~min}$ at $13000 \mathrm{rpm}$ and RT. Pellet was resuspended in $150 \mu \mathrm{l}$ of $\mathrm{E} 1$ solution by vortexing and $150 \mu \mathrm{l}$ of $\mathrm{E} 2$ lysis solution was added followed by incubation for 5 min at RT. After neutralization with $150 \mu$ of E3 solution, samples were incubated for $10 \mathrm{~min}$ on ice, and centrifuged for $15 \mathrm{~min}$ at $15000 \mathrm{rpm}$ and $4^{\circ} \mathrm{C}$. RNase $\mathrm{A}$ solution (10 $\mu \mathrm{g} / \mathrm{ml}$ final concentration) was added to the supernatant followed by incubation 
for $30 \mathrm{~min}$ at $37^{\circ} \mathrm{C}$. Finally, plasmid DNA was phenol/chlorophorm extracted and precipitated with ethanol (2.2.2.1).

\subsubsection{Plasmid DNA midi-preparation}

JETstar ${ }^{\circledR}$ Kit was used for plasmid DNA preparation from $50 \mathrm{ml}$ of over night E.coli culture. Cells were pelleted by centrifugation (4000 rpm, $10 \mathrm{~min}, 4^{\circ} \mathrm{C}$ (Rotanta RPK, Hettich)) and resuspended in $4 \mathrm{ml}$ of $\mathrm{E} 1$ solution until homogeneous. Then E2 solution was added with gentle mixing and samples were incubated for $5 \mathrm{~min}$ at RT. After addition of E3 solution, samples were mixed by multiple inversions and cell debris were removed by centrifugation for $10 \mathrm{~min}$ at $4000 \mathrm{rpm}$ and RT. Cleared supernatant was applied to a JETstar column equilibrated with E4 solution followed by washing twice with $10 \mathrm{ml}$ of E5 solution. DNA was eluted with $5 \mathrm{ml}$ of E6 solution, precipitated with 0.7 volume of isopropanol and pelleted by centrifugation for $15 \mathrm{~min}$ at $15000 \mathrm{rpm}$ and $4^{\circ} \mathrm{C}$. Fin ally, DNA pellet was washed with $70 \%$ ethanol, dried at $3^{\circ} \mathrm{C}$, and redissolved in $10 \mu$ of double distilled water ( $\mathrm{ddH} 2 \mathrm{O}$ ).

\subsubsection{Polymerase Chain Reaction (PCR)}

PCR process usually consists of a series of 25-50 cycles carried out in an automated thermal cycler and comprises three major steps: DNA denaturation, primer annealing, and primer extension. During denaturation step at $9^{\circ} \mathrm{C}$, the do uble-stranded DNA opens into singlestranded DNA. Then two specific primers complementary to sequence, which flanks the target DNA loci, hybridize to a single-stranded template at primer annealing temperature $\left(T_{A}\right)$. Finally, a thermostabel DNA polymerase builds up a complementary DNA strand beginning from 3' end of the primer. During PCR amplification, the amount of target DNA fragment grows exponentially. The following general PCR mixture was used for amplification on plasmid and genomic DNA templates:

\begin{tabular}{|l|l|}
\hline \multicolumn{1}{|c|}{ Reaction mix } & \\
\hline Template DNA & $50-100 \mathrm{ng}$ \\
Primer N1 $(10 \mathrm{pmol} / \mu \mathrm{l})$ & $1-2 \mu \mathrm{l}$ \\
Primer N2 $(10 \mathrm{pmol} / \mu \mathrm{l})$ & $1-2 \mu \mathrm{l}$ \\
Polymerase & $1-2 \mathrm{U}$ \\
10x Polymerase buffer & $5 \mu \mathrm{l}$ \\
dNTPs $(10 \mathrm{mM})$ & $1 \mu \mathrm{l}$ \\
dd $\mathrm{H}_{2} \mathrm{O}$ & up to $50 \mu \mathrm{l}$ \\
\hline
\end{tabular}

The following typical cycling protocol was used with modifications of annealing temperature, elongation time, and/or elongation temperature depending on the primer pair used and on the length of PCR fragment: 


\begin{tabular}{|l|c|c|}
\hline \multicolumn{1}{|c|}{ Step } & Temperature & Time \\
\hline 1. & $95^{\circ} \mathrm{C}$ & $3 \mathrm{~min}$ \\
2. Polymerase addition & $85^{\circ} \mathrm{C}$ & $2 \mathrm{~min}$ \\
3. & $94^{\circ} \mathrm{C}$ & $1 \mathrm{~min}$ \\
4. & $\mathrm{~T}^{*}$ & $1 \mathrm{~min}$ \\
5. & $72^{\circ} \mathrm{C}$ & $1 \mathrm{~min}$ \\
6. & $72^{\circ} \mathrm{C}$ & $10 \mathrm{~min}$ \\
Step 2-5: 30x repeat cycles & & \\
\hline
\end{tabular}

* $\mathrm{T}_{\mathrm{A}}$ : Optimal primer annealing temperature calculated by following equation:

$T_{A}=\left(T_{m 1}+T_{m 2}\right) / 2-3^{\circ} \mathrm{C}$, where $T_{m 1}$ and $T_{m 2}$ are melting temperatures of Primer 1 and Primer 2 , accordingly;

$\mathrm{T}_{\mathrm{m}}$ of PCR primers were calculated using the following equation: $\mathrm{T}_{\mathrm{m}}\left[{ }^{\mathrm{C}}\right]=69.3+0.41(\% \mathrm{G}+\mathrm{C})-650 / \mathrm{N}$ (Chester and Marshak, 1993)

$30 \mu$ of Chill-out ${ }^{\mathrm{TM}}$ Wax (2.1.7) was added on top of each PCR mix in order to avoid the sample evaporation during PCR in thermal cycler (2.1.11).

\subsubsection{Spectrophotometric determination of DNA concentration}

Absorption of ultra-violet (UV) light by the ring structure of purines and pyrimidines is the basis of the spectrophotometric DNA analysis. DNA samples were diluted in $\mathrm{ddH}_{2} \mathrm{O}(1: 10$ or 1:100) depending on estimated concentrations. DNA concentration were determined by measuring the absorbance at $\lambda=260 \mathrm{~nm}\left(\mathrm{~A}_{260}\right)$ using a spectrophotometer and a quartz cuvette. The concentration was calculated based on the assumption that $A_{260}=1.0$ is equal to $50 \mu \mathrm{g} / \mathrm{ml}$ of double-stranded (ds) DNA, to $40 \mu \mathrm{g} / \mathrm{ml}$ of single-stranded (ss) DNA and RNA, and to $20 \mu \mathrm{g} / \mathrm{ml}$ of oligonucleotides. The purity of DNA was assessed by the $A_{260} / A_{280}$ ratio. Ratios between 1.8 and 2.0 are indicative of pure, protein-free DNA.

\subsubsection{Agarose gel electrophoretic analysis of DNA}

DNA molecules can be separated according to their size by electrophoretic migration.

For preparative and analytical DNA analysis 1\%-2\% agarose gel electrophoresis was used. The agarose was dissolved in 1XTBE buffer (2.1.9) in a microwave. Then $0.5 \mu \mathrm{g} / \mathrm{ml}$ of ethidium bromide (2.1.9) was added and the gel was poured into a horizontal gel-forming chamber. Samples were mixed with 0.5 vol. of loading buffer (2.1.9). Gels were run in 1 XTBE buffer at the constant electric field power of 5-10 V/cm. DNA in the gel was visualized under UV light at $305 \mathrm{~nm}$ using UV transilluminator (2.1.11).

\subsubsection{Denaturing polyacrylamide gel electrophoresis (A.L.F-PAGE)}

Automated Laser Fluorescence DNA Sequencer (A.L.F.-DNA sequencer 2.1.11) allows direct detection of fluorescently labelled DNA. During electrophoresis DNA fragments migrate 
downwards through the gel. The laser beam excites fluorescently labelled DNA and the emitted light is detected by fluorescent detection system. Collected photo-detector signals are then digitized and sent to a computer for further processing. Results are represented in the form of intensity peaks plotted against the running time scale. Reaction products of all activity assays performed with DNA modifying enzymes were analyzed by A.L.F.-sequencer (2.1.11). DNA samples were mixed with A.L.F.-marker (2.1.9) and applied onto $11 \%$ denaturing polyacrylamide/urea gel $(30 \times 28 \times 0.5 \mathrm{~cm})$.

$11 \%$ A.L.F.-PAGE protocol:

\begin{tabular}{|l|l|}
\hline Reagent & Amount \\
\hline Urea & $29.43 \mathrm{~g}(7 \mathrm{M})$ \\
Acrylamide (30\%) & $24.84 \mathrm{ml}(10.65 \%)$ \\
Bisacrylamide (2\%) & $12.42 \mathrm{ml}(0.35 \%)$ \\
$10 X T B E$ & $8.40 \mathrm{ml}$ \\
APS (10\%) & $700 \mu \mathrm{l}$ \\
TEMED & $70 \mu \mathrm{l}$ \\
ddH $_{2} \mathrm{O}$ & up to $70 \mathrm{ml}$ \\
\hline
\end{tabular}

Sterile filtered A.L.F.-PAGE was poured in between two cleaned (water, ethanol, isopropanol) and thermostable glass plates and a plastic comb was inserted to form wells. Gel was polymerized for approximately $30 \mathrm{~min}$ at RT. Then comb was removed, wells were rinsed with water, gel was placed into electrophoresis chamber, and buffer reservoirs were filled with 1XTBE buffer (2.1.9). Before applying samples, the gel was preheated for $20 \mathrm{~min}$. DNA samples were mixed with A.L.F. marker ( $1 / 2$ sample volume), preheated for 5 min at $95^{\circ} \mathrm{C}$, and applied onto the gel loading up to $15 \mu \mathrm{l}$ into each well. The gel was run for $250 \mathrm{~min}$ at a constant power of $52 \mathrm{~W}, 52^{\circ} \mathrm{C}$, a laser power of $4 \mathrm{~mW}$, and a sampling power of $2 \mathrm{~s}$.

Electrophoresis data were processed using Fragment Manager (GE Healthcare, see 2.1.13).

\subsubsection{DNA extraction from agarose gel}

To extract DNA from agarose gel, the desired band was excised with a sterile scalpel under UV light (305 nm). DNA was purified using NucleoTrap® (Macherey \& Nagel, section 2.1.8) purification kit, where agarose gel slices were dissolved in the presence of chaotropic salts (buffer NT1 and NT2) and DNA was bound to a silica matrix. After several washing steps of silica matrix, pure DNA was finally eluted under low ionic strength conditions (NE buffer). NT1, manufacturer provided NT2 and NE buffers.

\subsubsection{Site-directed mutagenesis using PCR (modified Stratagene protocol)}

PCR based mutagenesis allows to introduce site-specific mutations in double-stranded plasmid DNA. This procedure utilizes a supercoiled dsDNA vector with an insert of interest 
and a pair of complementary oligonucleotide primers containing a desired mutation (Figure9). During amplification in an automated thermocycler, Pfu DNA polymerase extends the primers and linear mutated plasmid is generated. Then parental DNA is eliminated by enzymatic digestion using Dpnl restriction nuclease specific for methylated and hemimethylated DNA. Finally, newly synthesized mutated plasmid is transformed into competent E.coli cells where it undergoes repair by endogenous bacterial machinery (Figure9).

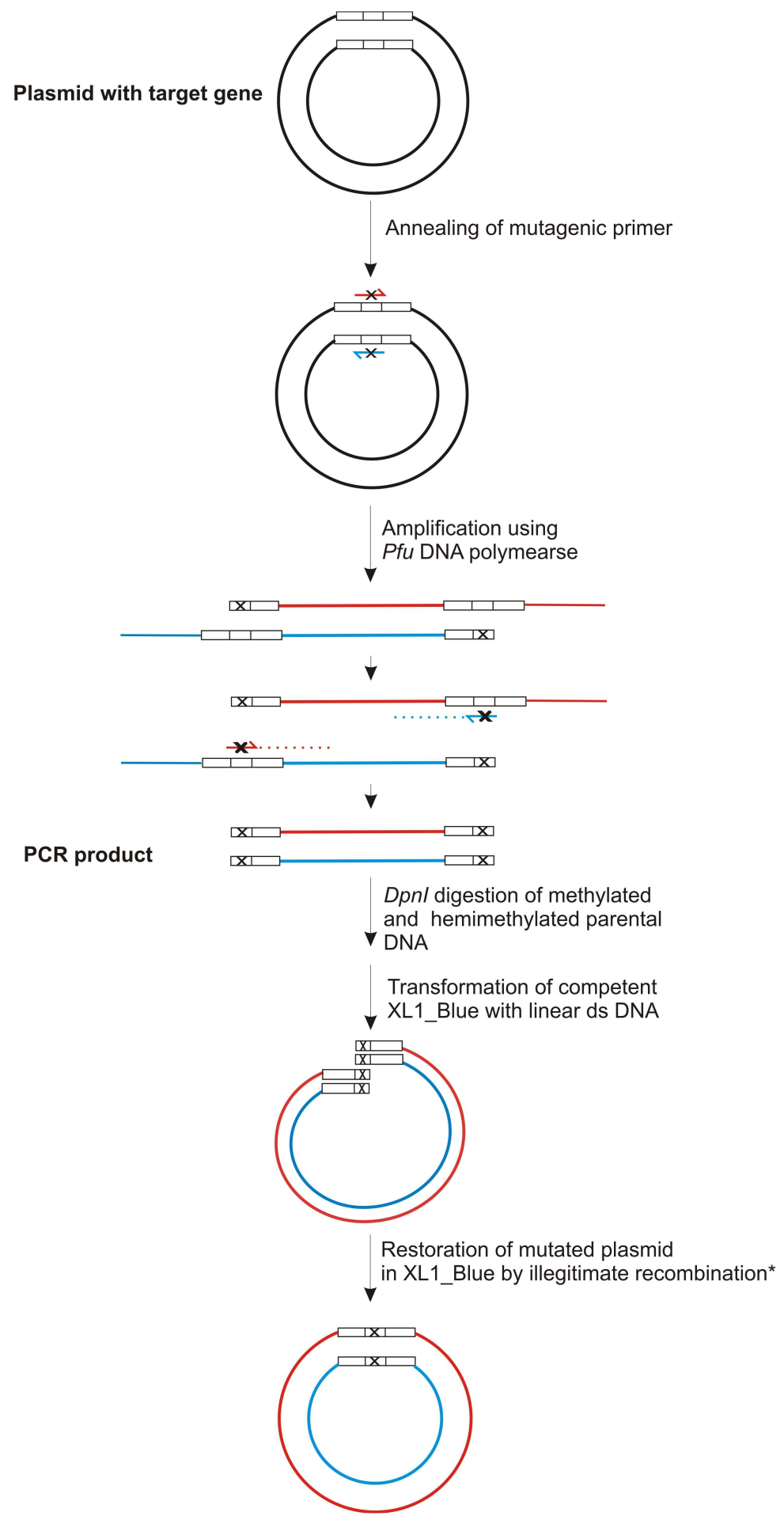

Figure 9: Schematic representation of the site-directed mutagenesis

*(Conley et al., 1986; Jones, 1994; Yamashita et al., 1999) 
The following general PCR mixture and cycling protocol were used for linear amplification on plasmid DNA templates:

\begin{tabular}{|l|l|}
\hline PCR mix components & Amount \\
\hline Template DNA & $50 \mathrm{ng}$ \\
Primer N1 $(100 \mathrm{nmol} / \mu \mathrm{l})$ & $125 \mathrm{ng}$ \\
Primer N2 $(100 \mathrm{nmol} / \mu \mathrm{l})$ & $125 \mathrm{ng}$ \\
Pfu polymerase & $2.5 \mathrm{U}$ \\
10x Pfu buffer $\left(+\mathrm{MgSO}_{4}\right)$ & $5 \mu \mathrm{l}$ \\
dNTPs $(10 \mathrm{mM})_{\text {dd }_{2} \mathrm{O}}$ & $1 \mu \mathrm{l}$ \\
\hline
\end{tabular}

PCR protocol:

\begin{tabular}{|c|c|c|c|}
\hline Step & Temperature & Time & \\
\hline $\begin{array}{l}1 . \\
2 . \text { Polymerase addition } \\
3 . \\
4 . \\
5 . \\
6 . \\
\text { Step 3-5: 18x repeat cycles }\end{array}$ & $\begin{array}{l}95^{\circ} \mathrm{C} \\
85^{\circ} \mathrm{C} \\
95^{\circ} \mathrm{C} \\
65^{\circ} \mathrm{C} \mathrm{TA}^{*} \\
72^{\circ} \mathrm{C} \\
72^{\circ} \mathrm{C}\end{array}$ & $\begin{array}{l}1 \text { min } \\
2 \mathrm{~min} \\
50 \mathrm{sec} \\
50 \mathrm{sec} \\
10 \mathrm{~min} \\
15 \mathrm{~min}\end{array}$ & \\
\hline \multicolumn{4}{|c|}{$\mathbf{T}_{\mathbf{A}}$ indicates an annealing temperature for mutagenic primer estimated using following formula: } \\
\hline \multicolumn{4}{|c|}{$\mathbf{T}_{\mathbf{m}}=81.5+0.41(\% \mathrm{G}+\mathrm{C})-675 / \mathrm{N}-\%$ mismatch, where } \\
\hline
\end{tabular}

Usually 5X $50 \mu \mathrm{l}$ PCR mixtures were linear amplified in an automated thermocycler (2.1.11) using Pfu DNA polymerase (2.1.6, Fermentas), pooled down and ethanol precipitated (2.2.2.1, Figure 1, A). DNA was resuspended in $8 \mu \mathrm{l}$ of $\mathrm{ddH} 2 \mathrm{O}$ and subjected to Dpnl (2.1.6,Fermentas) digestion $\left(1 \mu \mathrm{l}\right.$ of $D p n$ for $1 \mathrm{~h}$ at $\left.37^{\circ} \mathrm{C}\right)$ in $10 \mu \mathrm{l}$ total volume, followed by preparative DNA agarose gel electrophoresis and DNA gel extraction (2.2.2.7 and 2.2.2.9, Figure 11, B and C). $50 \mu \mathrm{l}$ of electro competent XL1-Blue E.coli cells (2.1.1.6) were transformed with $2 \mu \mathrm{l}$ of gel purified mutated plasmid DNA and incubated overnight on dYT/Amp ${ }^{100} /$ Tet $^{25}$ (2.1.10) agar plates. 10-20 single colonies were used for plasmid preparation (2.2.2.3 and 2.2.2.4), followed by a preliminarily restriction analysis with Xhol/Ncol restriction endonucleases (Fermentas 2.1.6, Figure 11, D). Finally, DNA from a minimum of 10 transformants was verified for desired point mutation by sequencing. One of the positive clones was subsequently used for mutant protein production (2.2.3.3.). 
2.2.2.11 Transformation of competent $E$. coli by electroporation (Dower et al., 1988). $200 \mu \mathrm{l}$ of over night E.coli culture were inoculated into $50 \mathrm{ml}$ of dYT medium (2.1.10) and grown to mid-log phase $\left(\mathrm{OD}_{600^{\sim}} 0,6\right)$ at $37^{\circ} \mathrm{C}$ on a shaker. Cells were harvested by centrifugation in $50 \mathrm{ml}$ falcon tubes for $10 \mathrm{~min}$ at 4.000 r.p.m. and $4^{\circ} \mathrm{C}$ (Rotanta/RPK, Hettich), carefully resuspended in $50 \mathrm{ml}$ of ice-cold $\mathrm{H}_{2} \mathrm{O}$ and incubated on ice for 20 min. Then cell suspension was centrifuged and cell pellet was washed 4 times by resuspention in ice-cold $\mathrm{H} 2 \mathrm{O}(40 \mathrm{ml}, 30 \mathrm{ml}, 20 \mathrm{ml}$ and $10 \mathrm{ml}$ ), followed by centrifugation after each wash. Finally, pellet was dissolved in 1-2 $\mathrm{ml}$ of $\mathrm{H}_{2} \mathrm{O}$ and left on ice. For the transformation, 1-2 $\mu \mathrm{l}$ of DNA solution $(2 \mu \mathrm{g})$ were mixed with $75 \mu \mathrm{l}$ of electrocompetent cells and incubated on ice for 5 min. DNA-cell mixture was transferred into a chilled electroporation cuvette and subjected to the pulse at $2.5 \mathrm{kV}, 200 \Omega$ and $2.5 \mu \mathrm{F}$ (2.1.11). Then transformants were immediately resuspended with 1-2 $\mathrm{ml}$ of $\mathrm{dYT}$ medium (2.1.10), incubated for $1 \mathrm{~h}$ at $37^{\circ} \mathrm{C}$ on a shaker and $100 \mu \mathrm{l}$ aliquots (with or without dilution) were plated out onto dYT agar plates containing appropriate antibiotics. Untransformed competent cells used as a negative control were also plated on antibiotics containing agar plates.

\subsubsection{DNA cleavage by restriction endonucleases}

For effective DNA cleavage optimal temperatures and buffers recommended by manufacturer were used (2.1.6). $50 \mathrm{U}$ of enzyme was used for preparative DNA cleavage (minimum $5 \mu \mathrm{g}$ ) in $100 \mu \mathrm{l}$ assay volume for $1 \mathrm{~h}$ or maximal $16 \mathrm{~h}$. For analytical DNA cleavage (300-500 ng), 5 $U$ of restriction enzyme in $20 \mu \mathrm{l}$ assay volume were used. In case of double digestion, if no single buffer could be found where both enzymes would show 50-100\% activity, two subsequent digestion reactions were performed. After first digestion, DNA was ethanol precipitated (2.2.2.1).

\subsubsection{Preparation of oligonucleotide substrates for activity assays}

For endonuclease assays, $0.01 \mathrm{pmol} / \mu \mathrm{l}$ substrate stocks were prepared by hybridization of $5 \mathrm{pmol}$ of a fluorescein-labelled oligonucleotide with 25 pmol of an opposite strand oligonucleotide in $100 \mu \mathrm{l}$ of 1 XSSC buffer (2.1.9) using an automated termocycler (Program: $90^{\circ} \mathrm{C}, 15 \mathrm{sec}$; $80^{\circ} \mathrm{C}, 3 \mathrm{~min}$; $50^{\circ} \mathrm{C}, 15 \mathrm{~min}$; $20^{\circ} \mathrm{C}, 15 \mathrm{~m}$ in), followed by a $1: 5$ dilution with water. In case of a single-stranded (ss) substrate preparation, 5 pmol of fluorescein-labelled oligonucleotides were mixed with $100 \mu \mathrm{l}$ of 1 XSSC buffer and $400 \mu \mathrm{l}$ of water subsequently. For EMSA substrates preparation, 100 pmol of 40_PRI_AP_Dunkel, PRINCE_U_Dunkel, PRINCE_C_Dunkel, PRINCE_T_Dunkel (not fluorescein-labelled) were hybridized with 100 pmol of PRINCE_G_35mer or PRINCE_G_40mer opposite strand in $100 \mu \mathrm{l}$ of 1XSSC buffer (2.1.9). 


\subsubsection{Electrophoretic Mobility Shift Assay}

The Electrophoretic Mobility Shift Assay (EMSA) also referred to as the gel shift assay is based on the fact that DNA-protein complexes migrate slower relative to free DNA molecules when subjected to a non-denaturing polyacrylamid gel electrophoresis. We used EMSA to investigate protein-DNA binding activity.

Gel-shift assays were performed by incubating of purified protein with 1 pmol ( 26ng) of a respective unlabelled oligonucleotide substrate (EMSA substrate 2.2.2.13) for $5 \mathrm{~min}$ at $65^{\circ} \mathrm{C}$ in $10 \mu \mathrm{l}$ of EMSA buffer (2.1.9) containing $10 \%$ glycerol. Reaction products were analysed on 10\% TE-PAGE (see Table 4). Gels were run at room temperature for $50 \mathrm{~min}$ at $10 \mathrm{~V} / \mathrm{cm}$ in $1 \times T E$ (2.1.9) running buffer and stained with SYBRO ${ }^{\circledR}$-Gold (Invitrogen, 2.1.7) according to the manufacturer protocol. DNA was visualised by UV-Transilluminator (2.1.11) at $302 \mathrm{~nm}$.

Competitive EMSAs were carried out as described previously, except that EMSA substrate ologonucleotides were mixed with increasing amount of unlabelled competitor DNA for $5 \mathrm{~min}$ at $6^{\circ} \mathrm{C}$ in EMSA buffer followed by adding appropriate amount of pure protein to a final volume of $15 \mu \mathrm{l}$ and further incubation for $5-10 \mathrm{~min}$ at $65^{\circ} \mathrm{C}$. The amount of competitor DNA added was calculated as molar equivalents of nucleotide relative to substrate in case of entire pET-vector and as molar equivalents of DNA ends in case of blunt 20-mer dsDNA oligonucleotides correspondently.

Table 4: 10\% TE-PAGE $(60 \mathrm{ml})$ recipe:

\begin{tabular}{|l|c|}
\hline Reagent & Volume \\
\hline Acriylamid/Bisacrylamid 30\% (37.5:1) & $20 \mathrm{ml}$ \\
\hline $10 X T B E$ buffer & $6 \mathrm{ml}$ \\
\hline $10 \%$ ammonium persulfate (APS) & $400 \mu \mathrm{l}^{*}$ \\
\hline TEMED & $30 \mu \mathrm{l}^{*}$ \\
\hline $\mathrm{H} 2 \mathrm{O}$ & $33.9 \mathrm{ml}$ \\
\hline
\end{tabular}

\subsubsection{DNA sequence analysis}

DNA sequence analysis was made by Goettingen Genomics Laboratory (G2L) or by SEQLAB (Goettingen) using chain termination method by Sanger (Sanger et al., 1977). DNA samples were prepared by mixing a template DNA, a sequencing primer and $\mathrm{dd}_{2} \mathrm{O}$ to a final volume and concentrations recommended by G2L or SEQLAB. Sequence data were analyzed using Chromas $^{\odot}$. 


\subsubsection{Protein biochemical methods}

\subsubsection{Sodium dodecyl sulphate polyacrylamide gel electrophoresis}

Gel electrophoresis provides a means of separating molecules that migrate through a porous matrix in response to an electric field. In denaturing sodium dodecyl sulphate polyacrylamide gel electrophoresis (SDS-PAGE) (Laemmli, 1970), sodium dodecyl sulphate (SDS) - an anionic detergent - confers a negative charge to polypeptides in proportion to their length and ß-mercaptoethanol - a reducing agent - reduces disulfide bridges in proteins. Consequently, proteins are separated based on their molecular mass. Laemmli gels are composed of two different gels (stacker and running gel). SDS-PAGE (mini-gels: $7.5 \mathrm{~cm} \times 8 \mathrm{~cm}$ and $0.75 \mathrm{~cm}$ thick) were prepared as shown in Table 5:

Table 5: 15\% mini SDS-PAGE recipe:

\begin{tabular}{|l|l|l|}
\hline Components & $15 \%$ Resolving gel $(60 \mathrm{ml})$ & $5 \%$ Stacking gel $(35 \mathrm{ml})$ \\
\hline Acriylamid/Bisacrylamid 30\% (37.5:1) & $30 \mathrm{ml}$ & $5.9 \mathrm{ml}$ \\
\hline $1.875 \mathrm{M}$ Tris- $\mathrm{HCl}, \mathrm{pH} 8.8$ & $12 \mathrm{ml}$ & - \\
\hline $1.25 \mathrm{M}$ Tris- $\mathrm{HCl}, \mathrm{pH} 6.8$ & - & $3.5 \mathrm{ml}$ \\
\hline $10 \%$ sodium dodecyl sulphate (SDS) & $600 \mu \mathrm{l}(1 \%$ final) & $350 \mu \mathrm{l}(1 \%$ final) \\
\hline $\mathrm{dH} 2 \mathrm{O}$ & $17.2 \mathrm{ml}$ & - \\
\hline $10 \%$ ammonium persulfate (APS) & $200 \mu \mathrm{l}$ & $120 \mu \mathrm{l}$ \\
\hline TEMED* & $30 \mu \mathrm{l}$ & $35 \mu \mathrm{l}$ \\
\hline${ }^{*}$ Added just before pouring the gel & &
\end{tabular}

$15 \%$ resolving gels were poured between two glass plates, overlaid with isopropanol to compose the flat gel surface and polymerized for $30 \mathrm{~min}$ at room temperature (RT). Then $5 \%$ stacking gel mix was maid, poured onto top of set resolving gel, a comb was inserted and gel was let to polymerize for $30 \mathrm{~min}$ at RT. Protein samples were mixed with $1 / 5$ volume of loading buffer (2.1.9) and denatured by heating for $5 \mathrm{~min}$ at ${ }^{9} 5^{\circ} \mathrm{C}$ just before loading onto the gel. Gels were run in 1x Laemmli buffer (2.1.9) at $20 \mathrm{~mA}$ constant current, followed by staining with Coomassie brilliant blue R250 (2.1.9).

\subsubsection{Silver staining of SDS-PAGE}

To detect low amounts of proteins (as little as $1 \mathrm{ng}$ ), silver staining was used to visualize protein bands in SDS-PAGE (modified protocol by (Blum et al., 1987). After electrophoresis, gels were incubated with fixation solution (2.1.9) for $1 \mathrm{~h}$ at RT with gentle agitation, washed three times with $50 \%$ ethanol ( $/ \mathrm{v})$ for $20 \mathrm{~min}$, followed by incubation with wash solution $(0.01 \%$ sodium thiosulphate, 2.1 .9$)$ for $1 \mathrm{~min}$. Then gels were immediately washed with $\mathrm{dH}_{2} \mathrm{O}$ (2 times $\times 30 \mathrm{~s}$ ), incubated with silver stain solution (2.1.9) for $20 \mathrm{~min}$, washed again with $\mathrm{dH}_{2} \mathrm{O}(2$ times $\times 30 \mathrm{~s}$ ) and incubated in developing solution (2.1.9) for about $10 \mathrm{~min}$. 
Developing reaction was stopped by incubation the gels with $10 \mathrm{mM}$ EDTA-containing stop solution for $10 \mathrm{~min}$. Finally the gels were washed with water, placed between 2 plastic foils and sealed.

\subsubsection{Heterologous protein expression}

pET expression system ( $\mathrm{pET}$ vector (2.1.2.1) and E. coli BL21 (DE3) strain (2.1.1.2)) was chosen for over-expression of recombinant proteins. In $\mathrm{pET}$ vector target gene is regulated by strong T7 promoter (bacteriophage origin), which is selectively recognised only by T7 RNA polymerase. BL21 (DE3) expression host possesses T7 RNA polymerase gene, lac-promoter and lac-operator incorporated in its genome. Expression of T7 RNA polymerase and consequently the target gene can be activated by addition of lactose or its analogue isopropyl- $\beta$-D-thiogalactopyranosid (IPTG) to a cell growth medium.

Usually $20 \mathrm{ml}$ of appropriate E.coli expression strain (2.1.1.3 or 2.1.1.4) grown over night on a selective medium and freshly transformed with respective expression vector (2.1.2.1) was used to inoculate $1 \mathrm{~L}$ of $d Y T$ selective medium (2.1.10) in $3 \mathrm{~L}$ Erlenmeyer flasks. Culture was grown at $3^{\circ} \mathrm{C}$ with shaking to an $\mathrm{OD}_{600}$ of 0.6 . Gene expression was induced by addition of IPTG to a final concentration of $1 \mathrm{mM}$ and cell culture was further incubated for $3 \mathrm{~h}$ at $30^{\circ} \mathrm{C}$. Cells were harvested by centrifugation for $30 \mathrm{~min}$ at 4000 r.p.m. and $4^{\circ} \mathrm{C}$ (Rota Silenta/RP, Hettich, Germany), resuspended in $25 \mathrm{ml}$ of IMAC-washing buffer (2.1.9) and centrifuged for $30 \mathrm{~min}$ at 9000 r.p.m and $4^{\circ} \mathrm{C}$ (SS-34 Rotor, Sorvall ${ }^{\circledR} \mathrm{RC} 5 \mathrm{C}$, Kendro). Cell pellet was frozen and stored at $-80^{\circ} \mathrm{C}$. After thawing and resuspension in $20 \mathrm{ml}$ of IMACwashing buffer (2.1.9), cells were homogenized by sonication on ice for $2 \times 3$ min using Branson Sonifier 250 (output level 5, duty cycle 50\%) and disrupted by passage through a Constant Systems Ltd (Daventry, England) cell disruptor at $180 \mathrm{MPa}$ and ${ }^{4}{ }^{\circ} \mathrm{C}$. Cell debris were precipitated by centrifugation for $1 \mathrm{~h}$ at 15.000 r.p.m. and $4^{\circ} \mathrm{C}$ (SS-34 Rotor, Sorvall ${ }^{\circledR}$ $\mathrm{RC5C}$, Kendro). To purify proteins originated from thermostable organisms, E.coli cell lysate was incubated for $40 \mathrm{~min}$ at $65^{\circ} \mathrm{C}$ and recentrifuged (15.000 r.p.m., $30 \mathrm{~min}, 4^{\circ} \mathrm{C}$ ). Clear cell lysate was subjected to Immobilized Metal Ion Affinity Chromatography (IMAC) (2.2.3.4). Cell pellets were also analysed by SDS-PAGE (2.2.3.1) to check for possible aggregation of target protein. Test expression of recombinant protein was performed in $50 \mathrm{ml}$ E.coli culture, where induced and non-induced E.coli cells were harvested by centrifugation, ressuspended in $1 x$ Laemmli buffer (2.1.9) and analyzed by 15\% SDS-PAGE.

\subsubsection{Immobilized Metal Ion Affinity Chromatography}

Immobilized Metal Ion Affinity Chromatography (IMAC) is based on highly specific coordinate binding of amino acids to immobilized metal ions. Recombinant proteins cloned into an expression vector such as pET_B001 (2.1.2.1) are provided with polyhistidine-tag (here 
6xHis) at their $\mathrm{C}$ - or $\mathrm{N}$-terminus. Imidazole ring of histidine residue possess high affinity to $\mathrm{Ni}^{2+}$ ions that in case of IMAC are immobilized on a sepharose matrix. During IMAC purification, cell lysate is incubated with affinity matrix, washed with buffer and the target protein is then eluted with imidazole gradient.

IMAC column was prepared by pouring $5 \mathrm{ml}$ of $50 \%$ slurry of Chelating Sepharose ${ }^{\mathrm{TM}}$ Fast Flow (2.1.7), previously equilibrated in IMAC buffer, into $5 \mathrm{ml}$ plastic syringe and let it settle down by gravity force. Then the column was equilibrated with 1 column volume $(5 \mathrm{ml})$ of $100 \mathrm{mM} \mathrm{NiCl}_{2}$, washed with 5 column volumes of water, and equilibrated with 3 column volumes of IMAC washing buffer (2.1.9). Clear bacterial cell lysate, prepared as described in 2.2.3.3, was applied onto the IMAC column followed by $2 x$ washing each time with two column volumes of IMAC-washing buffer (2.1.9). Target protein was eluted from the column by passing two column volumes of IMAC elution buffer (2.1.9), one at a time (imidazole concentration: 30, 40, 50, 60, 70, 80, 90, 100, 300 and $500 \mathrm{mM}$ ). Collected IMAC fractions were analyzed by $15 \%$ SDS-PAGE (2.2.3.1). Fractions containing protein of interest were combined and concentrated to a final volume of $5 \mathrm{ml}$.

\subsubsection{Heparin affinity chromatography}

Heparin affinity chromatography was performed on a pre-packed POROS ${ }^{\circledR}$ HE20 (Perfusion chromatography, PerSeptive Biosistems) column using Vision Workstation (BioCad ${ }^{\circledR}$ Family, Applied Biosistems, 2.1.11) designed for automated control of essential chromatographic parameters such as: flow-rate, pressure, $\mathrm{pH}$, elution volume, fraction volume etc., and sophisticated computerized data analysis. Heparin coupled with a high number of anionic sulphate groups is a high-capacity cation exchanger that allows specific purification of positively charged DNA binding enzymes from protein mix. Specific proteins can be then selectively dissociated from heparin with a salt gradient. Heparin column was equilibrated with heparin washing buffer (2.1.9) at a flow rate of $4 \mathrm{ml} / \mathrm{min}$. Then $5 \mathrm{ml}$ of concentrated IMAC protein solution described in 2.2.3.4 was diluted 1:10 with heparin washing buffer (up to $50 \mathrm{ml}$ final volume) and applied onto heparin column at same flow rate. The column was washed with $30 \mathrm{ml}$ of heparin washing buffer. Proteins retained in the column were eluted with 15 column volumes of a continuous $0-1.5 \mathrm{M} \mathrm{NaCl}$ salt gradient and collected in $1 \mathrm{ml}$ fractions. Protein elution was monitored at 260 and $280 \mathrm{~nm}$ by a computer-controlled spectrophotometer and results were displayed as a dual line chromatogram (Figure 13). Pick heparin fractions were analyzed by SDS-PAGE (2.2.3.1). Fractions containing protein of interest were combined and concentrated (2.2.3.8). 


\subsubsection{Spectrophotometric determination of protein concentration}

Concentration of purified proteins was determined by measuring the absorbance at 250-300 nm (UV-Region). Aromatic amino acids (tyrosine, phenylalanine and tryptophan) exhibit a strong UV-light absorbance. Consequently, proteins absorb UV-light in proportion to their aromatic amino acids content and total concentration. The molar concentration of protein solutions were estimated using Lambert-Beer low and following equation:

$$
A=\varepsilon \cdot c \cdot d \quad \Leftrightarrow \quad c=\frac{A}{\varepsilon \cdot d} \quad ; \text { Where } \begin{aligned}
& \mathrm{A}=\text { Absorbance } \\
& \mathrm{C}=\text { molar concentration } \\
& \mathrm{d}=\text { light path }(\mathrm{cm}) \\
& \varepsilon_{280}=\text { molar extinction coefficient at } 280 \mathrm{~nm}^{*}
\end{aligned}
$$

*The molar extinction coefficient $\left(\varepsilon_{280}\right)$ was calculated for each particular protein from its amino acid sequence using following equation (Pace et al., 1995):

$\varepsilon_{280}\left(M^{-1} \mathrm{~cm}^{-1}\right)=\sum \operatorname{Trp} \cdot 5500+\sum$ Tyr $\cdot 1490+\sum$ Cystine $\cdot 125$

\subsubsection{Protein concentration determination by Bradford assay}

Bradford protein determination is based on a shift in absorbance maximum of free Coomassie Brilliant Blue G-250 dye (465 nm) relative to a dye-protein complex (595 nm). Furthermore, G-250 selectively binds to arginine, lysine, histidine and aromatic residues (Bradford, 1976). An increase in $A_{595}$ of protein-bound dye is proportional to the amount of protein present in the sample. First, a standard curve is made using standard protein concentrations. Then the amount of protein in experimental samples is determined from the standard curve with respect to the samples volumes and dilution factors, if any.

Bovine serum albumin (BSA) was used as a protein standard. $100 \mu \mathrm{l}$ of standard BSA solutions $(0,25,50,75,100,150 \mu \mathrm{g} / \mathrm{ml})$ were prepared by dilution of $1 \mathrm{mg} / \mathrm{ml}$ or $10 \mathrm{mg} / \mathrm{ml}$ stocks in 1 xPBS buffer. Then $5 \mathrm{ml}$ of Bradford dye solution (2.1.9) were added to each $100 \mu \mathrm{l}$ BSA standard solution and the whole mix was left for $10 \mathrm{~min}$ in the dark at RT, followed by measurement of absorption at $595 \mathrm{~nm}$ in a spectrophotometer (2.1.11). Standard curve was made by plotting $A_{595}$ values of standard samples against total amount of protein. Protein samples of unknown concentration were diluted in PBS buffer up to a final volume of $100 \mu \mathrm{l}$ and incubated with Bradford reagent as described above. Then absorption at $595 \mathrm{~nm}$ was measured and protein concentration was determined using the standard curve.

\subsubsection{Protein samples concentration and storage}

Purified proteins were concentrated up to $0.5-1 \mathrm{ml}$ final volume using $20 \mathrm{ml}$ centrifugal concentrators (Vivaspine, Vivascience ${ }^{\circledR}$ ) with appropriate Molecular Weight Cut Off (MWCO) at $3000 \mathrm{rpm}$ and $4^{\circ} \mathrm{C}$ (Rotanata/RPC, Hettich). The protein concentration was determined measuring absorbance at $280 \mathrm{~nm}$ using a spectrophotometer (2.2.3.6 and 2.1.11). 
Concentrated protein solutions were mixed with glycerol at a $1: 1$ ratio and stored at $-20^{\circ} \mathrm{C}$ or $-80^{\circ} \mathrm{C}$.

\subsubsection{Endonuclease assay:}

$0.12 \mathrm{pmol}$ of appropriate substrate (2.2.2.13) was pre-incubated in endonuclease buffer (2.1.9) for $10 \mathrm{~min}$ at the optimum temperature of the tested enzyme. Then an appropriate amount of enzyme was added to a final volume of $50 \mu \mathrm{l}$ and reaction mix was incubated for 20 min unless otherwise specified. Then $25 \mu \mathrm{l}$ of A.L.F.-marker (2.1.9) was added, samples were heated for $5 \mathrm{~min}$ at $95^{\circ} \mathrm{C}$ and applied onto the $11 \%$ A.L.F.-PAGE (2.2.2.8) in $7 \mu \mathrm{l}$ total volume $(\sim 17 \mathrm{fmol}$ of fluoresceinlabelled material). 


\section{Results and discussion}

\subsection{Construction and properties of Mth212/D151N mutant}

This thesis is concerned with analysis of the interaction between Mth212 and its U-containing DNA substrate. The biochemical methods such as substrate binding studies and catalytic assays were performed with both wild-type Mth212 enzyme and its constructed mutants. Furthermore, the materials developed and the insights gained during the project were used for structural studies employing X-ray crystallography in collaboration with Department of Molecular Structural Biology (Georg-August University, Goettingen).

\subsubsection{Rationale for mutation of conserved Asp-151}

To examine the molecular and structural bases of Mth212 substrate recognition and catalysis, a catalytically inactive Mth212 enzyme with retained substrate-binding capacity was constructed. The rationale was that such a mutant would provide the information as to whether the newly discovered U-endonuclese (U-endo) activity of Mth212 is served by the same active site as the other enzymatic activities common to all characterised Exolll homologues. Given that Mth212 has a single catalytic site for both Ap-endo and U-endo activities, such catalytically inactive mutant should enable further studies of substrate recognition and catalysis using specific approaches such as: gel-retardation assay and cocrystallisation with DNA substrates containing an AP-site or a uracil residue. To identify Mth212 catalytically essential amino acid residues, a comparative amino acid sequence analysis was performed between Mth212 and other Exolll homologues with known 3D structures.

By the time this project was started the crystal structure of Ape1, a human Exolll homologue, and its active site essential amino acid residues had been reported (Barzilay et al., 1995; Mol et al., 2000). Furthermore, Rothwell and co-workers found that Asp-210 residue in human Ape1 is essential for the catalytic function of this enzyme but at the same time is dispensable for substrate recognition (Rothwell et al., 2000). Analysis of the three-dimensional structure (3D) of Ape1 in complex with AP-site-containing DNA showed that Asp-210 aligns with the scissile P-O3' bond resided in the active site of the enzyme (Gorman et al., 1997).

Amino acid sequence alignment of human Ape1 and Mth212 revealed Asp-151 in Mth212 as the equivalent residue to Asp-210 in human Ape1. Therefore, Asp-151 was chosen for the substitution experiment (Figure 10). 


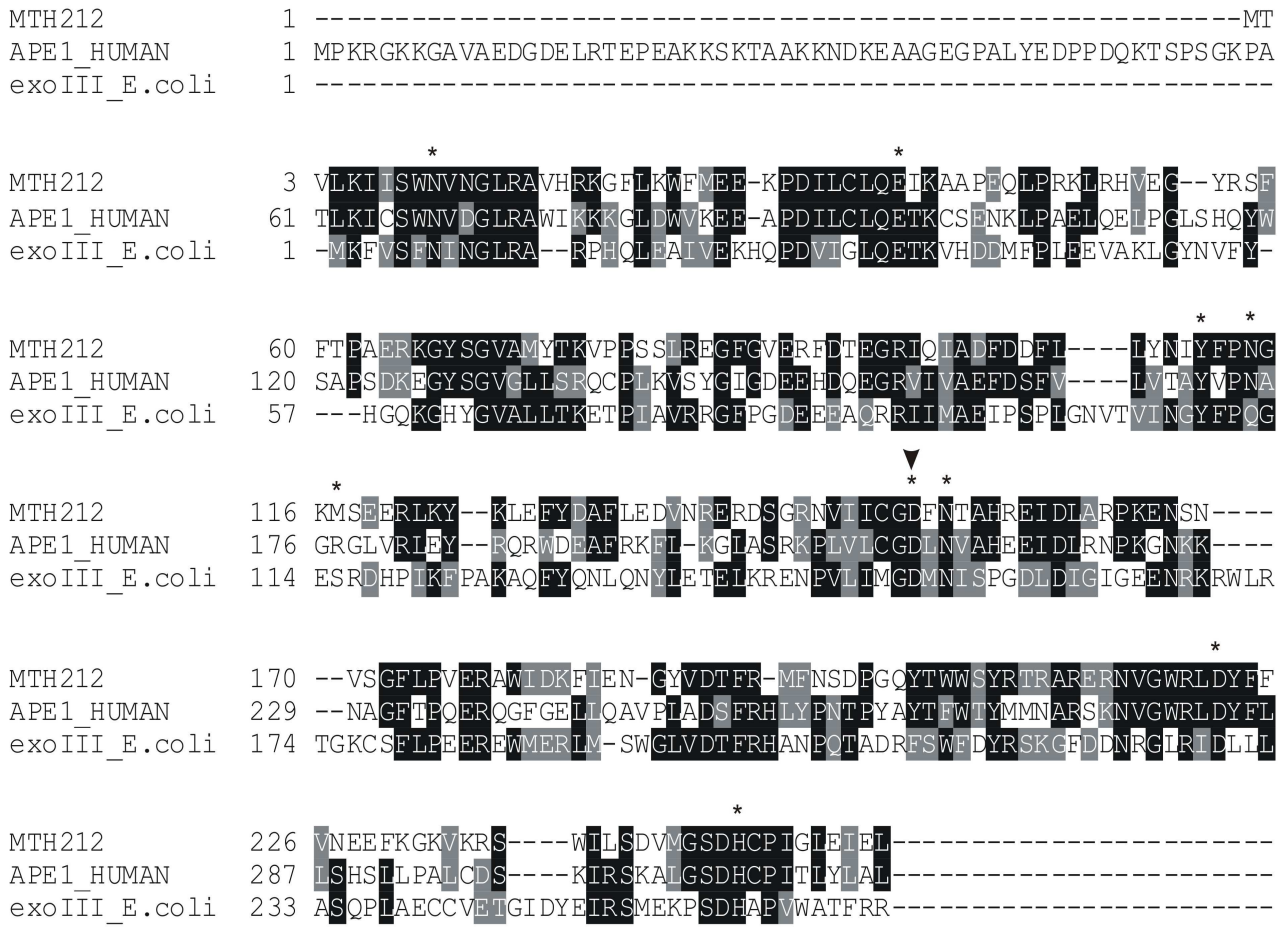

Figure 10: Multiple amino acid sequence alignment of Mth212 (Methanothermobacter thermautotrophicus) with Exolll (Escherichia coli) and Ape1 (Homo sapiens)

Amino acid residues involved in the catalysis by Ape1 according to (Mol et al., 2000) and (Rothwell et al., 2000) are marked with an asterisk. Arrow indicates the conserved Asp-151 residue in Mth212 active site that was mutated to Asn, Ala or Ser. Alignment was performed using WISCONSIN PACKAGE version 10.3 (Womble, 2000) and arranged with BOXSHADE version 3.21.

\subsubsection{Mth212/D151 mutants: construction and expression}

mth212 gene, inserted in pET_B_001 expression vector (2.1.2.1) between $\mathrm{Ncol}$ and Xhol restriction sites by Jens Georg during his diploma project (Georg, 2005), was used for the site-directed mutagenesis. Mth212 gene was mutated to replace the codon for Asp-151 with one encoding an asparagine (Asn or $\mathrm{N}$ ), alanine (Ala or $\mathrm{A}$ ) or serine (Ser or $\mathrm{S}$ ). There were two reasons for generation Ala and Ser variants. First, to exclude the possibility of spontaneously arising revertants in case of D151N variant, where only one of the three original nucleotides was changed ( $G A C \rightarrow A A C$, changed nucleotide shown in red). Substitution of Asp codon by Ala codon introduces two different nucleotides (GAC $\rightarrow$ GCA) and in case of Ser codon all three nucleotides are different from the original ones $(\mathrm{GAC} \rightarrow \mathrm{TCA})$. The second reason was to eliminate remaining endonucleolytic activity resulting from Mth212/D151N during endonuclease assay with AP/G substrate $(2.1 .4,2.2 .2 .13)$ and 100:1 enzyme/substrate ratio.

Three Asp-151 mutants were generated using PCR based site-directed mutagenesis as described in section 2.2.2.10. Generation of D151N variant is shown in Figure 11 as an example. The two other mutant variants, D151A and D151S were created using same procedure (data not shown). All site-specific mutations were verified by DNA sequence 
analysis (see Appendix 7.1.3). The obtained mutants were designated as Mth212/D151N, Mth212/D151A and Mth212/D151S.

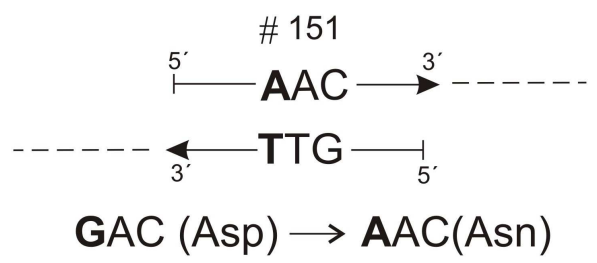

c

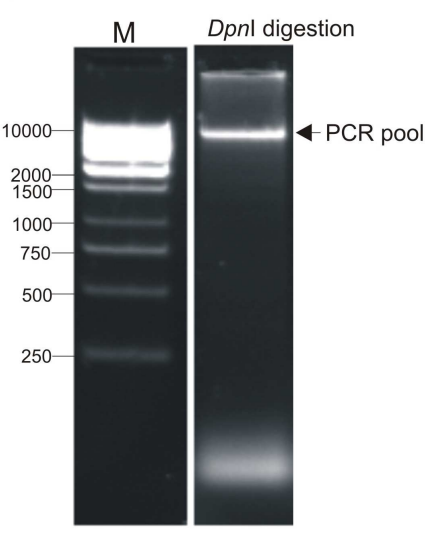

B
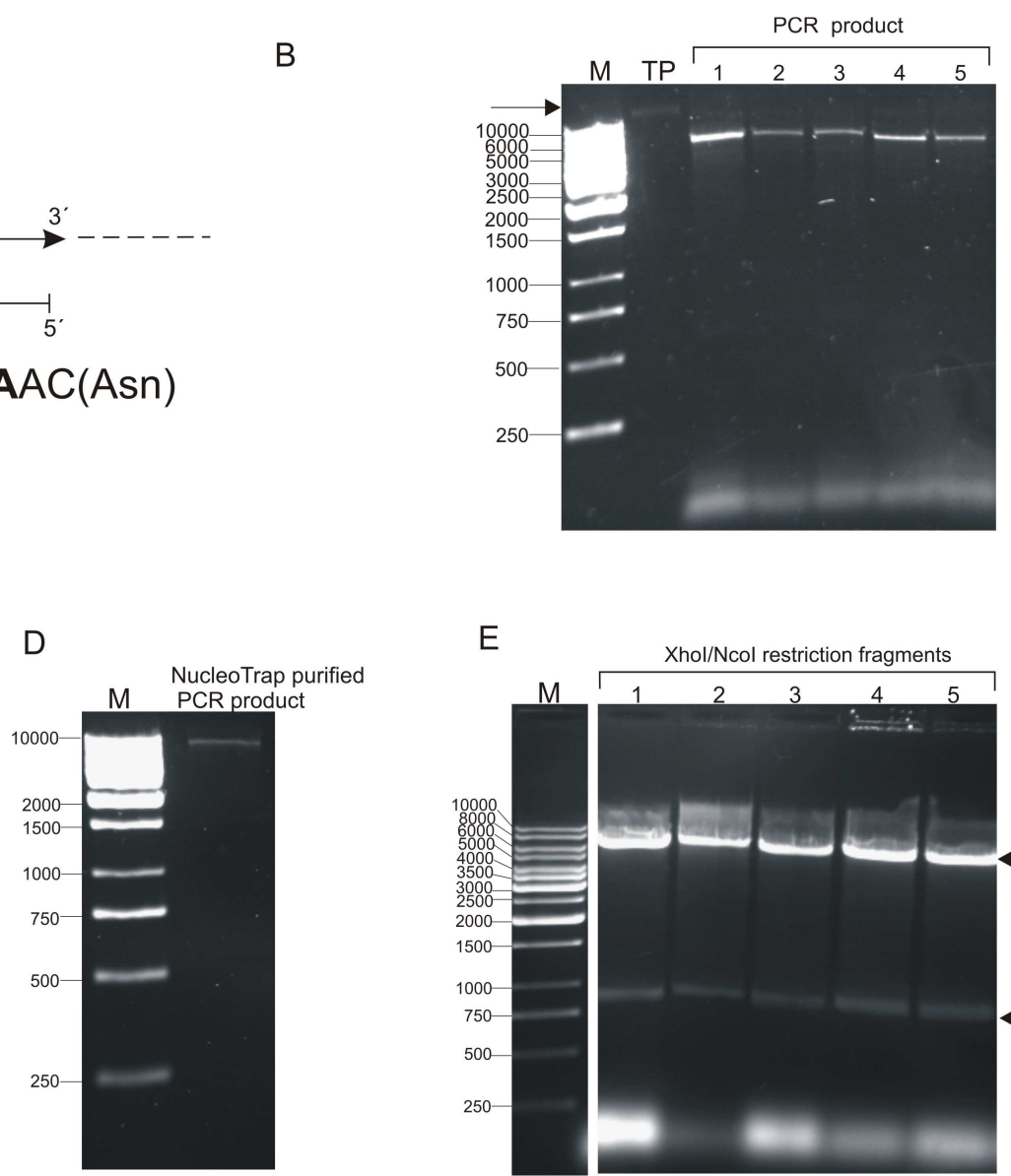

E

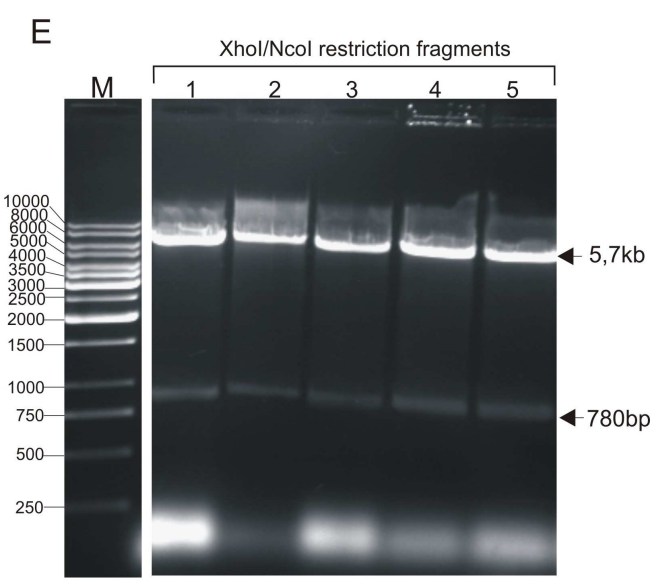

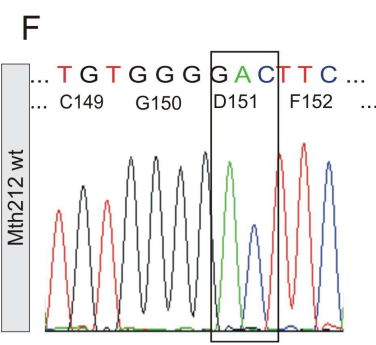
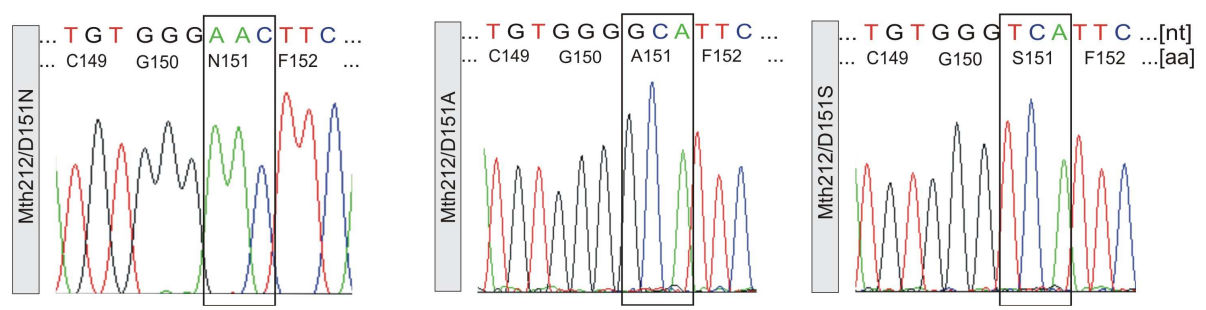

Figure 11: Quick-Change mutagenesis of Mth212

$1 \%$ agarose gel analysis (2.2.2.7) during site-directed mutagenesis of $m$ th212 (2.2.2.10).

A: Schematic representation of mutagenic primers (black arrows): 212_D151N_For (top) and 212_D151N_Rev (bottom) used for substitution of Asp-151 to Asn (changed bases are outlined). B: PCR amplification products (Lane 1-5) were combined for Dpnl digestion. TP: Template DNA (pET_B001_Mth212, 68 ng). Arrow indicates the band corresponding to the relaxed circular template DNA. M: Molecular length marker (GeneRuler ${ }^{T M} 1 \mathrm{~kb}$ DNA Ladder, Fermentas). C: PCR amplification products after Dpnl digestion (2.2.2.10). D: NucleoTrap® purified PCR product used to transform E.coli XL1-Blue (2.1.1.5). E: Xhol/Ncol restriction endonuclease fragment analysis (2.2.2.12) of pET_B001_Mth212/D151N derivatives. Arrows indicate restriction fragments: $~ 5.7 \mathrm{~kb}$ corresponds to the linear pET_B001 vector and 780 bp to the length of Mth212 gene. F: Fragments of sequencing data of wildtype (wt) Mth212 and its three Asp-151 (D151) mutants represented in Chromas 2.33. Indications in grey bars are: Mth212 wt (wild-type Mth212) and Mth212/D151X, where X: N (Asn), A (Ala) and S (Ser). Black rectangle highlights wt and mutated codon in mth212 nucleotide sequence [nt] and one letter symbol and number of changed amino acid in Mth212 protein sequence [aa], respectively. 
Each of the three mutant variants was produced in ung E.coli BL21_UX (2.1.1.3) strain, isolated as described in 2.2.3.3 and purified through IMAC (2.2.3.4) (Figure 12), followed by Heparin affinity chromatography (2.2.3.5) (Figure 13A, B and C). The obtained proteins were checked for purity by SDS-PAGE (2.2.3.1) (Figure 13D, E and F) and concentrated to the final volume of $1 \mathrm{ml}$. Their final concentrations were calculated as described in section 2.2.3.6 and comprised $7.03 \mathrm{mg} / \mathrm{ml}, 8 \mathrm{mg} / \mathrm{ml}$ and $14 \mathrm{mg} / \mathrm{ml}$ for Mth212/D151N, Mth212/D151A and Mth212/D151S, correspondingly.

A Mth212D151N

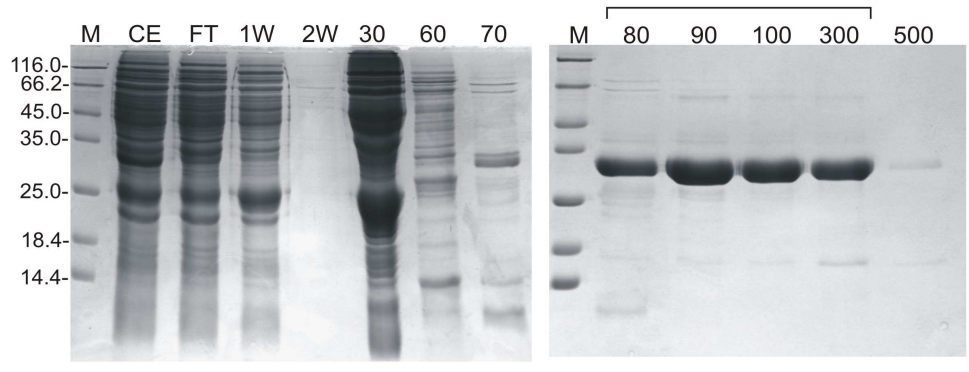

B Mth212D151A

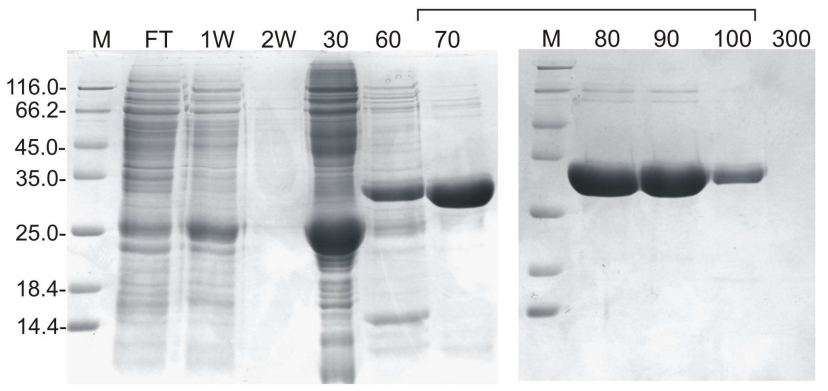

C Mth212D151S

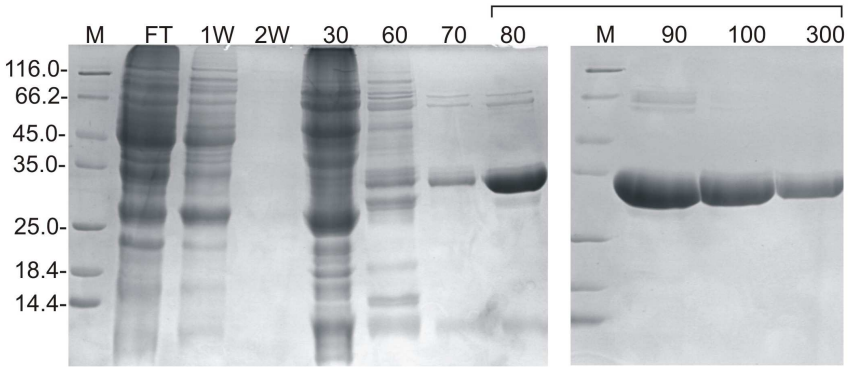

Figure 12: Immobilized-metal-ion affinity chromatography of His-tagged Mth212 mutants IMAC were carried out using $5 \mathrm{ml}$ columns packed with Chelating Sepharose ${ }^{\mathrm{TM}}$ Fast Flow (2.1.7) as described in section 2.2.3.4. A-C: 15\% SDS-PAGE analysis (2.2.3.1) of IMAC fractions of Mth212/D151N (A), Mth212/D151A (B) and Mth212/D151S (C). M: Molecular weight marker (Fermentas, 2.1.5). CE: Clarified E.coli BL21_UX lysate containing Mth212/D151 variants prepared by sonication/homogenization as described in 2.2.3.3. FT: Flowthrough fraction (cell lysate eluted from IMAC column). $\mathbf{1 W}$ and $\mathbf{2 W}$ : First and second column wash fractions. 30500: Protein elution with $80 \mathrm{ml}$ step gradient of 30-500 mM imidazole in IMAC wash buffer (2.1.9), where 1 column volume comprised $5 \mathrm{ml}$. Brackets indicate fractions pooled for subsequent heparin affinity chromatography (2.2.3.5). 
A

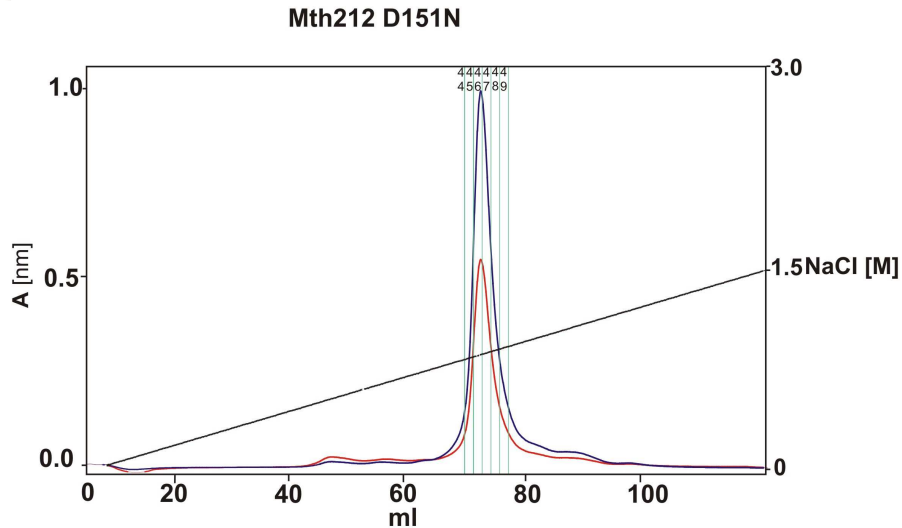

B

Mth212D151A

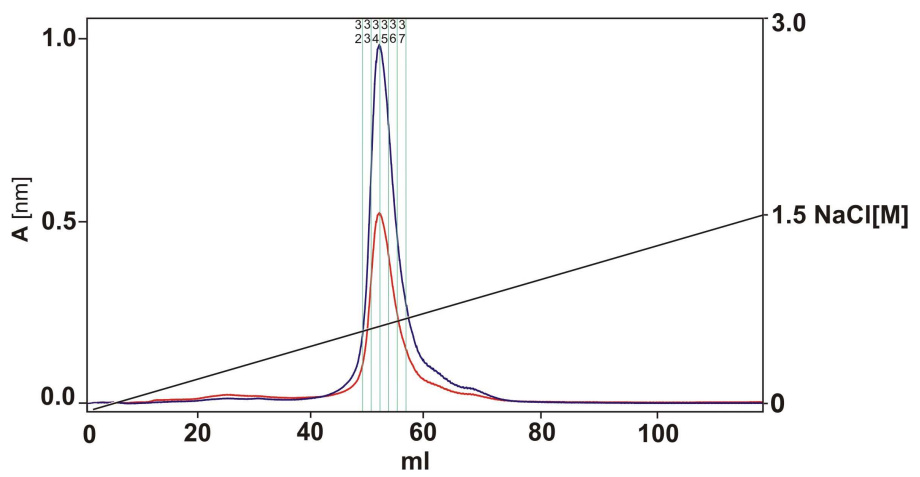

C

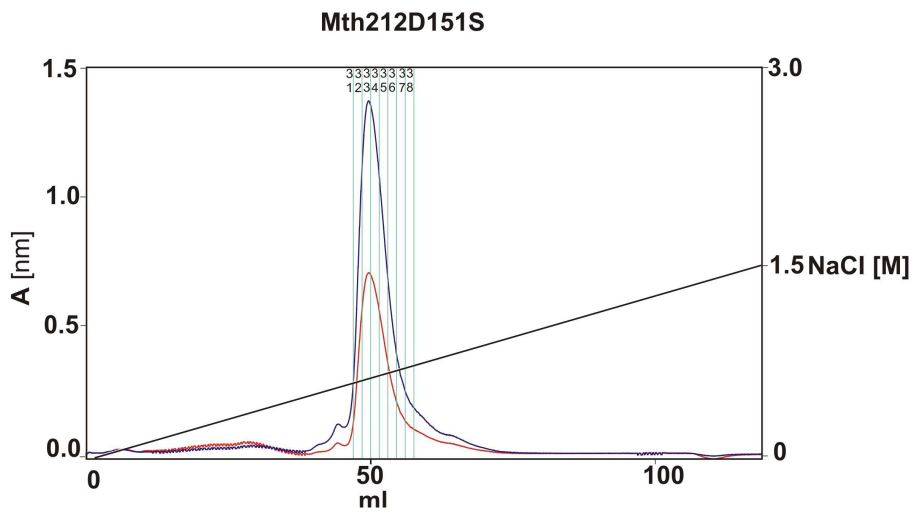

D
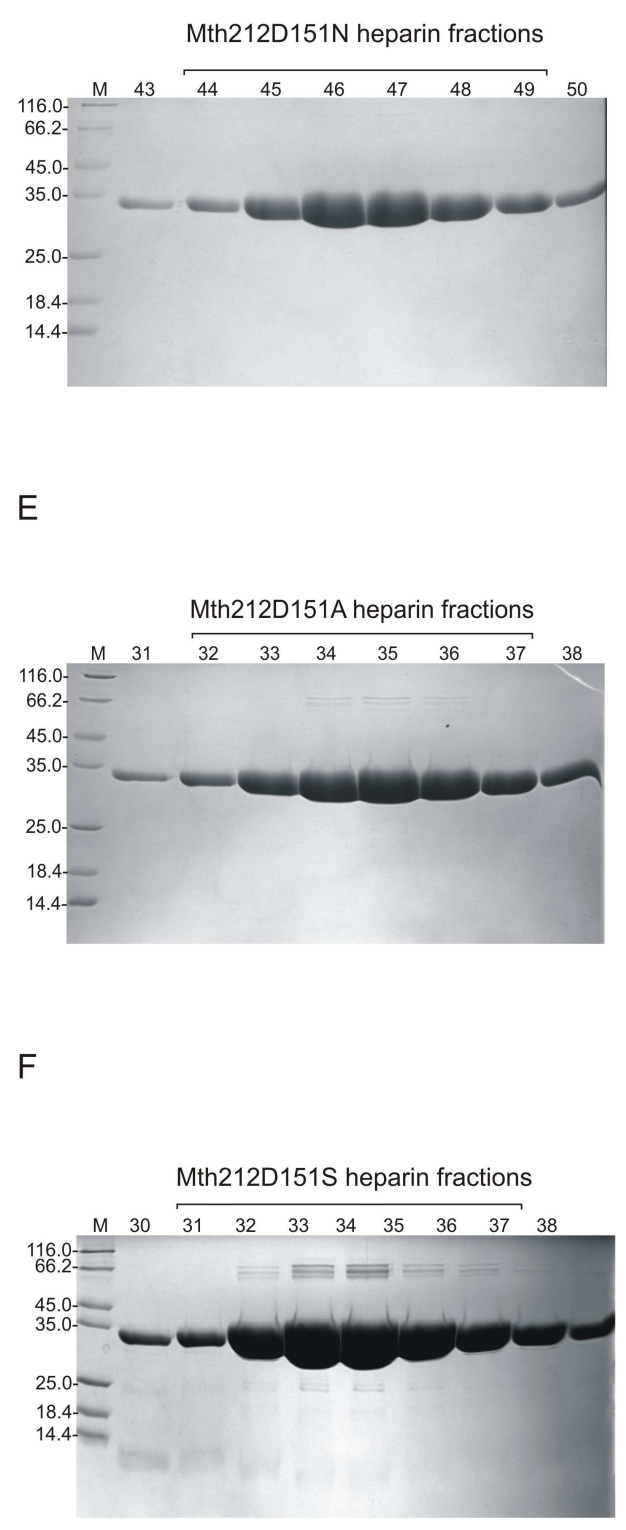

Figure 13: Heparin affinity chromatography of Mth212 mutants.

A-C: Heparin affinity chromatography elution pattern of Mth212/D151N (A), Mth212/D151A (B) and Mth121/D151S (C) (for details see section 2.2.3.5). Heparin chromatography was performed on BioCAD ${ }^{T M}$ Workstation (Appied Biosystems) and POROS ${ }^{\circledR} \mathrm{HS} 20 \mu \mathrm{m}$ column (10 mm x $\left.100 \mathrm{~mm}, 7.89 \mathrm{ml}\right)$ at a $4 \mathrm{ml} / \mathrm{min}$ flow rate. Left ordinate: absorption at $260 \mathrm{~nm}$ (red) and $280 \mathrm{~nm}$ (blue); Right ordinate: concentration of $\mathrm{NaCl}$ in $\mathrm{mol}$ [M]; Abscissa: elution volume in $\mathrm{ml}$. Green lines and numbers above the chromatogram indicate fractions that were analysed by $15 \%$ SDS-PAGE (2.2.3.1) shown in panels D-F. M: Protein molecular weight marker (2.1.5). Brackets indicate fractions pooled and concentrated (2.2.3.8) for subsequent enzymatic characterization. 
All three heterologous produced mutant proteins were fully soluble in E.coli and had chromatographic properties and electrophoresis mobility parameters similar to those of wild-type (wt) Mth212 (for the details see (Georg et al., 2006)).

\subsubsection{Endonuclease assays with Mth212/D151 variants}

In order to study the effect of Asp-151 substitution on the enzymatic activity, Mth212/D151 mutant variants were analysed by endonuclease assay. The assay was made as described in 2.2.3.9 using 40-mer double-stranded DNA oligonucleotide substrates containing an AP/G (where AP is an abasic site analogue, Figure 14B) or a U/G mismatch at position 24. One of two DNA strands in substrate duplex was labelled with fluorescein group on its 5 'end. A schematic representation of assay substrate is shown in Figure 14A. Reaction products obtained during endonuclease assays were analysed under denaturing conditions by $11 \%$ A.L.F.-polyacrylamid gel (A.L.F.-PAGE, see section 2.2.2.8) (Figure 14C, D, E and F). 


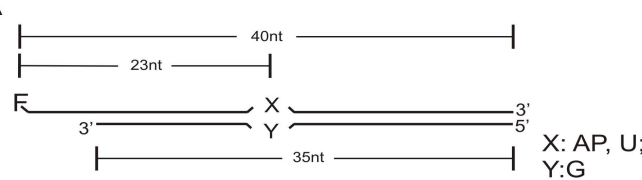

C

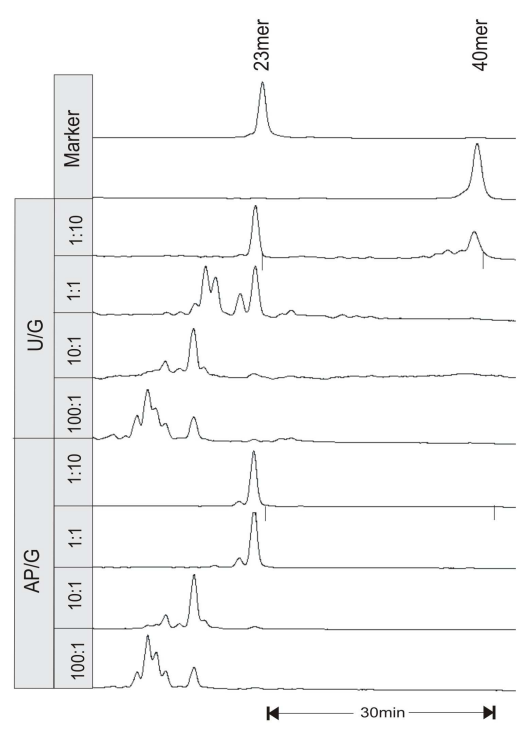

$\mathrm{E}$

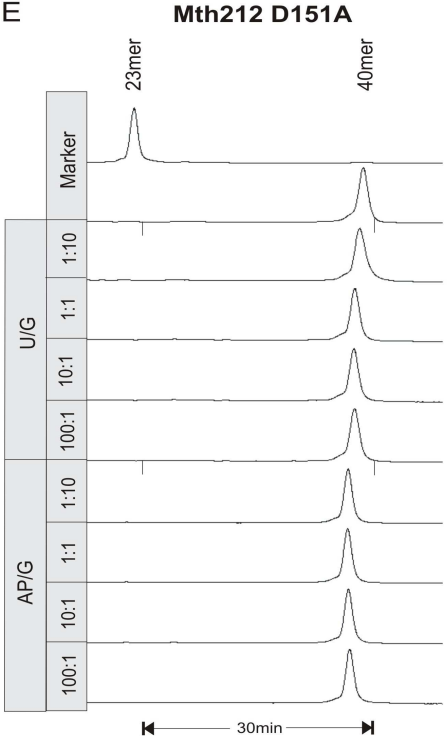

B

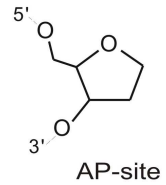

$\mathrm{D}$

Mth212 D151N

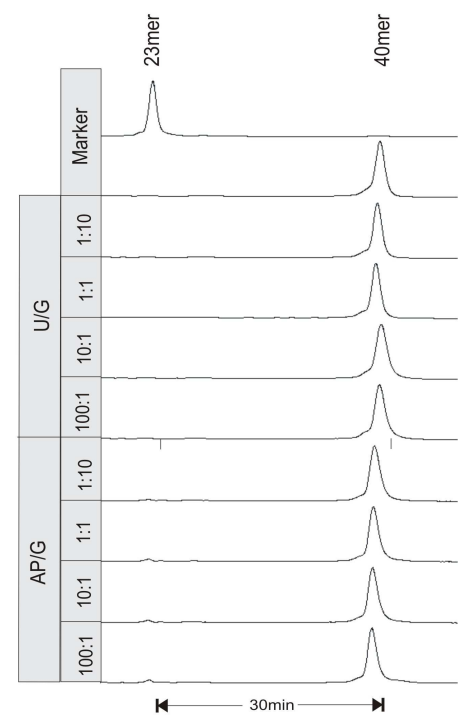

$\mathrm{F}$

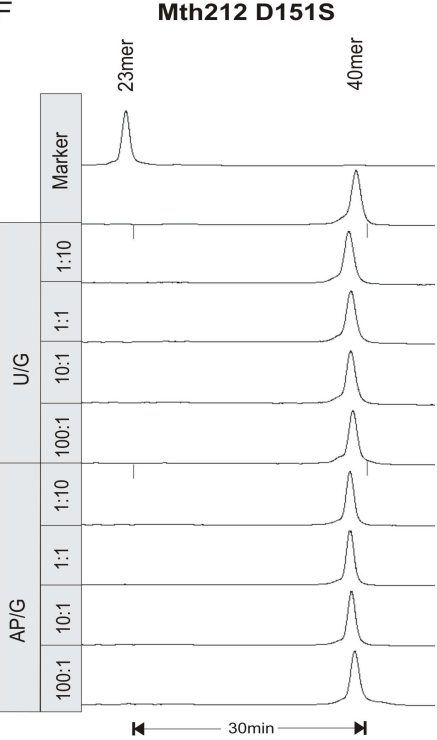

Figure 14: Endonuclease assay with wt Mth212 and Mth212/D151 mutants

Endonuclease assays were carried out with substrate containing an AP-site or a U/G mismatch at position 24 and conducted as described in 2.2.3.9. A: A schematic representation of substrate and expected length of reaction products (F: fluorescein, nt: nucleotides, AP: a stable AP-site model residue as shown in panel B). Prince-U, 40_PRI_AP and Prince-G oligonucleotides were used for substrate preparation (sections 2.1.4 and 2.2.2.13).

C- $\overline{\mathbf{F}}$ : $11 \%$ A.L.F-PAGE analysis (2.2.2.8) of endonucleolytic assays performed with AP/G- and U/G-containing substrates and wt Mth212 (C), Mth212D151N (D), Mth212D151A (E) and Mth212D151S (F). 0.12 pmol of each substrate was incubated with different amounts of purified enzymes for $15 \mathrm{~min}$ at $65^{\circ} \mathrm{C}$ in $50 \mu$ l of endo nuclease buffer (2.1.9). Molar enzyme/substrate ratios are indicated in gray bars. 30 min: Gel running time difference between marker oligonucleotides.

Wild-type Mth212 showed strong activity with both AP/G and U/G specific substrates (Figure 14C). This confirms our previously published data (Georg et al., 2006). The product peak 
with 23-mer marker electrophoretic mobility and a series of additional peaks shorter then 23-mer product were clearly detectable. Additional peaks were considered as a result of further degradation of main 23-mer products by Mth212 $3^{\prime} \rightarrow 5^{\prime}$ exonucleolytyc activity (Figure 14C). In contrast to wt Mth212, Mth212/D151 mutants did not yield 23-mer products neither with $A P / G$ nor with $U / G$ mismatch-containing oligonucleotide substrates (Figure 14D, $\mathrm{E}$ and $\mathrm{F}$ ). It has to be noted, that small peak corresponding to 23-mer marker was observed in case of D151N mutant and AP-site-containing oligonucleotides at 100:1 enzyme/substrate ratio. This could result from Mth212/D151N remaining activity and/or from wt Mth212 that might have been produced by spontaneous revertants (see section 3.1.2).

Mth212 mutational analysis revealed that D-151 by analogy with Ape1/D-210 (Rothwell et al., 2000) is required for Mth212 enzymatic catalysis. The fact that Asp-151 substitution eliminated both AP-endonuclease and U-endonuclease activities indicates that both enzymatic activities must originate from the same active site. However, the presence of a single active site in Mth212 can only be proved by still ongoing structural studies.

It is known that an amino acid substitution may affect a specific catalytic function not only due to the lack of catalytically essential functional group, but also through impact on the global structural features, leading to a complete loss of enzymatic activity. To provide additional data to substantiate this point gel-retardation assays were performed

\subsubsection{Gel-retardation assays with Mth212/D151 variants}

The activity assay presented in section 3.1.3 revealed that all three Mth212/D151 mutants were completely deficient in endonuclease activity. To analyse the effects of Asp-151 substitution on the overall protein structure perturbations and substrate binding properties the gel-retardation assays were performed using purified D-151 mutants and double stranded DNA oligonucleotides. The Following issues were addressed:

1) Substrate binding efficiency of Mth212/ D151 variants

2) Binding of specific AP-site- and dU-containing substrates

3) Substrate binding strengths in the presence of unspecific competitor DNA

4) Binding to substrate's ends (3'recessed, 3'protruding or blunt)

\subsubsection{EMSA with Mth212/D151N and Substrate I}

To assess the potential impact of Asp-151 substitution on Mth212 substrate binding, gelretardation assays (electrophoretic mobility shift assays (EMSAs) were performed. EMSAs were carried out as described in section 2.2.2.14, using constant amounts of unlabelled double-stranded (ds) DNA substrate, namely Substrate I (1xblunt and 1x3' recessed ends, Figure 15A) containing an AP-site analog or a U/G mismatch at position 24 (2.1.4) and 
increasing amounts of purified Mth212/D151N mutant. C/G substrate containing a normal Watson-Crick base pair at position 24 was used as a control (Figure 15).

A

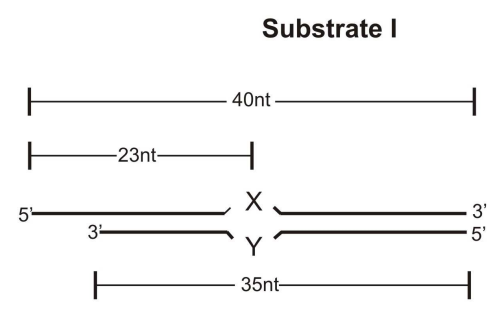

$X: A P, U$ or $C$

Y: $\mathbf{G}$
B

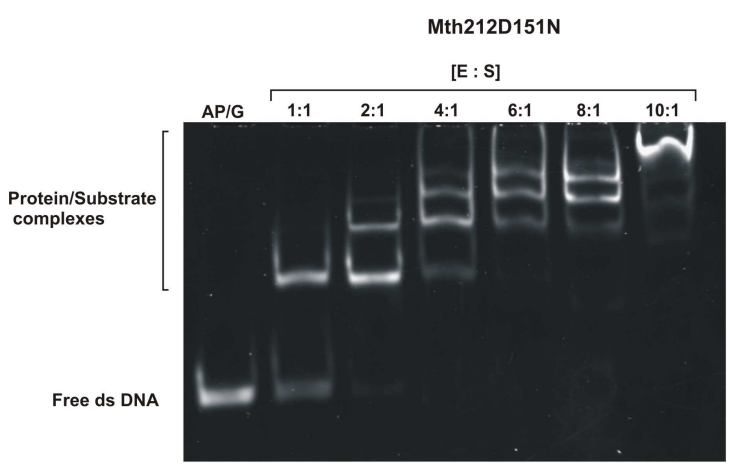

C

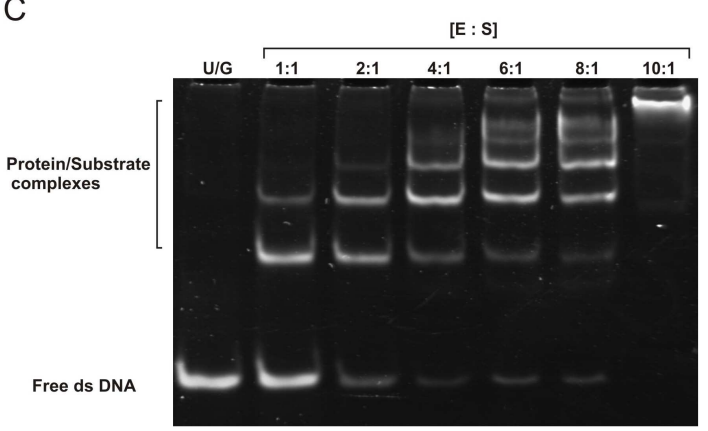

D

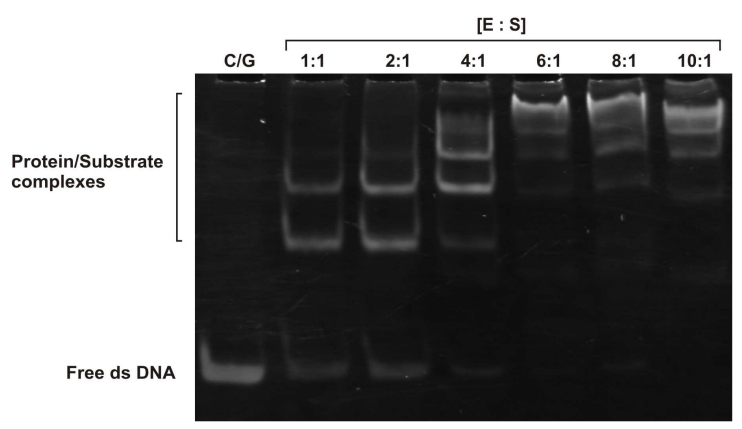

Figure 15: Mth212/D151N substrate binding test

A: A schematic representation of Substrate I used in band-shift assays shown in panels B-D (AP: a stable AP-site (for details see Figure 14), nt: nucleotides)). B-D: 10\% TE-PAGE analysis of Electrophoretic Mobility Shift Assays (EMSA). EMSAs were performed as described in section 2.2.2.14 using Mth212/D151N and Substrate I containing an AP-site (B), a U/G mismatch (C) or a normal $\mathrm{C} / \mathrm{G}$ base pair (D). Enzyme/substrate ratios are indicated above the gel tracks. AP/G, U/G or C/G: Substrate I containing an AP/G or a U/G misspairs or a normal $\mathrm{C} / \mathrm{G}$ base pair incubated in EMSA buffer (2.1.9) without an enzyme and applied onto the gel as a control. Positions of bands corresponding to free ds DNA and protein/substrate complexes are indicated on the left.

When interpreting gel-retardation results, it is important to keep in mind that all assays were done with short DNA oligonucleotides, which elevate the probability of [Enzyme/DNA-end] complex formation. Also, all EMSA samples were incubated for 5 min with D151N mutant protein and immediately applied onto the TB-PAGE (for details see section 2.2.2.14). Moreover, use of catalytically inactive Mth212/D151N mutant in binding assays imposed its own restrictions on extrapolation of results on wt Mth212 behaviour.

Gel-retardation assays presented in Figure 15 revealed that D151N variant was proficient in binding of specific AP-site- and $U / G$ mismatch-containing substrates. Mth212/D151N mutant protein was found to retain it's substrate binding property, confirming that substitution of conserved Asp-151 in Mth212 analogically to Asp-210 in human Ape1 
(Rothwell et al., 2000) does not influence substrate binding. Based on this result it was assumed that Mth212/D151N protein was properly folded and could be used for further functional and structural analysis.

The binding efficiency of Mth212/D151N to AP-site-containing substrate was obviously higher than to $U / G$ substrate. At 4:1 enzyme/substrate ratio, almost all free AP-site-containing substrate was bound, while unbound free DNA bands were still present in case of $U / G$ substrate. (Figure 15B, Lane 4:1). Comparing the gel shift patterns obtained with $A P / G$ and $U / G$ substrates, it was noticed that number of shift-bands was different even at 1:1 enzyme/substrate ratio (Figure 15B and C, Lanes 1:1). In case of AP-site-containing substrate, only one shift-band corresponding to protein/substrate complex was clear to detect, while U/G substrate gave a second shift-band with higher retention properties at the same enzyme/substrate ratio. The first shift-band could result from a 1:1 enzyme/substrate binding or mono binding, whereas the second and subsequent ones from a 1:X binding (where $X=2,3 \ldots$ ) or multiple binding. Similar shift-band patterns were identified in case of specific $U / G$ mismatch-containing substrate and $C / G$ duplex-containing substrates, indicating that $\mathrm{D} 151 \mathrm{~N}$ binds $\mathrm{C} / \mathrm{G}$ duplex as strong as specific $\mathrm{U} / \mathrm{G}$ substrate (Figure $15 \mathrm{C}$ and $\mathrm{D}$ ). For better discrimination between specific $U / G$ substrate and unspecific $C / G$ duplex, the following gel-retardation assays were performed in presence of unspecific competitor DNA (see sections 3.1.4.2 and 3.1.4.4). The unspecific competitor DNA was expected to compete for the binding with substrate DNA oligonucleotides eliminating shifted bands.

\subsubsection{EMSA with Mth212/D151N, Substrate I and pET-vector as a competitor DNA}

Mth212/D151N binding efficiency to $A P / G$ and $U / G$ mismatch-containing DNA oligonucleotides was assessed by competitive gel mobility shift assays (EMSAs). The entire pET-vector ( 5.4kb) was used as a competitor DNA. EMSAs were carried out as described in section 2.2.2.14, using Substrate I containing an AP-site or a $U / G$ mismatch. Substrate oligonucleotides were pre-incubated with competitor DNA followed by addition of purified Mth212/D151N. The enzyme/substrate ratio used here was 4:1, at which almost all substrate DNA was bound (see Figure 15, Lane 4:1). The amount of competitor DNA added to the samples was calculated as molar equivalents of nucleotide relative to substrate correspondingly (Figure 16). 
A

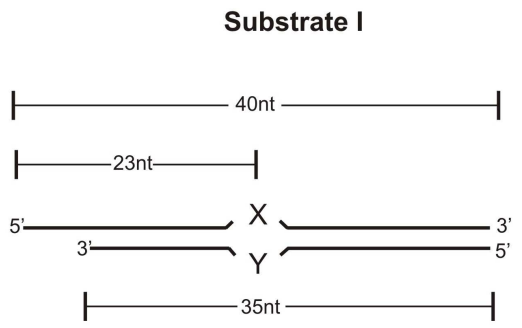

$\mathrm{X}: \mathrm{AP}, \mathrm{U}$ or C

Y: G

C

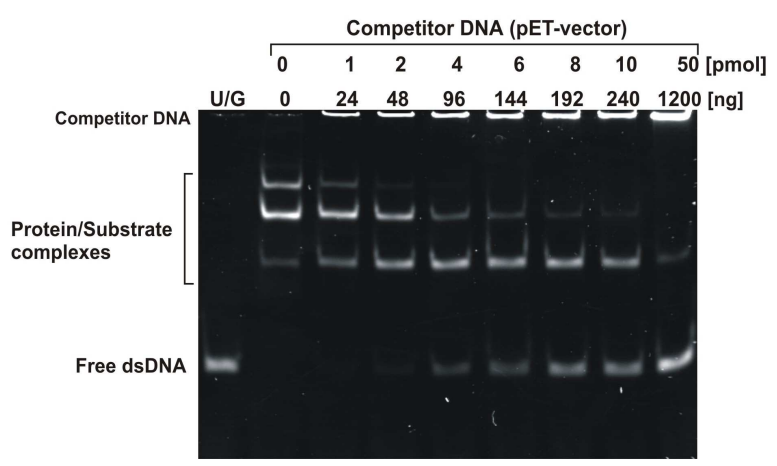

B

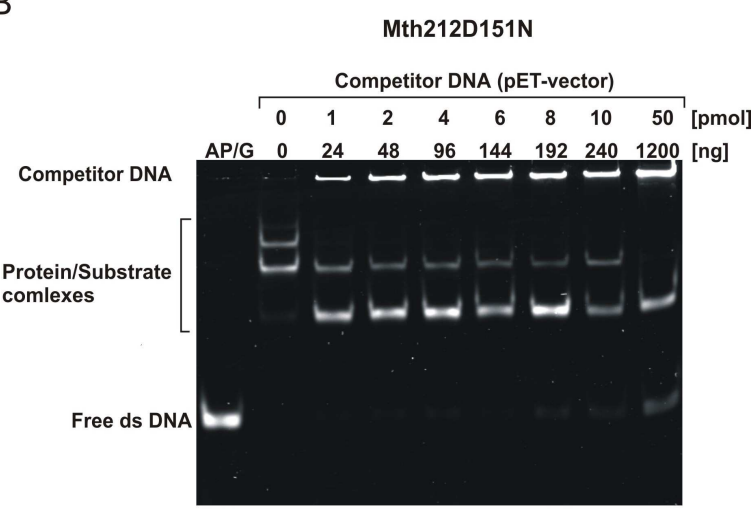

D

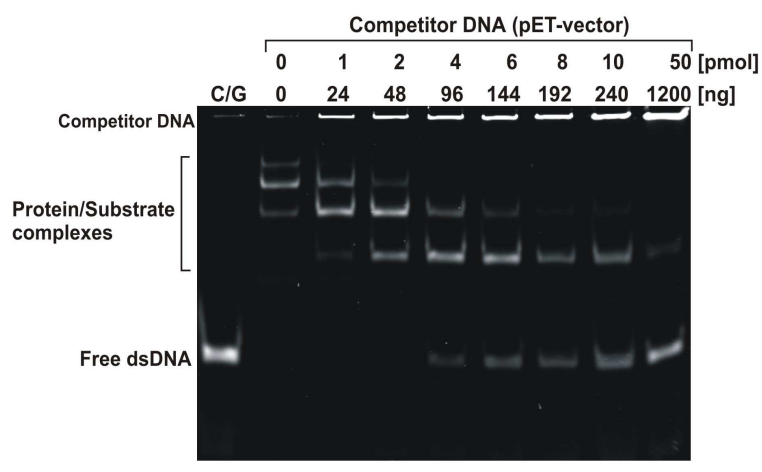

Figure 16: Mth212/D151N gel-retardation assay with Substrate I and pET vector as a competitor DNA

A: A schematic representation of Substrate I used in band-shift assays shown in panels B-D (AP: a stable APsite, nt: nucleotides). B-D: 10\% TE-PAGE analysis of Electrophoretic Mobility Shift Assays (EMSA). EMSAs were conducted as described in section 2.2.2.14 using 4 pmol of purified Mth212/D151N, 1 pmol (24 ng) of Substrate I containing an AP-site (B), a U/G mismatch (C) or a normal $C / G$ base pair (D) and increasing amounts of competitor DNA (entire pET-B001 vector, 5.7kb). Amounts of competitor DNA were calculated as nucleotide equivalents relative to substrate oligonucleotides and indicated above the gel tracks in pmol. Positions of bands corresponding to competitor DNA, free dsDNA and protein/substrate complexes are indicated on the left.

The data presented in Figure 16B indicate strong specific binding of AP-site-containing substrate by Mth212/D151N mutant, where small amounts of unbound free substrate DNA appeared first at 8-fold excess (192 ng) of competitor DNA. Moreover, in presence of 50-fold excess (1200 ng) of competitor DNA the specific shift-band (first shift-band from the bottom) was still very intensive. U/G mismatch-containing substrate was bound by Mth212/D151N with relatively high efficiency, but weaker than AP-site-containing substrate. Here bands corresponding to free dsDNA appeared already at 2-fold excess (48 ng) of competitor DNA. Unexpectedly, competitive gel-retardation assays revealed that $\mathrm{D} 151 \mathrm{~N}$ mutant bound specific $U / G$ mismatch-containing substrate insignificantly stronger than control C/G duplex. This result was reproducible, namely U/G- and C/G-containing oligonucleotides gave almost similar gel-retardation patterns (Figure 16C and D). The other two Mth212 mutants, namely 
D151S and D151A (see section 3.1.2) were also tested for their binding properties with respect to $U / G$ mismatch-containing substrate in comparison to $D 151 \mathrm{~N}$ mutant.

\subsubsection{EMSA with Mth212/D151A and Mth212/D151S, Substrate I and pET-vector as a competitor DNA}

First round of gel-retardation analysis done with D151N mutant protein showed no difference in binding of specific U/G substrate and C/G-containing duplex. To determine which one from three Aps-151 mutants displays the highest affinity to $U / G$ substrate for possibly better discrimination between $U / G$ substrate and $C / G$ duplex, a new series of band-shift assays were carried out. The assays were performed largely as described in section 3.1.4.2, using U/G mismatch-containing Substrate I and purified D151N, D151A and D151S mutant proteins (see section 3.1.2 and Figure 17).

A

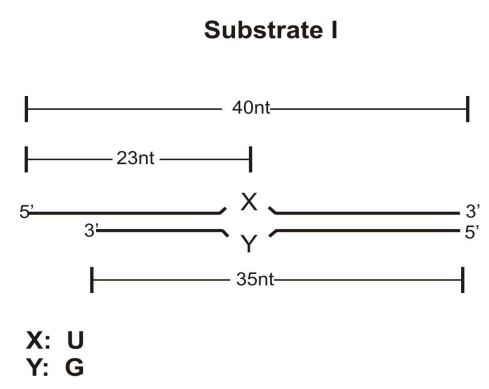

C

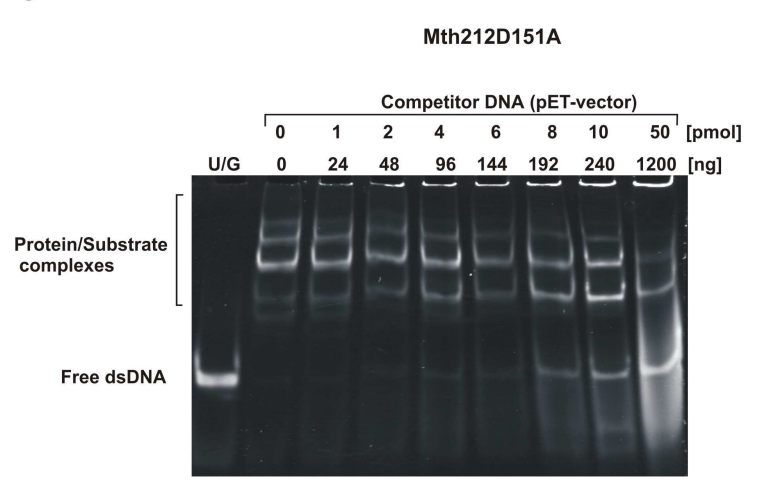

B

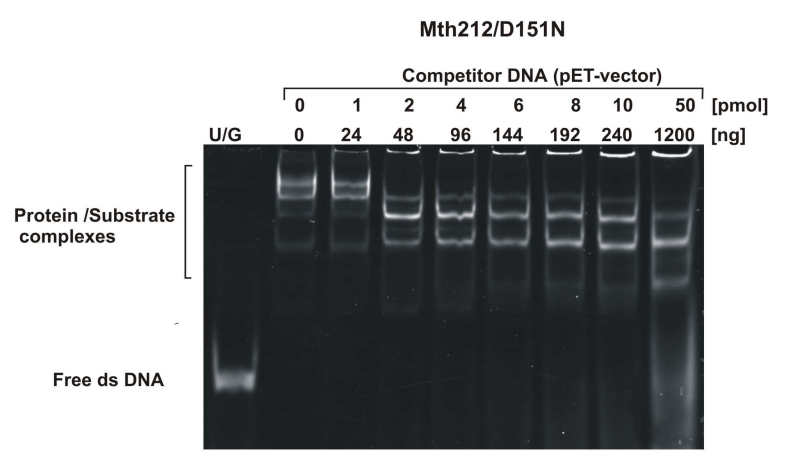

D

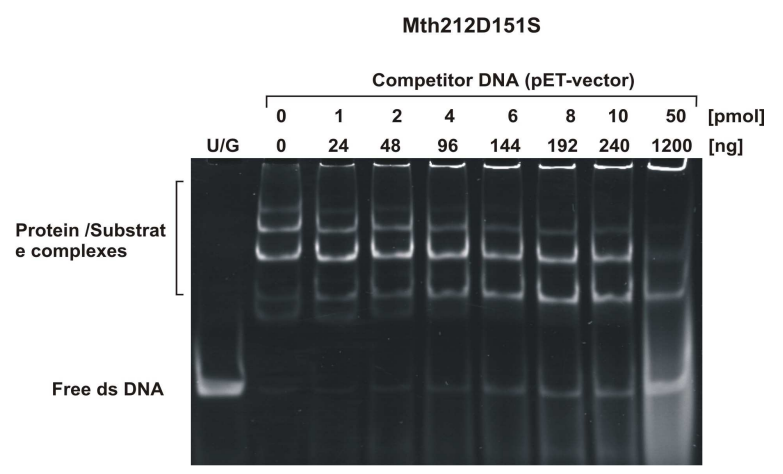

Figure 17: Mth212D151N, Mth212D151S and Mth212D151A gel-retardation assays with U/G mismatchcontaining Substrate I and $p E T$ vector as a competitor DNA

A: A schematic representation of Substrate I used in band-shift assays shown in panels B-D (AP: a stable AP-site, nt: nucleotides). B-D: 10\% TE-PAGE analysis of Electrophoretic Mobility Shift Assays (EMSA). EMSAs were performed as described in 2.2.2.14 and Figure 16, using Substrate I containing a U/G mismatch, increasing amounts of competitor DNA (entire pET_B001 vector, $5.7 \mathrm{~kb}$ ) and purified Mth212D/151N (B), Mth212/D151A (C) and Mth212/D151S (D). Amounts of competitor DNA were calculated as nucleotide equivalents relative to substrate oligonucleotides and indicated above the gel tracks in ng and in pmol. 
However, almost no difference in binding strength of D151A and D151S to the specific U/G substrate was found (Figure 17C and D). Mth212/D151N exhibited the highest binding efficiency to $U / G$ substrate compared to other two Asp-151 mutants (Figure 17B, C, and D, Lane: $240 \mathrm{ng}$ ). Therefore, Mth212/D151N was used for further binding experiments and Xray crystallographic analysis.

Some difficulties were encountered in interpretation of the multiple discrete shift-bands observed in samples with high protein concentration. Similar pattern of progressive gel-retardation could be interpreted as a multiple enzyme/substrate-binding (see section 3.1.4.1), where presumably more than one protein molecule is bound to the substrate oligonucleotide. Indeed, as an Exolll homologue, Mth212 displays strong 3' $\rightarrow 5$ ' exonuclease activity on 3' recessed ends and also has high affinity to blunt DNA ends (Pfeifer and Greiner-Stoffele, 2005). Additionally the oligonucleotide substrate used in the first round of gel-retardation experiments (Figures 16A and 17A) had one $3^{\prime}$ recessed and one blunt end. All these admit the assumption that catalytically inactive Mth212 with retained substrate binding properties is able to bind substrate ends as well. If indeed Mth212/D151N possessed high affinity to the substrate ends, the circular plasmid (pET-vector) with no ends would not be able to effectively compete for binding short substrate DNA oligonucleotides.

To test this hypothesis, two experimental parameters were changed during next round of binding assays: 1) a competitor DNA (short 20-mer DNA oligonucleotides with sequence context identical to that in substrate oligonucleotides) and 2) the structure of substrate ends (2x blunt or $2 \times 3$ ' recessed ends).

\subsubsection{EMSA with Mth212/D151N, Substrate II and 20-mer oligonucleotides as a competitor DNA}

Multiple shift-bands observed in binding assays presented in sections 3.1.4.3 suggest that Mth212/D151N can bind DNA oligonucleotide substrates not only at the mismatch position, but also at their ends, resulting in multiple enzyme/substrate complexes. Such strong DNA-ends affinity was expected to be better competed by short 20-mer ds DNA oligonucleotides. Obviously, at equal amounts of ds DNA oligonucleotides, 20-mer competitors should have 2-fold excess of ends compared to 40-mer substrate oligonucleotides. In case these 20-mer oligonucleotides better compete for binding to DNA ends, one should expect to see one or two reproducible shift-bands even at high amount of competitor DNA.

To substantiate this point, a second round of binding assays was carried out as described in section 3.1.4.1 and 2.2.2.14, using Substrate II (a 40-mer blunt dsDNA oligonucleotides) containing an AP-site or a U/G mismatch (Figure 18A), Mth212/D151N and 20-mer blunt oligonucleotides as a competitor DNA. The amount of competitor DNA added 
was calculated as molar equivalents of DNA ends relative to the substrate ends accordingly. To exclude false interpretation of shift-bands observed, 20-mer oligonucleotides were incubated with mutant protein and applied onto the gel as a control (Figure 18).

A

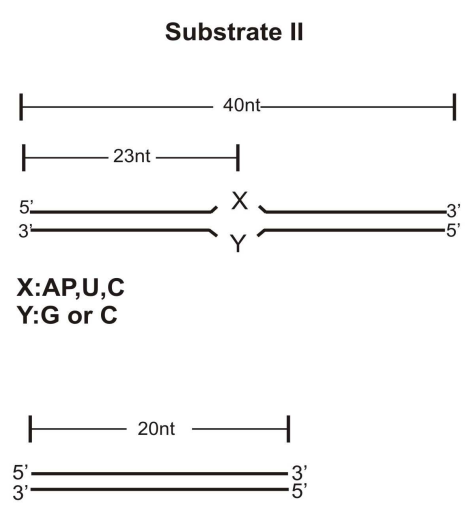

D

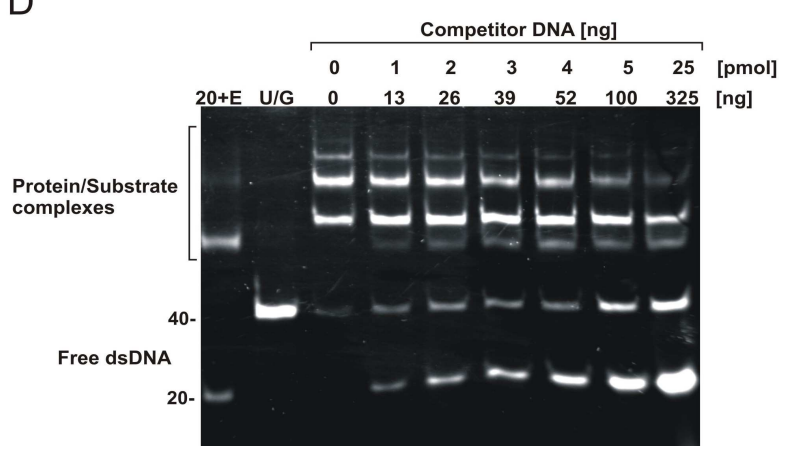

C

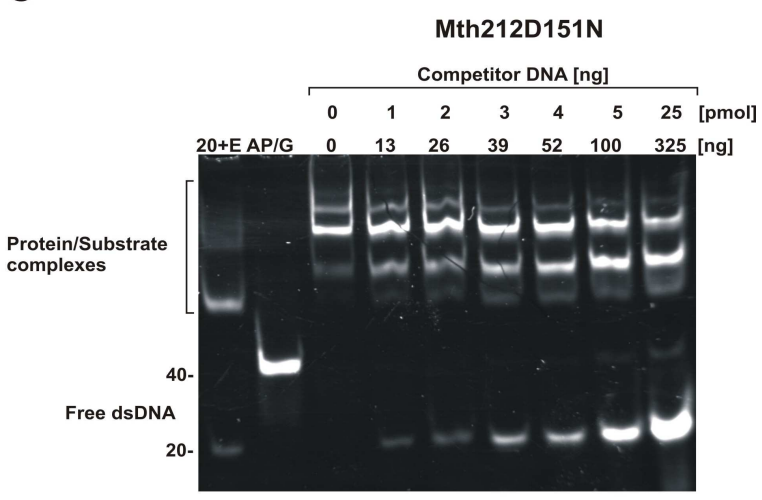

$E$

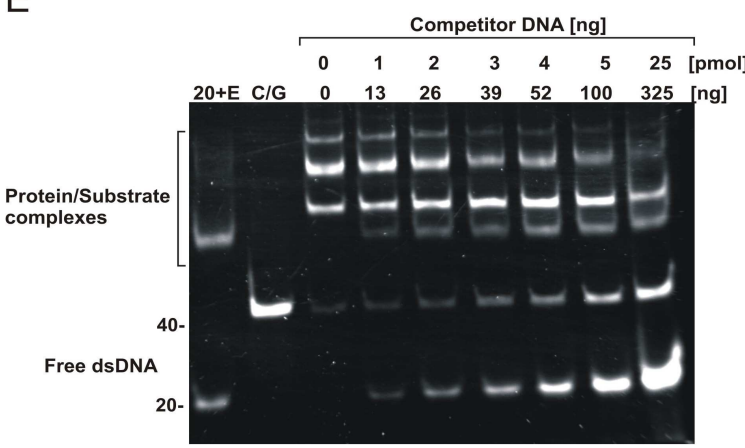

Figure 18: Mth212/D151N gel-retardation assay with Substrate II and 20-mer oligonucleotides as a competitor DNA

A-B: A schematic representation of Substrate II and 20-mer ds competitor DNA used in band-shift assays shown in panels C-E (AP: a stable AP-site, nt: nucleotides). C-E: 10\% TE-PAGE analysis of band-shift assays. EMSAs were carried out as described in section 2.2.2.14 and Figure 16, using purified Mth212/D151N, Substrate II containing an AP-site (C), a U/G mismatch (D) or U/C base pairs (E) and increasing amounts of competitor DNA. 20+E: 4 pmol of ds 20-mer competitors DNA were incubated with 4 pmol of Mth212/D151N for 5 min at $65{ }^{\circ} \mathrm{C}$ in $15 \mu \mathrm{l}$ of EMSA buffer (2.1.9) and applied onto the gel.

In binding assays with Mth212/D151N, Substrate II (2x blunt ends) and 20-mer competitor DNA, three shift-bans corresponding to enzyme/substrate complex were observed. It should be noted that shift-bands resulted from competitor-DNA/protein complex were ignored. Control samples made without competitor DNA (Figure 18, Lane 0) resulted in shift-bands of different thickness and intensity. In case of AP/G substrate, the second shift-band from the bottom was most intensive, while in case of $U / G$ substrate both bands the first and the second one were equally intensive. Furthermore, comparison of Substrate I with Substrate II (compare Figure 16 and Figure 18, Lanes 0) suggested that Mth212/D151N bound Substrate II mostly in form of multi-enzyme/substrate complex. 
Assays with Mth212/D151N, blunt U/G substrate and short competitor DNA revealed again no difference between $\mathrm{C} / \mathrm{G}$ duplex and specific $U / \mathrm{G}$ substrate binding (Figure 18D and E). Consistent specific binding of Mth212/D151N to AP/G substrate was observed, where free dsDNA band appeared only at 25x molar excess of competitor DNA (325ng). In case of $U / G$ substrate, free dsDNA bands appeared even at $1 x$ molar excess of competitor DNA. It was also found that increasing amounts of competitor DNA lead to slow reduction of band intensity and eventually to elimination of the third and the second shift-bands, while the first sift-band became more intensive. These results confirm our hypothesis that short oligonucleotides compete more effectively for protein binding than coiled plasmid. At the same time presence of two intensive sift-bands even at high amount of competitor DNA provide evidence for strong specific binding of Mth212/D151N to the blunt ends.

It was experimentally found that wt Mth212 has no exonucleolytic activity on single stranded DNA or on DNA duplexes with 3'protruding ends (Svetlana Ber, this department, unpublished). If the structure of substrate ends influences Mth212/D151N binding strength, it can be assumed that 3 'overhangs would prevent to some extend formation of protein/DNA-end complex (an exo-complex). To verify this assumption, a new substrate, namely Substrate III possessing two 3' protruding ends, was synthesised and used in the next series of binding assays.

\subsubsection{EMSA with Mth212/D151N, Substrate III and 20-mer oligonucleotides as a competitor DNA}

Previous results suggest that Mth212/D151N mutant possesses high affinity to the blunt substrate ends (section 3.1.4.4). This presumably caused the appearance of additional shiftbands making it more complicated to discriminate between specific $U / G$ substrate and $C / G$ duplex and to interpret the results. In order to decrease affinity of Mth212/D151N to the blunt ends, the third round of binding assays was made, using Substrate III (40-mer dsDNA with 5-nucleotide long 3'overhangs on both ends) containing an AP-site or a U/G mismatch (Figure 19A). 
A

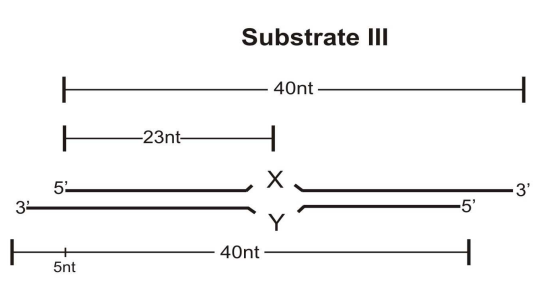

$X: A P, U$ or $C$

Y: $\mathbf{G}, \mathbf{C}$

B

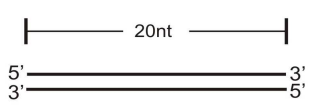

D

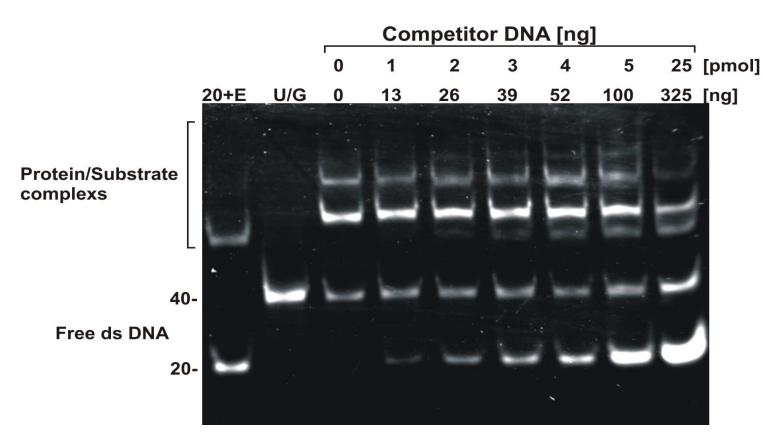

C

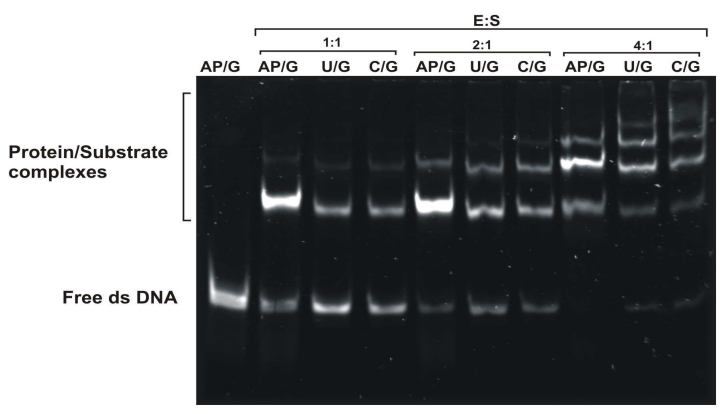

$E$

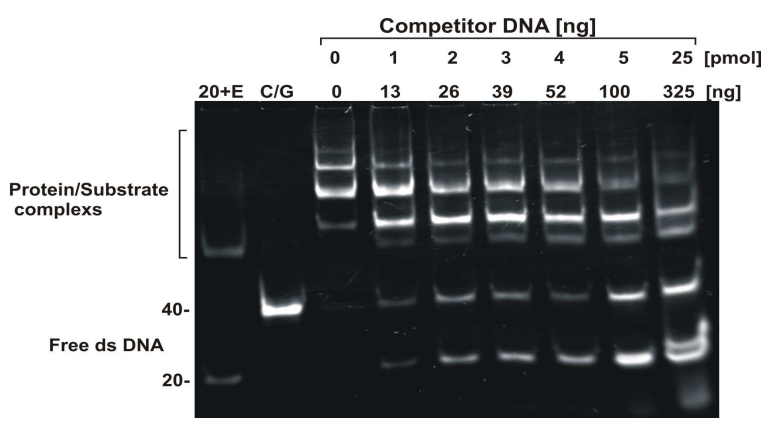

Figure 19: Mth212D151N gel-retardation assay with Substrate III and 20-mer oligonucleotides as a competitor DNA

A-B: A schematic representation of Substrate III and 20-mer ds competitor DNA used in band-shift assays shown in panels C-E (AP: a stable AP-site, nt: nucleotides). C-E: 10\% TE-PAGE analysis of band-shift assays. C: Substrate binding assays were conducted as described in section 2.2.2.14 using 1 pmol (26 ng) of Substrate III containing an AP-site, a U/G mismatch or a C/G base pair and increasing amounts of Mth212/D151N. D and E: EMSAs were carried out as described in section 2.2.2.14 and Figure 16, using purified Mth212/D151N, Substrate III containing a U/G mismatch (D) or U/C base opposition (E) and increasing amounts of competitor DNA. The amount of competitor DNA added was calculated as molar equivalents of DNA ends relative to the substrate and indicated above the gel tracks in ng and in pmol. 20+E: 4 pmol of double-stranded 20-mer competitors DNA were incubated with $4 \mathrm{pmol}$ of Mth212/D151N for $5 \mathrm{~min}$ at $65^{\circ} \mathrm{C}$ in $15 \mu \mathrm{l}$ of EMSA buffer (2.1.9) and applied onto the gel.

The third round of binding assays with Substrate III showed strong specific binding of AP/G substrate by D151N mutant (Figure 19C). Since this result was reproducible, only U/G substrate and $\mathrm{C} / \mathrm{G}$ control duplex were compared in the following series of gel-retardation assays. Competitor DNA effectively displaced Substrate III even at $1 \mathrm{x}$ molar excess resulting in appearance of free ds DNA bands (Figures 19D and E, Lane 1). When comparing band-shift assays done with all three substrate types (I, II and III), Mth212/D151N was found to bind Substrate III ( $2 \times 3^{\prime}$ protruding ends) less efficient than Substrate I and Substrate II (Figures $16 \mathrm{~A}$ and $18 \mathrm{~A}$ ). These results confirm the assumption that 5-nucleotide long 3'protruding end can be indeed the obstacle for an exo-Enzyme/Substrate complex formation. However, Mth212/D151N affinity to the specific U/G substrate possessing $2 \times 3$ ' protruding ends was again not significantly stronger than to the control C/G duplex. 
Taken together, these results demonstrate that $\mathrm{D} 151 \mathrm{~N}$ binds U/G-mismatch-containing substrate weaker than AP/G substrate and DNA ends. At the same time, D151N binds control $C / G$ duplex and specific $U / G$ substrate with same efficiency at least under these experimental conditions. Binding assays with AP/G-, U/G- substrates and $\mathrm{C} / \mathrm{G}$ duplex suggest that binding strengths between Mth212/D151N and short dsDNA substrates decrease in following order: $A P / G>D N A$ ends [3' recessed or blunt ends] $>U / G$.

\subsubsection{EMSA with Mth212/D151N and Substrate III (with U/C, U/T, U/A) and 20-mer oligonucleotides as a competitor DNA}

To shed light on Mth212 specificity of DNA-U recognition and binding energetics, further EMSA experiments were done with DNA duplexes containing following non-canonical base oppositions: U/A, U/T and U/C. Gel-retardation analyses were done as described in section 3.1.4.5, using purified D151N and Substrate III (2x3' protruding ends) at 4:1 substrate to enzyme ratio (Figure 20). 
A

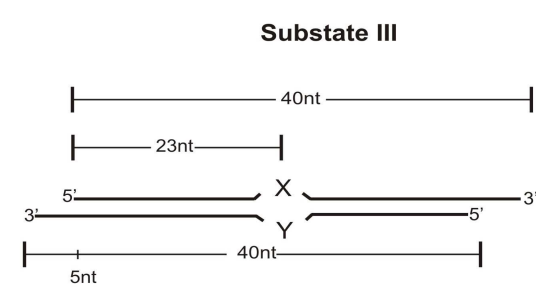

$X: U$

Y: C, T or A

B

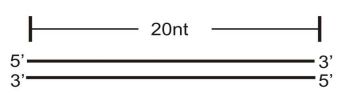

D

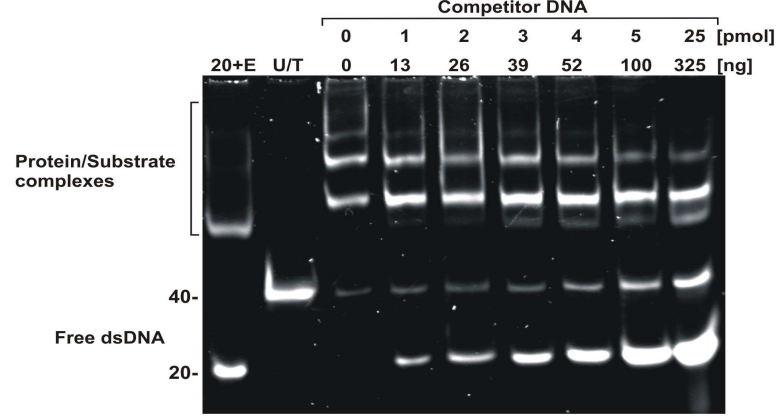

C

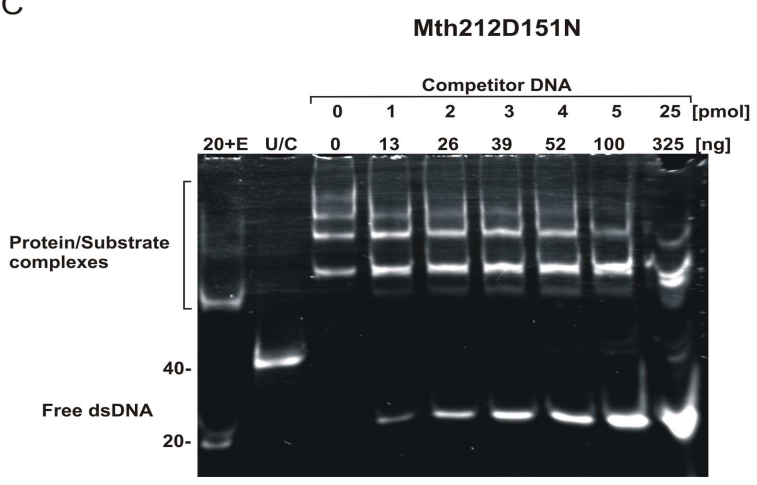

E

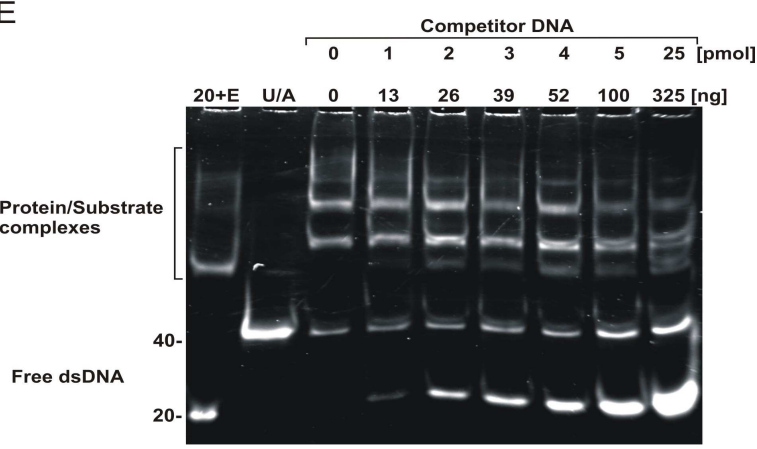

Figure 20: Mth212/D151N gel-retardation assay with Substrate III (U/C, U/T and U/A) and 20-mer oligonucleotides as a competitor DNA

A and B: A schematic representation of Substrate III and 20-mer ds competitor DNA used in band-shift assays shown in panels C-E (AP: a stable AP-site, nt: nucleotides). C-E: 10\% TE-PAGE analysis of binding assays. EMSAs were carried out as described in section 2.2.2.14 using 4 pmol of purified Mth212D151N, 1 pmol of Substrate III containing U/C (C), U/T (D) or U/A (E) base oppositions and increasing amounts of competitor DNA. 20+E: 4 pmol of ds 20-mer competitor DNA were incubated with 4 pmol of Mth212D151N for 5 min at $65^{\circ} \mathrm{C}$ in 15 $\mu \mathrm{l}$ of EMSA buffer (2.19) and applied onto the gel.

Binding assays with $U / A, U / T$ and $U / C$ base oppositions showed that $D 151 \mathrm{~N}$ variant bound U/C-containing duplex obviously stronger than U/A duplex and surprisingly stronger than $\mathrm{U} / \mathrm{T}$. Comparing these results with previous gel-retardation data, it was observed that $\mathrm{U} / \mathrm{C}$ duplex was bound by $\mathrm{D} 151 \mathrm{~N}$ almost as strong as AP-site-containing substrate (compare Figure 18C with Figure 20C). In both cases free substrate DNA band was detected only after addition of high amounts of competitor DNA (100-325 ng). Furthermore, U/T- and U/A-containing duplexes were bound by D151N with almost same affinity as U/G substrate (compare Figure 18D with and 20D, E). It should be noted that gel-retardation assays with $\mathrm{U} / \mathrm{T}, \mathrm{U} / \mathrm{A}$ and $\mathrm{U} / \mathrm{C}$ were repeated at least 3 times with each base opposition and revealed consistently strong binding of $\mathrm{D} 151 \mathrm{~N}$ to $\mathrm{U} / \mathrm{C}$ duplex. Unlike U/C-containing duplex, U/A- and $\mathrm{U} / \mathrm{T}$-containing duplexes were bound by $\mathrm{D} 151 \mathrm{~N}$ obviously weaker resulting in similar gelretardation pattern. Based on strong binding affinity of D151N to AP-site-containing substrate and $\mathrm{U} / \mathrm{C}$-containing duplex, it was decided that both $\mathrm{AP} / \mathrm{G}$ and $\mathrm{U} / \mathrm{C}$ oppositions would be the 
proper candidates for co-crystallization with Mth212/D151N and subsequent structural analysis of Protein-DNA complexes (for details see section 3.3).

The observed difference in Mth212/D151N substrate binding strengths can be explained by the assumption that Mth212, like many other mismatch DNA-repair enzymes, is equipped with base-flipping mechanism for mismatch recognition and catalysis (Mol et al., 1999). This mechanism involves two stages. At the first stage the enzyme binds DNA non-specifically building a transient protein-DNA complex. Thereafter the enzyme begins to slide along the DNA strand exploring the local helix instabilities resulting from base damage or base mispair accompanied with base flipping until the target mismatch is detected. Upon encountering the target base, the transient non-specific complex is converted into a catalytically competent or enzymatically productive complex where the target base is extruded from the DNA base stack into the substrate-binding pocket. This second stage is characterised by strong specific binding of the enzyme to the mismatch prior to the catalytic cut (Parikh et al., 1998). The observed D151N substrate binding strength (with exception of $\mathrm{U} / \mathrm{T}$ ) seem to hint a flipped-out conformation of the 2 'dU residue being crucial for making a stable Enzyme/Substrate complex.

It has already been found that various $U / X$ base oppositions (where $X$ is any of nucleobases) differ in their base pairing properties. Hence, in the context of a DNA double helix, different $U / X$ base oppositions are expected to require different energy input for $\mathrm{dU}$ flipping to occur. The expected order of energy request for extruding the target uracil from DNA base stack is: $U / A>U / G>U / C$ (Parikh et al., 1998; Pingfang Liu et al., 2008; V. Starcuviene and H.J. Fritz, 2002). Indeed this order is reflected in Mth212/D151N binding assays except for $\mathrm{U} / \mathrm{C}$, which was bound by $\mathrm{D} 151 \mathrm{~N}$ stronger than $\mathrm{U} / \mathrm{T}$ (Figure 20). This phenomenon cannot be explained by proposed base-flipping mechanism, since U/C and U/T duplexes were expected to have similar base pairing properties. This particular case led to the second assumption that Mth212 can interact with a nucleotide placed opposite to the target uracil. According to the binding assay results shown in Figure 20 interaction with cytosine opposite uracil was more stable than with thymine at least at these experimental conditions.

Based on the structure of ds DNA oligonucleotide substrates used in binding assays several in vitro substrate binding modes for Mth212 were proposed:

1. Binding to oligonucleotide ends, forming so-called exo-complex ([ES $]_{\text {exo }}$, see Equation 1);

2. Binding at a target mismatch, building an endo-complex ([ES $]_{\text {endo }}$ ), in which the target base is flipped-out towards the active site;

3. Binding in between a substrate end and a mismatch position, resulting in an unspecific complex ([ES $\left.]_{\text {usp }}\right)$ formation; 
Given that all three [ES] complexes exist in reaction system in parallel and their correlation can be described as dynamic equilibrium, the following scenario for Mth212 in vitro catalysis can be considered:

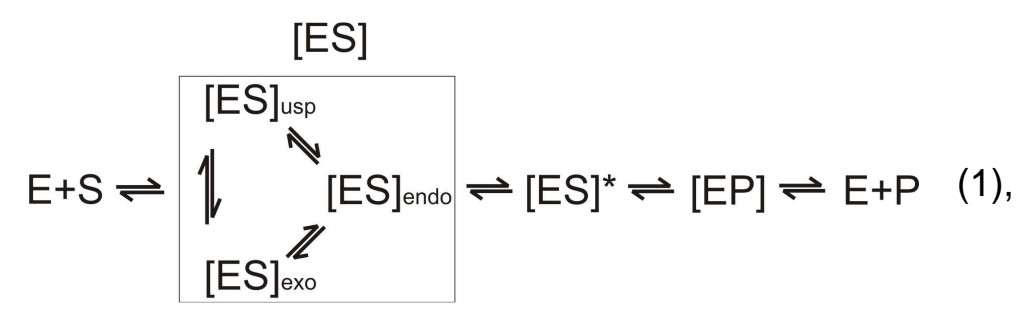

Where:

$\mathbf{E}$ indicates an enzyme, $\mathbf{S}$ a substrate and $\mathbf{P}$ a reaction product;

[ES]usp indicates an unspecific enzyme/substrate complex;

$[E S]_{\text {endo }}$ indicates a specific enzyme/substrate complex in the endo binding mode (e.g. at dU residue );

[ES] exo indicates a specific enzyme/substrate complex in the exo binding mode (i.e. at physical DNA ends);

[ES ${ }^{*}$ indicates a transition state of enzyme/substrate complex (a high-energy intermediate or activated complex);

[EP] indicates enzyme/product complex;

Given that transformation rate of $[E S]_{\text {endo }}$ into $[E P]$ complex is similar for all $U / X$ base oppositions and according to Equation 1, the equilibrium of $[E S]_{\text {endo }}$ complex formation is expected to determine the overall reaction rate. If reaching the flipped-out conformation in productive $[E S]_{\text {endo }}$ complex is a rate-limiting factor, it would be expected that the order of substrate binding strengths in binding assays to be reflected in similar order of substrate cleavage rates in enzymatic activity assays. This hypothesis was tested by semi-quantitative determination of the substrate cleavage efficiency in enzymatic cleavage assays.

\subsection{Semi-quantitative analysis of wt Mth212 substrate cleavage rate}

In order to test if the gradual changes in substrate binding strength reflect the substrate cleavage rates, endonuclease assays with wt Mth212 and DNA duplexes containing U/A, $\mathrm{U} / \mathrm{T}, \mathrm{U} / \mathrm{C}$ and $\mathrm{U} / \mathrm{G}$ base oppositions were carried out. The assays were performed as described in 2.2.3.9 at 1:1 enzyme/substrate ratio. DNA duplexes were incubated with the enzyme for 5 and $10 \mathrm{~min}$ that correspond to the incubation times used in EMSAs (see section 2.2.2.14, Figure 21). 
A
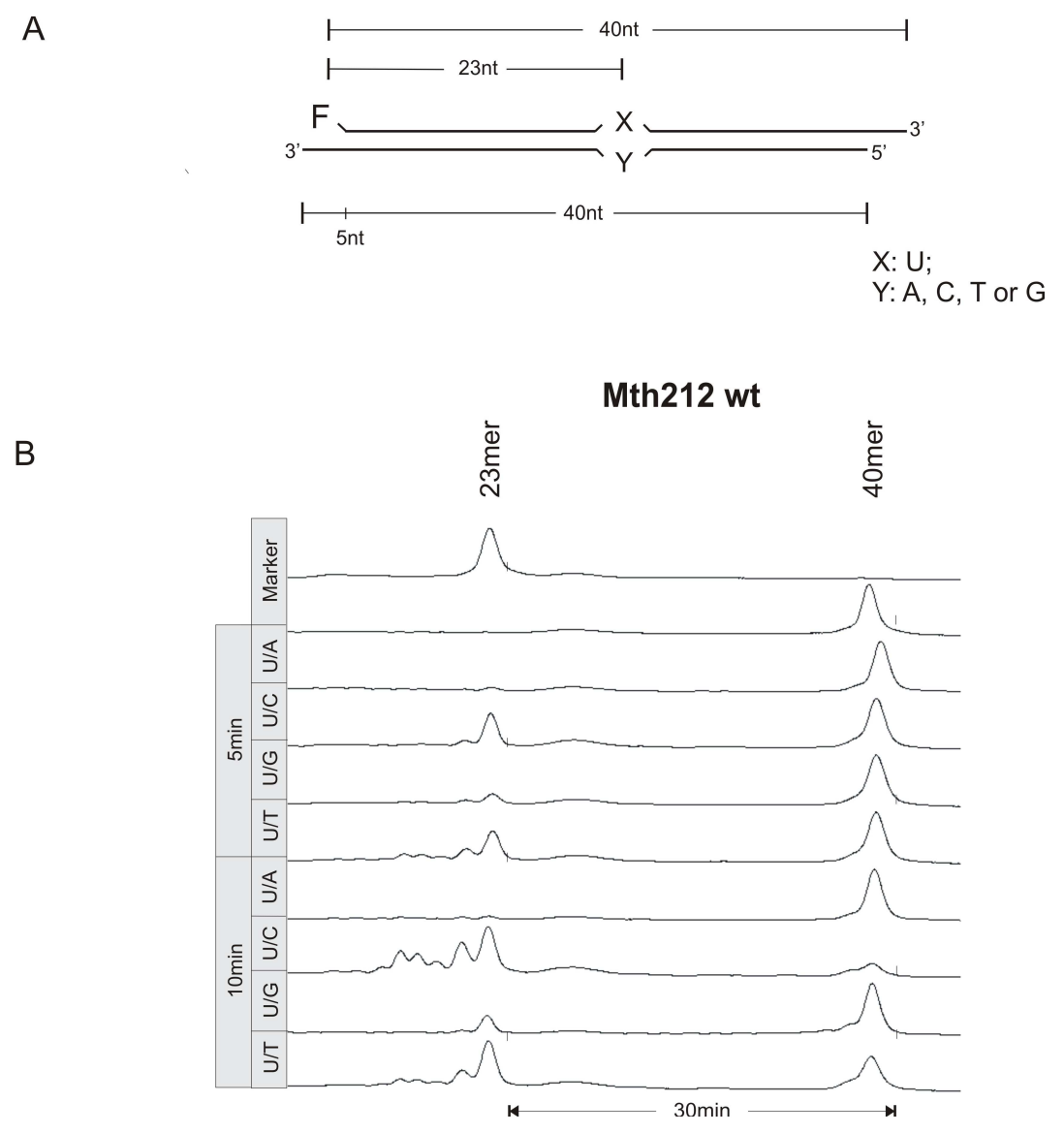

Figure 21: Endonuclease assay with wt Mth212 and U/Pu- or U/Py-containing oligonucleotides

A: A schematic representation of substrate used in endonucleolytic assays displayed in panel $B(F$ : fluorescein, nt: nucleotides). B: 11\% A.L.F.-PAGE analysis (2.2.2.8) of Mth212 endonuclease assays. The assays were performed as described in section 2.2.2.9 using substrates containing $U / A, U / G, U / T$ or $U / C$ base oppositions. $0.12 \mathrm{pmol}$ of appropriate substrate was incubated with $0.12 \mathrm{pmol}$ of wt Mth212 in $50 \mu$ of endonuclease buffer (2.1.9) for 5 and $10 \mathrm{~min}$ at $65^{\circ} \mathrm{C}$. Samples were mixed with $25 \mu \mathrm{l}$ of A.L.F. marker (2.1.9) and heated at $95^{\circ} \mathrm{C}$ for 5 min. $7 \mu \mathrm{l}$ of each sample were applied onto the $11 \%$ A.L.F.-PAGE. $30 \mathrm{~min}$ : Gel running time difference between marker oligonucleotides.

wt Mth212 was able to incise dsDNA duplexes containing uracil base oppositions (U/A, U/G, $\mathrm{U} / \mathrm{C}, \mathrm{U} / \mathrm{T}$ ) at position 24 , which is consistent with our previously published data (Georg et al., 2006). An endonucleolytic cut next to DNA uracil residue was evidenced by appearance of product peak with 23-mer marker elecrophoretic mobility (Figure 21B). However, a gradual change in substrate cleavage rates was observed. In case of U/C and $\mathrm{U} / \mathrm{T}$ duplexes 23-mer product peaks were clearly detectable after 5 min incubation with wt Mth212, while U/G substrate was less efficiently degraded and there was no 23-mer substrate peak observed in case of U/A substrate. Even more pronounced difference in substrate cleavage rates was observed after $10 \mathrm{~min}$ incubation time. U/C substrate was almost completely cleaved to 23-mer intermediate products (compare height of $\mathrm{U} / \mathrm{C}$ substrate peaks after 5 and $10 \mathrm{~min}$, Figure 21B), which were further degraded by $3^{\prime} \rightarrow 5^{\prime}$ exonuclease activity of Mth212 (see series of peaks faster than 23-mer marker, Figure 21B). 
$\mathrm{U} / \mathrm{T}$-containing duplex was slightly less degraded in $10 \mathrm{~min}$ than $\mathrm{U} / \mathrm{C}$, but obviously more efficiently than $U / G$ substrate. $U / A$ duplex remained almost undigested after $10 \mathrm{~min}$ incubation with the enzyme. Thus, the rates of recognition and processing of different $U / X$ oppositions by Mth212 differed only at the early stage (i.e. mismatch recognition and baseflipping stages) of the enzymatic reaction, whereas after $20 \mathrm{~min}$ incubation time at 1:1 enzyme/substrate ratio Mth212 efficiently degraded all four uracil-containing oligonucleotides to their 23-mer intermediate products (Georg et al., 2006). These results support our hypothesis of a positive relationship between substrate binding strength and substrate cleavage rate (see section 3.1.4.6), in that the order of substrate cleavage rates by wt Mth212 reflects the order of substrate binding strengths by D151N, namely $\mathrm{U} / \mathrm{C}>\mathrm{U} / \mathrm{T}>\mathrm{U} / \mathrm{G}>\mathrm{U} / \mathrm{A}$.

Since in all DNA duplexes used in endonuclease assays $U / X$ oppositions had identical sequence context, the observed difference in relative substrate cleavage rates suggests that the nature of nucleotide placed opposite the target uracil (i.e. a purine or a pyrimidine) affects Mth212 enzymatic catalysis as well. In confirmation of this, Mth212 processed uracil opposite a cytosine more efficiently than uracil opposite a guanine or adenine. Moreover, Mth212 processed even U/C and U/T oppositions slightly different (Figure 21).

Given that Mth212 recognises and cleaves specific substrate using nucleotide-flipping mechanism, DNA base-pairing properties in U/Pu or U/Py pairs were expected to affect the rate of enzymatic base flipping from DNA backbone and ultimately the overall enzymatic reaction rate. The obtained results confirmed this assumption in that $\mathrm{U} / \mathrm{Py}$ base oppositions were more efficiently cleaved by wt Mth212 than U/Pu (Figure 21). Trends observed in wt Mth212 were similar to those found in other enzymes known or suspected to involve base-flipping mechanism for substrate recognition and catalysis. Representatives of UDG family enzymes, namely human UDG (Parikh et al., 1998), UNG and MUG from Escherichia coli (Pearl, 2000; Pingfang Liu et al., 2002; Pingfang Liu et al., 2008), TTUDGA and TTUDGB from Thermus thermophilus (V. Starcuviene and H.-J. Fritz, 2002), and TDG from M. thermautotrophicus were tested for substrate selectivity. It was found that a uracil is less efficiently repaired from base pairs that approximate Watson-Crick configuration, e.g. a U/A, whereas it is more efficiently repaired from $U / C$ or from the wobble $U / G$ base pairs. Such mode of enzymatic activity was attributed primarily to the difference in base pairing properties of various $\mathrm{U} / \mathrm{X}$ oppositions and to the energetic costs required for the extruding of the target uracil from DNA base stack. Hence, the observed decrease in wt Mth212 substrate cleavage rates $(U / C>U / T>U / G>U / A)$, in correlation with the energy requirements, argues for the base flipping-out as a rate-limiting factor.

In conclusion, complete loss of enzymatic activity by Mth212 Asp-151 mutants 
alongside with retention of substrate binding properties provides evidence for the unique catalytic site for both AP-endo and U-endonuclease activities. Mth212/D151N variant demonstrated the strongest binding affinity to AP-site-containing DNA that is in accordance with the data that wt Mth212 is the main AP-site-specific endonuclease of M. thermautotrophicus (Pfeifer and Greiner-Stoffele, 2005). Based on the gel-retardation analysis the following decrease in Mth212 substrate binding strength was proposed: AP-site $>$ DNA ends [3'recessed or blunt ends] $>U / P y>U / P u$. It seems that binding strength between Mth212 and its DNA substrate is determined by the mode of substrate binding, which ultimately determines the efficacy of enzymatic catalysis.

Differences in Mth212 activity (binding strength and cleavage rate) towards different U/X oppositions within identical sequence context implicate a putative base-flipping mechanism of Mth212 enzymatic catalysis. Given that Mth212 is equipped with base-flipping mechanism, potential rate-limiting factors of Mth212 enzymatic catalysis in vitro would be the following:

- Mode of substrate binding (see Equation 1);

- Stability of uracil in its stacked conformation in DNA duplex.

Concerning Mth212 mode of action, it is more likely that Mth212, similar to other damagespecific DNA repair enzymes (Mol et al., 1999), binds DNA distortion unspecifically building a non-productive transient complex and slides on DNA strand until the target mismatch is encountered.

To shed light on Mth212 active-site structure and mechanism of enzymatic catalysis, X-ray crystallographic analysis of wt Mth212 together with its catalytically inactive variant bound to DNA substrate was performed (see section 3.3).

\subsection{Mth212 structure analysis}

Mth212/D151N was over-expressed, purified as described in Materials and Methods (see section 2.2) and co-crystallised with a double-stranded DNA oligonucleotide substrate containing a $U / G, U / T$ or $U / C$ base oppositions. wt Mth212 used for the crystallographic analysis was produced in appropriate amounts by L. Schomacher and C. Preiß (this department). X-ray crystallographic analysis as well as production of some protein batches has been performed by Kristina Lakomek (Department of Molecular Structural Biology, Institute of Molecular Biology and Genetics, Georg-August University of Goettingen).

Structurally conserved amino acids residues constituting the active site pocket of Mth212 enzyme have been found by comparative analysis of 3D structures of Mth212, Exolll and Ape1. Glu-38, Asp-151, Asp-222 and His-248 in Mth212 (K. Lakomek, 2009) were proposed to be the functional equivalents of catalytically essential Glu-34, Asp-151, Asp-229 
and His-259 in Exolll (Mol et al., 1995), and Glu-96, Asp-283, Asp-210 and His-309 in Ape1 (Gorman et al., 1997) (see Figure 22).

A

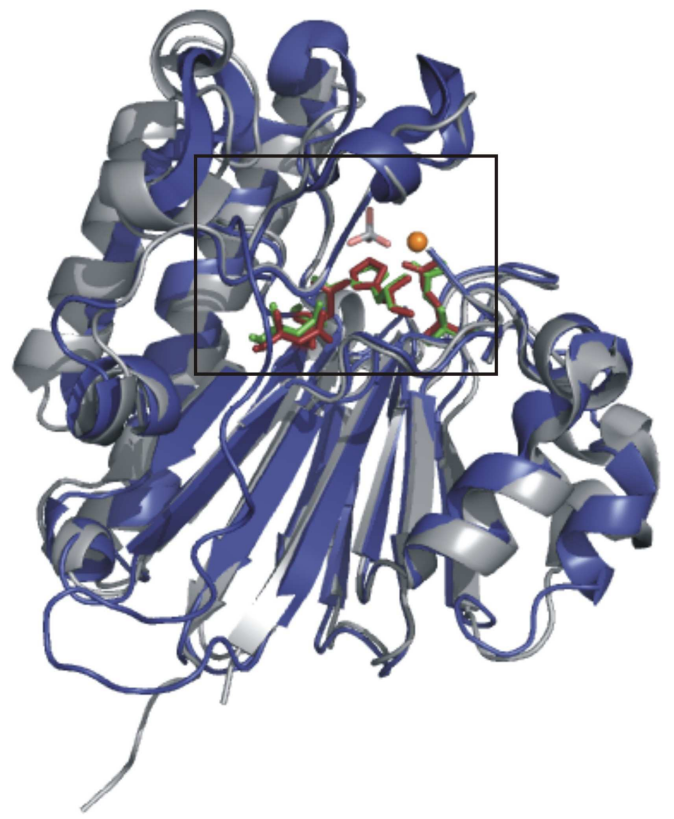

B

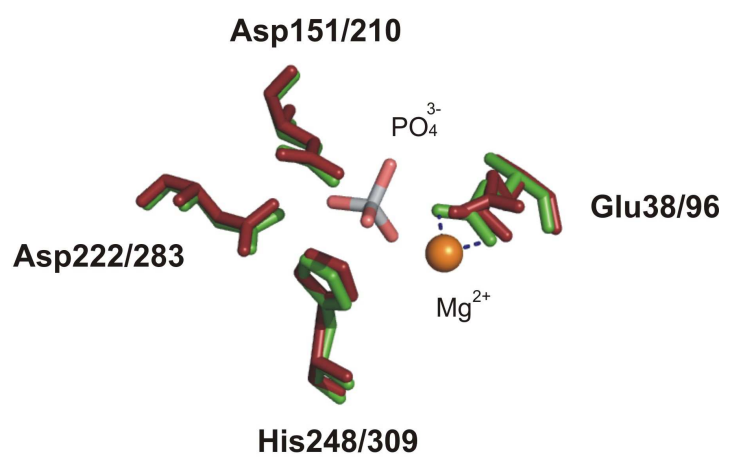

Figure 22: 3D structure of Mth212 superimposed with human Ape1

A: A cartoon representation of overall view of superimposed Mth212 apo-structure (3G91) shown in grey and Ape1 (1DEW) shown in dark blue. The catalytically essential amino acid residues of Ape1 are represented as ruby sticks and of Mth212 as green sticks. The active site comprising amino acid residues enclosed in a black square are shown in enlarged view in panel B. B: A close-up view of Mth212 active site residues: Asp-151, Glu38, His-248 and Asp-222 (green sticks) superimposed with Ape1 active site residues: Asp-210, Glu-96, His-309 and Asp-283 (ruby sticks). A divalent metal ion (here $\mathrm{Mg}^{2+}$ ) and a phosphate ion $\left(\mathrm{PO}_{4}{ }^{3-}\right.$ ) bound in Mth212 active site are shown as an orange sphere and grey-pink sticks, respectively. The cartoon was slightly tilted and rotated with respect to the overall view shown in panel $A$.

In several Mth212 structures exhibiting wild-type Asp-151 residue a divalent metal ion $\mathrm{Mg}^{2+}$ was bound in the active site by the side chains of Asn-12 and Glu-38. In contrast, none of Mth212/D151N structures revealed a metal ion in the active site. These data, together with the complete loss of enzymatic activity by D151N mutant indicate that both Asp-151 and $\mathrm{Mg}^{2+}$ are prerequisite for the proper orientation of the target PO3' scissile bond in Mth212 active site prior to the enzymatic cleavage (Figure 22).

Structure analysis of wt Mth212 and Mth212/D151N in complex with specific DNA substrates identified specific mode of DNA binding. Both wt Mth212-DNA and Mth212/D151N-DNA complexes were found in form of an exo-complex, where 3' end of the DNA duplex was fixed in the active site through numerous ionic interactions involving Asn-10, Glu-38, Tyr-111, Asp-151/Asn-151, Asn-153 and His-248 (Figure 23). 
A

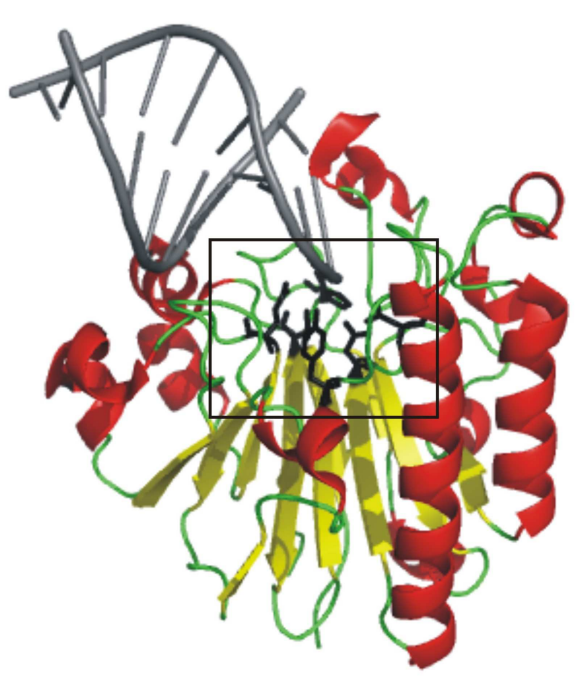

B

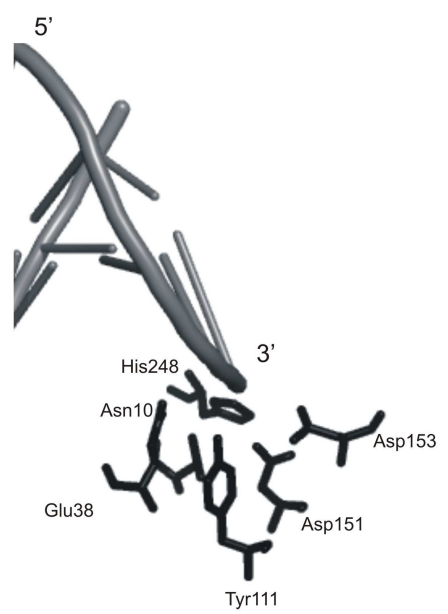

Figure 23: Mth212/D151N-DNA an exo-complex

A: An overview of Mth212/D151N (K. Lakomek, 2009) in complex with DNA showing one of the 3'ends of DNA duplex bound in the active site. Shown are: $\alpha$-helices (red coils), $\beta$-sheets (yellow arrows), coils (green tubes) and DNA helixes (grey tubes). B: A close-up view of the 3' end of DNA duplex (grey) fixed in Mth212/D151N active site by Asn-10, Glu-38, Tyr-111, Asn-151, Asp-153 and His-248 residues (black sticks).

Owing to the difficulty in obtaining Enzyme-DNA complex in endo binding mode, the exact mechanism of Mth212 U/G mismatch recognition and catalysis is unclear. Therefore, the obtained results were interpreted based on structural data known for other Exolll homologue, human Ape1. From the crystal structure of human Ape1 bound to AP-site-containing DNA and discovered extra-helical AP-site binding mode $\mathrm{Mol}$ and co-workers proposed the nucleotide flipping mechanism as an intrinsic property of AP-site-specific endonucleases (Mol et al., 2000). More recently, Jingyang Chen et al. have published an experimental study on structure and dynamics of DNA nucleotides with $A, T, G$, and $\mathrm{C}$ opposite an AP-site. The authors pointed out that the base placed opposite of target AP-site intrinsically influenced DNA conformation during Ape1-AP site interaction (Jingyang Chen, 2007).

The three-dimensional structure analysis revealed that Mth212/D151N-DNA exo-complex (K. Lakomek, 2009) mostly resembles Ape1-DNA endo-complex (Mol et al., 2000) (Figure 24). These results suggest that Mth212 can be equipped with Ape1-like mechanism of substrate recognition and catalysis. This resemblance however gives no clue as to what are the structural bases of Mth212 uracil specificity, as Ape1 lucks such U-endonuclease activity. Meanwhile, presence of a single active site in Mth212 for major enzymological hallmarks suggests that recognition of an AP-site, 3' end and DNA-U residue occurs via same set of structural elements providing Mth212 with definite mechanism of molecular catalysis. 
A

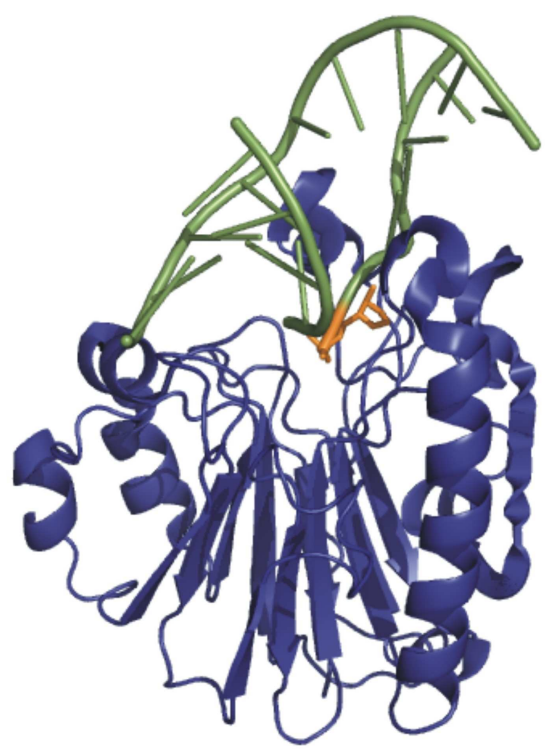

B

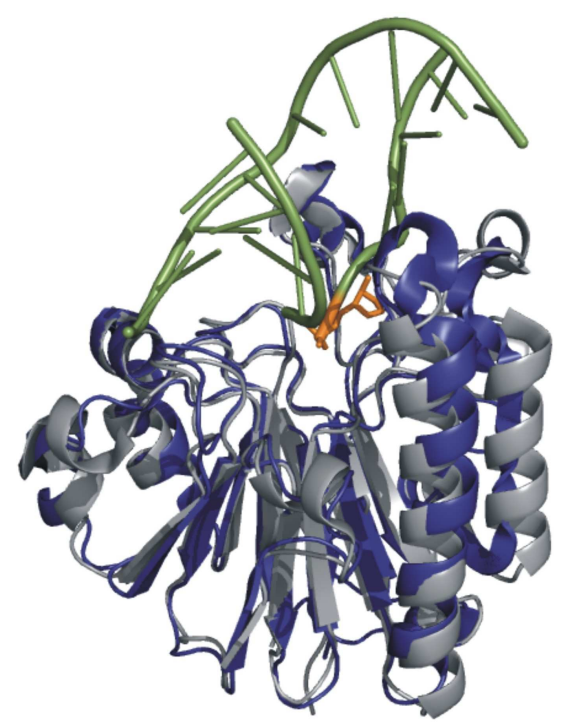

Figure 24: 3D structure of human Ape1-DNA complex superimposed with Mth212D151N-DNA complex A: An overall view of Ape1 complex with AP-site containing DNA in a cartoon representation. DNA (in green) with the target AP-site (orange) bound to Ape1 (dark blue) (from the co-crystal structure of Ape1-DNA (1DEW), Mol et al., 2000). B: Superimposed human Ape1 (dark blue) in complex with AP-site (orange) containing DNA (green) and Mth212/D151N-DNA complex (grey) (3G38, here same structure as shown in Figure 23A, except for DNA molecule that was hidden). Structure data were processed using PyMOL (DeLano Scientific LLC) software.

In conclusion, based on the functional and structural analysis a putative mechanism of Mth212 specific substrate recognition and catalysis could be proposed. It is most likely that Mth212 similar to the other damage-specific DNA repair enzymes discriminates between damaged and undamaged DNA by flipping-out mechanism for the mismatched base recognition and cleaves damaged base extra-helically. However, the structural basis of the specific uracil recognition and discrimination against cytosine and thymine remains unclear. In the absence of the crystal structure of Mth212-DNA complex in endo binding mode, the assignment of Asp-151, as well as other conservative amino acid residues in Mth212 specific uracil residue recognition and catalysis is speculative and requires further studies. 


\section{Summary}

Spontaneous hydrolytic deamination of cytosine to uracil is one of the most frequent DNA modifications during cellular everyday metabolism. To counteract this mutagenic effect, most organisms eliminate uracil residues from DNA by means of the base-excision repair pathway (BER), which is initiated by a specific uracil-DNA glycosylase enzyme (UDG). UDGs are highly conserved and widespread DNA repair enzymes that are found in almost all living organisms. The most striking is perhaps the lack of UDG family genes in Methanothermobacter thermautotrophicus, a thermophilic Archaeon, suggesting an alternative DNA uracil repair system.

Mth212 from $M$. thermautotrophicus is the only enzyme within Exolll family members, which besides all enzymatic activities inherent in Exolll homologues recognises uracil in ds DNA and cleaves the phosphodiester linkage located to the 5' side of 2'dU residue.

The purpose of this project was to gain an insight into the mode of Mth212 specific substrate recognition and structural features providing Mth212 with uracil specificity. To address this, a conserved Asp-151 residue in Mth212 was substituted for Asn (D151 $\rightarrow N$ ). Mth212/D151N mutant was purified and analysed in vitro for enzymatic activity and substrate binding properties. D151 $\rightarrow \mathrm{N}$ substitution eliminated both AP-endo and U-endonuclease activities but did not influence the substrate binding. These data indicate that Mth212 has a single catalytic active site for both AP-endo and U-endonuclease activities. Furthermore, retention of the substrate binding properties provides evidence for the proper folding of Mth212/D151N mutant protein.

Analysis of D151N binding to the ds DNA substrates containing ether an AP-site or U/X oppositions (X: Py or $\mathrm{Pu}$ base type) revealed the following decrease in substrate binding strength: AP-site > DNA ends [3'recessed or blunt ends] > U/Py > U/Pu. These results suggest that in vitro Mth212 can bind DNA substrate in either endo- or exo-binding mode. It is most likely that the mode of substrate binding determines the strength of substrate binding and the efficacy of the overall enzymatic reaction.

The data on wt Mth212 substrate cleavage efficiency show that wt Mth212 processes different $U / X$ oppositions with different preferences at the early stages of enzymatic reaction. $\mathrm{U} / \mathrm{Py}$ base oppositions were cleaved faster than U/Pu and the order of substrate cleavage rates reflected the order of substrate binding strengths. Such mode of enzymatic activity can be attributed to the difference in base pairing properties of various $U / X$ oppositions and to the energetic costs required for the extruding of the target uracil from DNA base stack. Moreover, the observed difference in substrate cleavage rates, in correlation with the energy requirements, argues for the base flipping-out as a rate-limiting factor in the overall enzymatic reaction. Based on binding assays and in substrate cleavage results a putative 
nucleotide-flipping mechanism for the uracil-containing mismatch discrimination and processing was proposed.

The crystallographic analysis of Mth212/D151N in complex with specific DNA substrates revealed all Protein-DNA complexes in form of exo-binding mode, where one of the 3 ' ends of DNA duplex is fixed in the active site. Since free DNA ends in vivo is a rare event, it is more likely that Mth212, similar to other damage-specific DNA repair enzymes, binds DNA distortion unspecifically building a transient complex and slides along DNA strand until the target mismatch is encountered. 


\section{Abbreviations:}

aa amino acids

Amp Ampicillin

AP- apyrimidinic/apurinic site

APS Ammoniumperoxodisulfat

bp base pare

BSA bovine serum albumin

i.e. id est (that is; in other words)

e.g. exempli graciā (for example)

etc. et cetera (and so forth)

ORF open reading frame

$C$ degree Celsius

$\mathrm{Cm}$ Chloramphenicol

C-terminal carboxy-terminal

DNA Deoxyribonucleic acid

DNA-U-Rep DNA-Uridin-Repair

dNTP deoxyribonucleoside triphosphate

ddNTP dideoxyribonucleoside triphosphate

ssDNA double stranded DNA

DTT Dithiothreitol

dYT double yeast tryptone

$\boldsymbol{\varepsilon}_{280}$ molar extinction coefficient at $280 \mathrm{~nm}$

EDTA ethylenediaminetetraacetate

etc. et cetera

F Farad, electric capacitance

g gramm

h hours

HEPES 4-(2-Hydroxyethyl)-1-piperazin-ethan-sulfonic acid HhH Helix-hairpin-helix, GPD Glycin-Prolin-Aspartat

IMAC immobilized metal ion affinity chromatography

IPTG Isopropyl- $\beta$-D-thiogalaktopyranosid

kb Kilo-base pair

I Liter

LB Luria Bertani

M molar 
Mr relative molecular mass

$\mathrm{ml}, \mu \mathrm{l}$ milli- $\left(10^{-3}\right)$, mikro- $\left(10^{-6}\right)$ liter

min minutes

$\mu \mathrm{m}, \mathrm{nm}$ mikro- $\left(10^{-6}\right)$, nano- $\left(10^{-9}\right)$ meter

$\mathrm{N}$-terminal amino-terminal

ODx Optical density x nm

$\Omega$ Ohm, electrical resistance

ori origin of replication

p Pico $\left(10^{-12}\right)$

PA / PAGE Polyacrylamid / Polyacrylamid-Gel electrophoresis

PBS phosphate buffered saline

PCR polymerase chain reaction

PEG Polyethylenglykol

Pfu-Polymerase, DNA-Polymerase B from Pyrococcus furiosus

Pol B, DNA-Polymerase B from Methanothermobacter thermautotrophicus Stamm $\Delta H$

$R$ universal gas constant, $R=8,314 \mathrm{~J} / \mathrm{K} \mathrm{mol}$

$\mathrm{RT}$ room temperature

rpm rotation per minute

sec second

SDS Sodiumdodecylsulfat

ssDNA single stranded DNA

T temperature

t time

Taq-Polymerase, DNA-Polymerase from Thermus aquaticus

TEMED N,N,N',N'-Tetramethylethylenamin

Tris Tris(hydroxymethyl)aminomethan

u enzymatic activity unit

U-Endo DNA-Uridin-Endonuclease

UDG Uracil-DNA-Glycosylase

Ugi Uracil-DNA-Glycosylase Inhibitor

Ung Uracil-N-Glycosylase from E.coli

UV Ultraviolet

V Volt

Vol. volume

$\mathrm{v} / \mathrm{v}$ volume/volume

$\mathrm{w} / \mathrm{v}$ weight/volume

3D three-dimensional 
DNA/RNA-Bases:
A Adenine
C Cytosine
G Guanine
$\mathrm{T}$ Thymine
U Uracil

\section{Amino acids:}
A / Ala Alanine
C / Cys Cysteine
D / Asp Aspartic Acid
E / Glu Glutamic Acid
F / Phe Phenylalanine
G / Gly Glycine
$\mathrm{H} / \mathrm{His}$ Histidine
I / Ile Isoleucine
K / Lys Lysine
L / Leu Leucine
M / Met Methionine
$\mathrm{N} /$ Asn Asparagine
P / Pro Proline
Q / Gln Glutamine
$\mathrm{R}$ / Arg Arginine
S / Ser Serine
$\mathrm{T} / \mathrm{Thr}$ Threonine
$\mathrm{V} / \mathrm{Val}$ Valine
W /Trp Tryptophan
Y / Tyr Tyrosine

Organism: Mth Methanothermobacter thermautotrophicus 


\section{References}

Aravind, L.K., E. V. (2000) The alpha/beta fold uracil DNA glycosylases: a common origin with diverse fates. Genome Biol, 1, RESEARCH0007.

Barrett, T.E., Savva, R., Panayotou, G., Barlow, T., Brown, T., Jiricny, J. and Pearl, L.H. (1998) Crystal structure of a G:T/U mismatch-specific DNA glycosylase: mismatch recognition by complementary-strand interactions. Cell, 92, 117-129.

Barzilay, G., Mol, C.D., Robson, C.N., Walker, L.J., Cunningham, R.P., Tainer, J.A. and Hickson, I.D. (1995a) Identification of critical active-site residues in the multifunctional human DNA repair enzyme HAP1. Nat Struct Biol, 2, 561-568.

Barzilay, G., Walker, L.J., Robson, C.N. and Hickson, I.D. (1995b) Site-directed mutagenesis of the human DNA repair enzyme HAP1: identification of residues important for AP endonuclease and RNase $\mathrm{H}$ activity. Nucleic Acids Res, 23, 1544-1550.

Bernstein, C.a.B., H. (1991) Aging, Sex and DNA Repair, Academic press,Inc.,San Diego. Academic press, Inc., San Diego.

Blum, H., Beier, H. and Gross, H. (1987) Improved silver staining of plant proteins, RNA and DNA in polyacrylamide gels. Electorphoresis, 93-99.

Bodil Kavli, O.S., Mansour Akbari, Marit Otterlei, Hilde Nilsen, Frank Skorppen, Per Arne Aas, Lars Hagen, Hans E. Krokan, and Geir Slipphaug. (2002) hUNG2 Is the Major Repair Enzyme for Removal of Uracil from U:A Matches, U:G Mismatches, and $U$ in Single-stranded DNA, with hSMUG1 as Broad Specificity Backup. The J.of Biol. Chem., 277, 39926-39936.

Bradford, M.M. (1976) A rapid and sensitive method for the quantitation of microgram quantities of protein utilizing the principle of protein-dye binding. Anal Biochem, 72 , 248-254.

Bruner, S.D., Norman, D.P. and Verdine, G.L. (2000) Structural basis for recognition and repair of the endogenous mutagen 8-oxoguanine in DNA. Nature, 403, 859-866.

Bullock, W.O., Fernandez, J.M. and Short,J.M. (1987) XL1-Blue: a high efficiency plasmid transforming recA Escherichia coli strain with beta-galactosidase selection. Biotechniques, 5, 376-387.

Chester, N. and Marshak, D.R. (1993) Dimethyl sulfoxide-mediated primer Tm reduction: a method for analyzing the role of renaturation temperature in the polymerase chain reaction. Anal Biochem, 209, 284-290.

Conley, E.C., Saunders, V.A., Jackson, V. and Saunders, J.R. (1986) Mechanism of intramolecular recyclization and deletion formation following transformation of Escherichia coli with linearized plasmid DNA. Nucleic Acids Res, 14, 8919-8932.

Dower, W.J., Miller, J.F. and Ragsdale, C.W. (1988) High efficiency transformation of E. coli by high voltage electroporation. Nucleic Acids Res, 16, 6127-6145. 
Erzberger, J.P. and Wilson, D.M., 3rd. (1999) The role of Mg2+ and specific amino acid residues in the catalytic reaction of the major human abasic endonuclease: new insights from EDTA-resistant incision of acyclic abasic site analogs and site-directed mutagenesis. J Mol Biol, 290, 447-457.

Friedberg, E.C. (2003) DNA damage and repair. Nature, 421, 436-440.

Fromme, J.C., Banerjee, A., Huang, S.J. and Verdine, G.L. (2004) Structural basis for removal of adenine mispaired with 8-oxoguanine by MutY adenine DNA glycosylase. Nature, 427, 652-656.

Gallinari, P. and Jiricny, J. (1996) A new class of uracil-DNA glycosylases related to human thymine-DNA glycosylase. Nature, 383, 735-738.

Georg, J. (2005) Gentechnische Production und enzymologischeCharakterisirung des ExolllHomologs von Methanothermobacter thermautotrophicus. Diplomarbeit, GeorgAugust-Universität Göttingen.

Georg, J., Schomoacher, L., Chong, J.P., Majernik, A.I., Raabe, M., Urlaub, H., Muller, S., Ciirdaeva, E., Kramer, W. and and Fritz, H.J. (2006) The Methanothermobacter thermoautotrophicus Exolll homolohue Mth212 is a DNA uridine endonuclease. Nucleic Acids Res, 34, 5325-5336.

Gorman, M.A., Morera, S. and Rothwell, D.G. (1997) The crystal structure of the human DNA repair endonuclese HAP1 suggests the recognition of extra-helical deoxyribose at DNA abasic sites. The EMBO Journal, 16, 6548-6558.

Grogan, D.W. (2004) Stability and repair of DNA in hyperthermophilic Archaea. Curr Issues Mol Biol, 6, 137-144.

Haushalter, K.A., Todd Stukenberg, M.W., Kirschner, M.W. and Verdine, G.L. (1999) Identification of a new uracil-DNA glycosylase family by expression cloning using synthetic inhibitors. Curr Biol, 9, 174-185.

Hendrich, B., Hardeland, U., Ng, H.H., Jiricny, J. and Bird, A. (1999) The thymine glycosylase MBD4 can bind to the product of deamination at methylated CpG sites. Nature, 401, 301-304.

Hinks, J.A., Evans, M.C., De Miguel, Y., Sartori, A.A., Jiricny, J. and Pearl, L.H. (2002) An iron-sulfur cluster in the family 4 uracil-DNA glycosylases. J Biol Chem, 277, 1693616940.

Hollis, T., Ichikawa, Y. and Ellenberger, T. (2000) DNA bending and a flip-out mechanism for base excision by the helix-hairpin-helix DNA glycosylase, Escherichia coli AlkA. Embo J, 19, 758-766.

Horst, J.P.a.F.H.J. (1996) Counteracting the mutagenic effect of hydrolytic deamination of DNA 5-methylcytosine residues at high themperature: DNA mismatch $\mathrm{N}$-glycosylase 
Mig.Mthl of the thermophilic archaeon Methanobacterium thermautotrophicum THF. Embo J, 15, 5459-5469.

Hoseki, J., Okamoto, A., Masui, R., Shibata, T., Inoue, Y., Yokoyama, S. and Kuramitsu, S. (2003) Crystal structure of a family 4 uracil-DNA glycosylase from Thermus thermophilus HB8. J Mol Biol, 333, 515-526.

Jie Hu, A.M.a.A.R.D. (2008) A two-step nucleotide-flipping mechanism enables kinetic discrimination of DNA lesions by AGT. PNAS, 105, 4615-4620.

Jingyang Chen, F.-Y.D., David A. Case, Christopher J. Turner and JoAnne Stubbe. (2007) DNA oligonucleotides with $A, T, G$ or $C$ opposite an abasic site: structure and dynamics. Nucleic Acids Res, 36,, 253-262.

Jones, D.H. (1994) PCR mutagenesis and recombination in vivo. PCR Methods Appl, 3, S141-148.

Kavli, B., Sundheim, O., Akbari, M., Otterlei, M., Nilsen, H., Skorpen, F., Aas, P.A., Hagen, L., Krokan, H.E. and Slupphaug, G. (2002) hUNG2 is the major repair enzyme for removal of uracil from $U: A$ matches, $U: G$ mismatches, and $U$ in single-stranded DNA, with hSMUG1 as a broad specificity backup. J Biol Chem, 277, 39926-39936.

Kelman, Z. and White, M.F. (2005) Archaeal DNA replication and repair. Curr Opin Microbiol, 8, 669-676.

Krokan, H.E., Drablos, F. and Slupphaug, G. (2002) Uracil in DNA--occurrence, consequences and repair. Oncogene, 21, 8935-8948.

Krokan, H.E., Standal, R. and Slupphaug, G. (1997) DNA glycosylases in the base excision repair of DNA. Biochem J, 325 ( Pt 1), 1-16.

Kunkel, T.A. and Wilson, S.H. (1996) DNA repair. Push and pull of base flipping. Nature, 384, 25-26.

Kyte, J. (1995) Mechanism in Protein Chemistry. Garland Publishing, Inc., New York and London.

L.Schomacher. (2007) Ein neu entdeckter Weg der Reparatur hydrolytisch geschädigter DNA-Cytosinereste, etabliert im thermophilen Archaeon Methanotermobacter thermautotrophicus H. Dissertation, Georg-August-Universität Göttingen.

Laemmli, U.K. (1970) Cleavage of structural proteins during the assembly of the head of bacteriophage T4. Nature, 227, 680-685.

Lakomek, K. (2009) Structural characterisation of the lysosomal 66,3kDa protein and of the DNA repair enzyme Mth0212 by means of X-ray crystallography, Georg-AugustUniversität,Göttingen.

Lienhard, G.E. (1973) Enzymatic catalysis and transition-state theory. Science, 180, 149154. 
Lindahl, T. (1974) An N-glycosidase from Escherichia coli that releases free uracil from DNA containing deaminated cytosine residues. Proc. Natl. Acad. Sci. USA, 71, 3649-3653.

Lindahl, T. (1993) Instability and decay of the primary structure of DNA. Nature, 362, 709715.

Lindahl, T., Ljungquist,S., Siegert,W.,Hyberg,B. and Sperens,B. (1977) DNA N-glycosidases: properties of uracil-DNA glycossidase from Escherichia coli.

Majernik, A.I., Jenkinson, E.R. and Chong, J.P. (2004) DNA replication in thermophiles. Biochem Soc Trans, 32, 236-239.

Mol, C.D., Arvai, A.S., Sanderson, R.J., Slupphaug, G., Kavli, B., Krokan, H.E., Mosbaugh, D.W. and Tainer, J.A. (1995a) Crystal structure of human uracil-DNA glycosylase in complex with a protein inhibitor: protein mimicry of DNA. Cell, 82, 701-708.

Mol, C.D., Izumi, T., Mitra, S. and Tainer, J.A. (2000) DNA-bound structures and mutants reveal abasic DNA binding by APE1 and DNA repair coordination [corrected]. Nature, 403, 451-456.

Mol, C.D., Kuo, C.F., Thayer, M.M., Cunningham, R.P. and Tainer, J.A. (1995b) Structure and function of the multifunctional DNA-repair enzyme exonuclease III. Nature, 374, 381-386.

Mol, C.D., Parikh, S.S., Putnam, C.D., Lo, T.P. and Tainer, J.A. (1999) DNA repair mechanisms for the recognition and removal of damaged DNA bases. Annu Rev Biophys Biomol Struct, 28, 101-128.

Neddermann, P. and Jiricny, J. (1993) The purification of a mismatch-specific thymine-DNA glycosylase from HeLa cells. J Biol Chem, 268, 21218-21224.

Neddermann, P. and Jiricny, J. (1994) Efficient removal of uracil from G.U mispairs by the mismatch-specific thymine DNA glycosylase from HeLa cells. Proc Natl Acad Sci U S A, 91, 1642-1646.

Nickoloff, J.A.a.H., M.F. (1998) DNA Damage and Rrepair, Volume I : DNA reapir in Prokaryotes and Lower Eukaryotes, Humana Press Inc., Totowa,New Jersey, USA. Humana Press Inc., Totowa,New Jersey, USA.

Pace, C.N., Vajdos, F., Fee, L., Grimsley, G. and Gray, T. (1995) How to measure and predict the molar absorption coefficient of a protein. Protein Sci, 4, 2411-2423.

Parikh, S.S., Mol, C.D., Slupphaug, G., Bharati, S., Krokan, H.E. and Tainer, J.A. (1998) Base excision repair initiation revealed by crystal structures and binding kinetics of human uracil-DNA glycosylase with DNA. Embo J, 17, 5214-5226.

Pearl, L.H. (2000) Structure and function in the uracil-DNA glycosylase superfamily. Mutation Research, 460, 165-181. 
Pettersen, H.S., Sundheim, O., Gilljam, K.M., Slupphaug, G., Krokan, H.E. and Kavli, B. (2007) Uracil-DNA glycosylases SMUG1 and UNG2 coordinate the initial steps of base excision repair by distinct mechanisms. Nucleic Acids Res, 35, 3879-3892.

Pfeifer, S. and Greiner-Stoffele, T. (2005) A recombinant exonuclease III homologue of the thermophilic archaeon Methanothermobacter thermautotrophicus. DNA Repair (Amst), 4, 433-444.

Pingfang Liu, Burdzy, A. and Sowers, L.C. (2002) Substrate Recognition by Family of UracilDNA Glycosylases: UNG, MUG and TDG. Chem. Research in Toxicology, 15, 10011009.

Pingfang Liu, Theruvathu, J.A., Darwanto, A., Lao, V.V., Pascal, T., III, W.G. and Sowers, L.C. (2008) Mechanisms of base selection by the Escherichia coli Mispaired Uracil Glycosylase. The J. of Biol.Chem., 283, 8829-8836.

Renos Savva, M.-H.K.B.T.P.L. (1995) The structural basis of specific base-excision repair by uracil-DNA glycosylase. Nature, 373, 487-493.

Rothwell, D.G., Hang, B., Gorman, M.A., Freemont, P.S., Singer, B. and Hickson, I.D. (2000) Substitution of Asp-210 in HAP1 (APE/Ref-1) eliminates endonuclease activity but stabilises substrate binding. Nucleic Acids Res, 28, 2207-2213.

Sandigursky, M. and Franklin, W.A. (1999) Thermostable uracil-DNA glycosylase from Thermotoga maritima a member of a novel class of DNA repair enzymes. Curr Biol, $\mathbf{9}$, 531-534.

Sandigursky, M. and Franklin, W.A. (2000) Uracil-DNA glycosylase in the extreme thermophile Archaeoglobus fulgidus. J Biol Chem, 275, 19146-19149.

Sanger, F., Nicklen, S. and A.R., a.C. (1977) DNA sequencing with chain-terminating inhibitors. Proc Natl Acad Sci U S A, 74, 5463-5467.

Sartori, A.A., Fitz-Gibbon, S., Yang, H., Miller, J.H. and Jiricny, J. (2002) A novel uracil-DNA glycosylase with broad substrate specificity and an unusual active site. Embo J, 21, 3182-3191.

Sartori, A.A., Schar, P., Fitz-Gibbon, S., Miller, J.H. and Jiricny, J. (2001) Biochemical characterization of uracil processing activities in the hyperthermophilic archaeon Pyrobaculum aerophilum. J Biol Chem, 276, 29979-29986.

Schmiedel, R., Kuettner, E.B., Keim, A., Strater, N. and Greiner-Stoffele, T. (2009) Structure and function of the abasic site specificity pocket of an AP endonuclease from Archaeoglobus fulgidus. DNA Repair (Amst), 8, 219-231.

Schomacher, L., Chong, J.P., McDermott, P., Kramer, W. and Fritz, H.J. (2009) DNA uracil repair initiated by the archaeal Exolll homologue Mth212 via direct strand incision. Nucleic Acids Res, 37, 2283-2293. 
Starcuviene, V. (2001) Identification andcharacterisation of thermistable uracil glycosylase from the archaeon Methanobacterium themautotrophicum and the bacterium Thermus thermophilus, PhD thesis, Georg- August-Universität Göttingen.

Starcuviene, V.a.H.-J.F. (2002) A novel type of uracil-DNA glycosylase mediating repair of hydrolytic DNA damage in the extremly thermophilic eubacterium Themusthermophilus. Nucleic Acids Res, 30, 2097-2102.

Thayer, M.M., Ahern, H., Xing, D., Cunningham, R.P. and Tainer, J.A. (1995) Novel DNA binding motifs in the DNA repair enzyme endonuclease III crystal structure. Embo J, 14, 4108-4120.

Varshney, U. and van de Sande, J.H. (1991) Specificities and kinetics of uracil excision from uracil-containing DNA oligomers by Escherichia coli uracil DNA glycosylase. Biochemistry, 30, 4055-4061.

Wang, Z.a.M., D.W. (1989) Uracil-DNA glycosylase inhibitor geneof bacterioohage PBS2 encodes a binding proteon specific for uracil-DNA glycosylase. J.Biol. Chem., 264, 1163-1171.

Weston, S.A., Lahm, A. and Suck, D. (1992) X-ray structure of the DNase I-d(GGTATACC)2 complex at 2.3 A resolution. J Mol Biol, 226, 1237-1256.

Womble, D.D. (2000) GCG: The Wisconsin Package of sequence analysis programs. Methods Mol Biol, 132, 3-22.

Yamashita, T., Hanada, K., Iwasaki, M., Yamaguchi, H. and Ikeda, H. (1999) Illegitimate recombination induced by overproduction of DnaB helicase in Escherichia coli. $J$ Bacteriol, 181, 4549-4553.

Zeikus, J.G. and Wolfe, R.S. (1972) Methanobacterium thermoautotrophicus sp. n., an anaerobic, autotrophic, extreme thermophile. J Bacteriol, 109, 707-715. 


\section{Appendix}

\subsection{Sequences (see attached CD):}

7.1.1 pET_B_001 sequence and restriction map

7.1.2 Mth212 nucleotide and amino acid sequences, restriction map

7.1.3 Mth212/D151X (X: N, A, S) mutants verification

7.1.3.1 pET_B001_Mth212/D151N sequencing chromatogram

7.1.3.2 pET_B001_Mth212D151A sequencing chromatogram

7.1.3.3 pET_B001_Mth212/D151S sequencing chromatogram 


\section{Gratitude}

My profound gratitude goes to Prof. Dr. Hans-Joachim Fritz, my supervisor, for his excellent care, intense discussions and enormous support to this work. I am particularly thankful for his really infernal patience and inestimable contribution to my training as a scientist.

I appreciate PD Dr. Wilfried Krammer's kind acceptance to be the co-referee of my thesis and valuable practical and theoretical advises.

Lars Schomacher I thank for his willingness and readiness to help and especially for a good working atmosphere. I also thank him for his grate research on Mth212 and for providing the lab with E.coli BL_UX and BL_UXX strains.

Many thanks go to Jens Georg for his valuable ideas and detailed characterization of Mth212.

I am thankful to Dr. Kristina Lakomek, Dr. Achim Dickmanns and Prof. Dr. Ralf Ficner from Department of Structural Biology for the detailed Mth212 structure analysis and also for the constructive and interesting dispute.

Special gratitude go to all members of our research group: Ber Svetlana, Khaliuna Tseden, Dr. Anke Schürer, Dr. Blagovesta Popova, Christiane Prieß, Sabine Smolorz, Stefan Schubert and of course to Dr. Kramer's Research group, namely Christopher Ede, Bettina Hucke, Sabrina Lehmann for the grate cooperation and truly home atmosphere at the lab.

I greatly appreciate Marita Kalck's high professionalism and care.

Thanks to the staff of Göttingen Genomics Laboratory (G2L) for the high-quality DNA sequencing.

Special thanks to Agelika Löffers, Jareck Sobkowiak, Olaf Waase and Patrick Regin for the excellent work in maintaining our department's equipment.

My highest gratitude goes to my beloved parents and my sister, as well as my friends for their boundless love, support and help.

And last but not the least my love and thanks to my little son and my husband - my best team to go through the life. 


\section{Curriculum vitae}

\section{Personal details:}

Name: $\quad$ Elena Ciirdaeva (born Jivotovscaia)

Date of birth: $\quad 04.02 .1972$

Place of birth: Cişhinău, Moldova

Marital status: married, one son (born in 1999)

Citizenship: Moldavian

\section{School education:}

1979-1989

Primary and Secondary education at School No.55, Cişhinău (Moldova). Grade: Matriculation certificate

\section{Academic background:}

1993-1998

1997-1998

1998

$1999-2002$

April 2003 - Feb. 2005

From 01.06.2005
Study of Biology at the Dept. of Biology and Pedology, State University of Moldova, Cişhinău (Moldova).

Graduate research project in the group of Prof. Dr A. Dascaliuc, Institute of Plant Physiology, Academy Of Science of Moldova, Chişinău (Moldova)

Project: Isolation of saponins (ginsenosides) from callus of ginseng (Panax ginseng) and investigation them by HPLC.

State examination (Subjects: biology and plant biochemistry)

Grade: Diploma; Specialization: Biology;

Qualifications: Biologist; Teacher of Biology and Chemistry.

Maternal leave

Fellowship, International Research School MPI, Max Planck Institute for Terrestrial Microbiology, Marburg (Germany).

PhD project under supervision of Prof. Dr. Hans-Joachim Fritz, Dept. Molecular Genetics und Preparative Molecular Biology, Institute of Microbiology and Genetics, University of Göttingen (Germany) 